\title{
LA VASECTOMÍA: ESTUDIO DE 300 INTERVENCIONES. REVISIÓN DE LA LITERATURA NACIONAL Y DE SUS COMPLICACIONES
}

\author{
P. ROMERO PÉREZ, F.J. MERENCIANO CORTINA, W. RAFIE MAZKETLI, \\ M. AMAT CECILIA, Mํㅡㄹ MARTÍNEZ HERNÁNDEZ*
}

Servicio de Urología. *Unidad de Enfermeria. Hospital General Universitario Marina Alta. Denia. Alicante.

\author{
Actas Urol Esp. 28 (3): 175-214, 2004
}

\section{RESUMEN}

LA VASECTOMÍA: ESTUDIO DE 300 INTERVENCIONES. REVISIÓN DE LA LITERATURA NACIONAL Y DE SUS COMPLICACIONES

OBJETIVOS: Los objetivos que nos hemos marcado en este trabajo son:

1. Estudiar la demanda e indicaciones de vasectomía en el área 12 de la Comunidad Valenciana

2. Analizar las complicaciones de nuestra serie y los factores de riesgo previsibles.

3. Revisar las complicaciones de las series nacionales.

4. Revisar las complicaciones referidas en las publicaciones internacionales.

PACIENTES Y MÉTODOS: Se realiza un estudio retrospectivo de 300 pacientes sometidos a vasectomía durante el periodo de tiempo comprendido entre enero de 1992 y diciembre de 2000 .

Se revisaron todas las historias clínicas evaluando 10 variables preestablecidas: edad, número de hijos, indicación, método contraceptivo utilizado pre-vasectomía, fecha de intervención, tipo anestesia, anatomía patológica, seminogramas de control, complicaciones, y posibles causas de las complicaciones (factores de riesgo).

Se realiza el estudio estadístico básico con ayuda de una base de datos de Microsoft Access y para la interpretación estadística de las distintas variables se utilizó una tabla de Excel.

RESULTADOS: La demanda de atención contraceptiva (vasectomía) constituye la $8^{\underline{a}}$ causa de consulta externa urológica y la $4^{\text {a }}$ de cirugía urológica local ambulatoria en nuestra área. Durante este periodo se realizaron 300 intervenciones de vasectomía. La edad media de los pacientes fue de 37,5 años (rango entre 23-51). El número de hijos osciló entre un mínimo de 1 y un máximo de 7 , con un promedio de 2,41 hijos/paciente.

Las indicaciones de la vasectomía fueron: planificación familiar voluntaria (86\%), enfermedades medicas de la mujer que contraindicaban la gestación (9\%), consejo genético $(4,33 \%)$, y problema socio-sanitario $(0,66 \%)$. Los métodos contraceptivos utilizados por las parejas previamente a la vasectomía se conocían en el $71,63 \%$ de los pacientes. Los más utilizados fueron: el DIU $(49,74 \%)$ y el preservativo $(25,88 \%)$.

Se presentaron complicaciones en 30 pacientes (10\%); de ellas en 29 pacientes fueron leves $(9,66 \%)$, siendo las más frecuentes: 12 orquiepididimitis (4\%), 5 granulomas espermáticos $(1,66 \%), 3$ orquialgias crónicas "sindrome del testículo doloroso", $(1 \%), 2$ hematomas escrotales $(0,66 \%)$ y 2 hemorragias de herida $(0,66 \%)$. Se presentó una complicación grave por impétigo escrotal estafilocócico con posterior sepsis estafilocócica $(0,33 \%)$. De todas las complicaciones sólo 1 caso requirió hospitalización (impétigo-sepsis) y 1 caso cirugía debido a granuloma espermático. No hubo embarazos no deseados ni demandas judiciales postvasectomía. La azoospermia definida al principio del estudio con 1 seminograma sin espermatozoides y en la actualidad con 2 seminogramas sin espermatozoides con una diferencia entre ellos de 15 días ó 30 días, se logró en el $81 \%$ de pacientes entre los 45 y 60 días post-vasectomía.

CONCLUSIONES: La vasectomía es un método seguro y simple para conseguir la esterilidad del varón. Es la intervención urológica más practicada en España. La técnica no está exenta de complicaciones (tasa de 0-18\%), y su gravedad varía, desde la simple equimosis, hasta la gangrena genital de Fournier, la endocarditis o la sepsis. En la información pre-vasectomía el facultativo incurre en negligencia si no informa al paciente de la posibilidad, remota pero existente, de recanalización espontánea de los deferentes, con recuperación de la fertilidad (fallo de la vasectomía). La información post-vasectomía, sobre prolongar la utilización del método contraceptivo habitual hasta confirmar la esterilidad y el seguimiento del paciente hasta la azoospermia demostrada con 2 espermiogramas, es fundamental para el urólogo si no quiere verse envuelto en problemas legales.

PALABRAS CLAVE: Vasectomía. Esterilización masculina. Contracepción masculina. Complicaciones. Revisión.

\section{ABSTRACT}

THE VASECTOMY: A STUDY OF 300 OPERATIONS. A REVIEW OF ITS ADVERSE EFFECTS AND OF NATIONAL LITERATURE. OBJECTIVES: The aims of this paper are:

1 . To study the demand and reasons why of the vasectomy in area 12 of Valencian Community.

2. To analyse the adverse effects of our series and the predictable risk factors.

3. To review the adverse effects in the national series.

4. To review the adverse effects referred to in international publications.

PATIENTS AND METHODS: A restrospective study was made of 300 patients who had submitted themselves to a vasectomy between january 1992 and december 2000. All the clinical dossiers were reviewed according to 10 pre-established variables. age, number of offspring, reasons why, pre-vasectomy anticontraceptives, date of operation, type of anaesthesia used, pathologic anatomy, semen analysis after vasectomy, adverse effects and their possible causes (risk factors).

The basic statistic study was done using a data base of Microsoft Access and the interpretations of the different variables using a table of Excel.

RESULTS: The demand for contraceptive attention (vasectomy) is the $8^{\text {th }}$ cause for external urological consulting and the $4^{\text {th }}$ for urological local ambulatory surgery of our area. 300 operations were done during that period. The average age of the patients was 37.5 years old (ranging from 25 to 51 ). The number of offspring ranged from 1 to 7 , with a promedia of 2.41 children/patient. The reasons why were: voluntary family planning (86\%), medical illnesses of the female which contraindicated gestation $(9 \%)$, genetic reasons $(4.33 \%)$ and social-sanitary problems $(0.66 \%)$. Contraceptive methods used by $71.63 \%$ are known: The widestused method being IUD (49.74\%) and the preservative $(25.88 \%)$.

30 patients (10\%) had adverse effects, 29 patients having light adverse effects. The most frequent were: 12 orchiepididymitis (4\%), 5 spermatic granulomas $(1.66 \%), 3$ chronic scrotal pain ( $1 \%), 2$ scrotal haematoma $(0.66 \%)$ and 2 bleeding $(0.66 \%)$. There was one serious complications and of all the cases mentionned above only one needed hospitalization (impetigo-sepsis) and another needed surgery due to a spermatic granuloma. There were no pregnancies or post-vasectomy court cases. $81 \%$ of the patients had been declared azoospermic within 45 to 60 days after the vasectomy in one or two consecutive semen analysis.

CONCLUSIONS: The vasectomy is a safe and simple way for male sterilization. It's the most widely done urologic operation in Spain. The technique isn t extent of adverse effects ( 0 to $18 \%$ ) and its seriousness varies from a simple ecchymosis to Fournier's gangrene, endocarditis or sepsis. A doctor would be considered negligent if he/she didn't inform the patient about the remote possibility of a spontaneous recanalisation of the vas deferens leading to renewed fertility (failure of the vasectomy). It is imperative to give post-vasectomy information where the patient must continue using his habitual anticonceptive method until the azoospermia shown in 2 semen analysis confirm the sterility of the patient so that the urologist has no legal problem.

KEY WORDS: Vasectomy. Male sterilization. Male contraception. Complications. Adverse effects. Review. 
L a vasectomía es un método eficaz de esterili$\operatorname{dad}^{1-4}$. Quizá sea el método más seguro y simple de esterilización masculina.

Es una intervención quirúrgica cuya indicación, la mayoría de las veces no la asienta el urólogo, sino que habitualmente es el propio paciente o la pareja los que acuden a consulta solicitando la esterilización voluntaria como método de planificación familiar o ¿personal?, cuando se trata de parejas estables que optan por no tener más hijos (cirugía satisfactiva) ${ }^{5}$. En otros casos, su práctica no es voluntaria si no que está condicionada a indicaciones médicas por riesgo para la mujer en la gestación, transmisión de enfermedades hereditarias (cirugía curativa); y excepcionalmente por orden judicial. En estas ocasiones se solicita a través de otros especialistas (Centro de Planificación Familiar, ginecólogos o pediatras), aduciendo estos motivos médicos:

1. Enfermedades de la mujer que contraindican el embarazo (gestación de alto riesgo).

2. Riesgo de transmisión de enfermedades hereditarias (consejo genético).

3. Contraindicación para la toma de anticonceptivos hormonales.

4. Orden judicial (hipersexualidad, retraso mental, etc.).

La primera encuesta nacional sobre la vasectomía, fue presentada en el LXV Congreso Nacional de Urología, celebrado en Madrid del 28-31 de mayo de 2000 durante el transcurso de la Mesa Redonda "Vasectomía ¿cuál es nuestra realidad?"6. En ella se hacía hincapié en que la vasectomía es la intervención urológica más practicada en España; estimándose en unos 100.000 los varones que se someten voluntariamente cada año a esta intervención, 30.000 de los cuales son intervenidos por "otros especialistas no urólogos", en centros de planificación familiar, gabinetes ginecológicos o consultas privadas; y en habitáculos que muchas veces no son el quirófano, sino salas de curas, consultorios, etc., con el consiguiente riesgo para el paciente.

La técnica quirúrgica es sencilla, realizándose bajo anestesia local en 20-30 minutos, sin necesidad de ingreso hospitalario. Sin embargo el resultado de esterilidad no es inmediato, manteniéndose la capacidad de fecundar durante unos
3 meses, debido al remanente de espermatozoides circulantes que quedan atrapados en las vías espermáticas distales a la ligadura deferencial y que serán eliminados en estos 3 meses o unas 20 eyaculaciones.

Esta inocuidad del procedimiento implica cierto grado de despreocupación en su seguimiento tanto por el paciente como por el propio urólogo, seguimiento que queda limitado habitualmente a la práctica de 1 ó 2 seminogramas pre-alta, actitud simplista que "aleja" de los resultados reales de la técnica al desconocerse sus posibles complicaciones, circunstancia que por otro lado acerca de manera preocupante a una creciente realidad: la de las demandas y pleitos judiciales en las que pueden verse involucradas tanto las instituciones sanitarias como los urólogos que efectúan las vasectomías.

No olvidemos que el solicitante de la vasectomía la mayoría de las veces no es un enfermo, y rara vez aceptará de buen grado complicación alguna por este procedimiento mal calificado "de banal”, pero además exigirá al método y al cirujano que el resultado final sea su esterilidad por azoospermia. Es aquí donde los urólogos tenemos que tener clara nuestra responsabilidad civil que vendrá marcada por el tipo de contrato que establezca la práctica médica entre el médico y el paciente. Así, hablaremos de responsabilidad contractual y responsabilidad extracontractual. Referente a la responsabilidad contractual, el Tribunal Supremo, desde muy antiguo, calificó reiteradamente el contrato entre los médicos y los enfermos que acuden para la curación de una enfermedad, como un contrato de arrendamiento de servicios pero no de resultados o fines (cirugía asistencial o curativa). Sin embargo, en aquellos casos, como la vasectomía, en que la medicina tiene un carácter meramente voluntario, es decir, en los que el interesado acude al médico no para la curación de una dolencia patológica sino para el mejoramiento de un aspecto físico o estético o, para la transformación de una actividad biológica, la actividad sexual, en forma tal que le permita practicar el acto sexual sin necesidad de acudir a otros métodos anticonceptivos (cirugía satisfactiva o estética), en estos casos, la responsabilidad civil es extracontractual y el contrato sin perder su carácter de arrendamiento de 
servicios, que impone al médico una obligación de medios, se aproxima ya de manera notoria al de arrendamiento de obra, que propicia la exigencia de una mayor garantía en la obtención del resultado que se persigue, ya que, si así no sucediera, es obvio que el interesado no acudiría al facultativo para la obtención de la finalidad buscada ${ }^{7-9}$.

Como se puso de relieve en la mesa redonda del LXV Congreso Nacional de Urología Madrid ${ }^{10}$, efectivamente existe una "falta de conocimiento real sobre la vasectomía", ya que la mayoría de publicaciones sobre su morbilidad se basan en contestaciones a encuestas a través de "cuestionarios postales" o bien "telefónicas".

La vasectomía, no está exenta de complicaciones, la más sonada de ellas es el embarazo tras vasectomía o “fallo de la vasectomía” con serias implicaciones legales para los urólogos. Pero existen otras complicaciones médicas referidas en la literatura. La tasa de complicaciones oscila entre $0-18 \%$, y su gravedad es variable desde la equimosis hasta la sepsis.

Aspecto éste, el de las complicaciones, con escasa atención en la literatura científica nacional, salvo raras excepciones ${ }^{11-14}$.

En los últimos años desde 1987 a 2000 han aparecido una docena de trabajos en la literatura nacional sobre la vasectomía, algunos de los cuales abordan tibiamente el problema de las complicaciones de la vasectomía ${ }^{2,3,5,15-23}$. Sin embargo de los escasos artículos referidos a estas complicaciones, la mayoría no reúnen los criterios mínimos para poder sacar conclusiones fiables.

El presente trabajo retrospectivo realizado en el ámbito de un hospital comarcal, intenta aportar un estudio más exhaustivo sobre esta intervención urológica, estudiando sus indicaciones, complicaciones, e implicaciones legales en 300 intervenciones de vasectomía. Por último, realizamos una revisión de la literatura nacional aportando referencias sobre la vasectomía en los Congresos Nacionales de Urología y de Andrología y en las series nacionales publicadas.

Finalizamos con la revisión de las series más numerosas de 22 autores con 34.159 pacientes, en los que el control de complicaciones se llevó a cabo en sólo 16.514 pacientes $(48,34 \%)$, por el método tan poco fiable del cuestionario postal o la encuesta telefónica. A pesar de ello se describie- ron 42 diferentes complicaciones en 1.338 pacientes $(8,10 \%)$, hechos que ponen en duda razonable la opinión de pacientes e incluso de urólogos sobre la técnica, descrita como: "habitualmente exenta de complicaciones", y cuya realidad es otra bien distinta: hay complicaciones, están cifradas porcentualmente según la mejor evidencia en un 8$10 \%$ de los pacientes, y el $1 \%$ de ellas pueden ser muy graves, aunque no conocemos ningún caso con resultado de muerte atribuible a esta intervención en España, pero sí en otros países como el publicado por Viddeleer y cols ${ }^{24}$.

\section{MATERIAL Y MÉTODOS}

Durante el periodo de septiembre de 1987 a diciembre de 2001 se han realizado en nuestro servicio un total de 586 vasectomías. Debido a las dificultades para la localización de los historiales y los problemas en el Archivo de Historias Clínicas, que ha sufrido varias inundaciones y se ha quedado pequeño, muchas historias han pasado "al pasivo" (habilitadas en otros espacios), por lo que sólo hemos podido estudiar para este trabajo las vasectomías realizadas entre 1992-2000 que suman un total de 300, cuyos historiales eran más accesibles.

Se realiza un estudio retrospectivo de estos 300 pacientes sometidos a vasectomía en el Hospital Marina Alta de Denia (Alicante), durante el periodo de tiempo comprendido entre enero de 1992 y diciembre de 2000 (9 años).

Los pacientes nos fueron remitidos, bien a través del Centro de Planificación Familiar (CPF), o a través de su Médico de Atención Primaria (Centro de Salud), y fueron atendidos en Consultas Externas de Urología, donde se les realizó historia clínica y exploración física escrotal para identificar el deferente y determinar la complejidad de cada caso, evaluar el tipo de escroto (laxo, corto, hipoplásico, dismórfico, etc.) y confirmar o descartar la existencia de patología intraescrotal (hernia, varicocele, hidrocele, quiste de cordón, etc.) o cutánea (micosis, foliculitis, heridas, psoriasis, etc.), que pudiera interferir con la intervención.

En la misma consulta, todos los pacientes firmaron el consentimiento informado (CI) previa explicación y entrega de una hoja informativa sobre la vasectomía y su preparación preoperatoria. 
El circuito asistencial de los pacientes es el de la cirugía ambulatoria (UCSI), donde el paciente acude al hospital a la hora concertada en ayunas de 4-6 horas, duchado, y con los genitales rasurados. Tras la cirugía, abandonan el hospital con un informe operatorio donde se especifica el tratamiento post-operatorio, los controles, o qué hacer y dónde acudir en caso de complicaciones.

Habitualmente la intervención se lleva a cabo bajo anestesia local, por infiltración, aunque podría realizarse con anestesia tópica con crema de EMLA. Sin embargo ciertos casos especiales serían imposibles con anestesia local y podría plantearse la necesidad de anestesia loco-regional o general:

1. Solicitud del propio paciente.

2. Concurrencia de otras patologias: hernia, cirugía ORL, etc.

3. Obesidad mórbida o escroto difícil.

4. Patología neuro-psiquiátrica que impida la inmovilidad del paciente durante la cirugia: epilepsia, temblor esencial o claustrofobia.

Una vez el paciente en quirófano y en la mesa operatoria, se realiza de modo protocolizado: canalización de vía venosa periférica, monitorización (pulso, frecuencia cardíaca, TA) y oximetría digital.

El método quirúrgico empleado para la realización de la vasectomía fue la técnica de Schmidt con incisión escrotal bilateral, resección de 1-2 $\mathrm{cm}$ de ambos deferentes, doble ligadura proximal (cabo cercano al testículo), ligadura simple distal con seda, y electrocoagulación de la luz de ambos deferentes seccionados.

Respecto a la técnica quirúrgica, tras localizar digitalmente el deferente, el método anestésico-quirúrgico consiste en la infiltración de piel y tejido celular subcutáneo con anestésico local mepivacaína clorhidrato al $2 \%$ (Scandinibsa), con $2 \mathrm{ml} \mathrm{de}$ bicarbonato 1/6 M para evitar el picor que produce la infiltración. Usamos la técnica de Schmidt o de doble incisión escrotal. Aislado el deferente con pinzas de Allis, se libera de su vaina serosa y se realiza resección de 1-2 cm, seguido de doble ligadura proximal y ligadura simple distal con seda $2 / 0$. Se electrocoagula la luz de ambos deferentes. Hemostasia con electrobisturí. Cierre cutáneo con Vicryl rapid 2/0. Apósito. Suspensorio escrotal. El segmento deferencial extirpado es remitido habitualmente a Anatomía Patológica.
En caso de bradicardia o hipotensión durante la infiltración anestésica o manipulación del cordón, administramos 1/2 ampolla de atropina i.v lenta y oxigenoterapia con gafas nasales.

El método de recogida de datos para el estudio de las diferentes variables en los pacientes se llevó a cabo mediante la elaboración de un "protocolo clínico de vasectomía", que incluye el estudio de 10 variables. Se ha evaluado historia por historia a todos los pacientes extrayendo los datos prefijados en el "protocolo de vasectomía" considerado útil a tal fin (Tabla I).

Para el manejo de las diferentes variables se utilizó una base de datos Microsoft Access y para su interpretación estadística una tabla de Excel.

Se realiza la estadística descriptiva de todas las variables de interés estudiadas realizando las medidas habituales de dispersión y centralización. Una descripción porcentual se aplicó en caso de variables cualitativas.

\section{TABLA I}

PROTOCOLO DE VASECTOMÍA. VARIABLES ESTUDIADAS

\begin{tabular}{|c|}
\hline 1. Edad \\
\hline 2. № de hijos \\
\hline $\begin{array}{l}\text { 3. Indicación: } \\
\text { Voluntaria } \\
\text { Enfermedad de la mujer } \\
\text { Consejo genético } \\
\text { Problema social } \\
\text { Problema judicial }\end{array}$ \\
\hline 4. Método contraceptivo previo \\
\hline $\begin{array}{l}\text { 5. Fecha de vasectomia: } \\
\text { Vasectomía } \\
\text { Otra cirugía simultánea }\end{array}$ \\
\hline 6. Tipo de anestesia \\
\hline 7. Estudio anatomopatológico \\
\hline $\begin{array}{l}\text { 8. Seminogramas de control: } \\
\qquad \begin{array}{r}\text { 1er Seminograma } \\
\text { Fecha } \\
\text { Resultado } \\
2^{\text {o }} \text { Seminograma } \\
\text { Fecha } \\
\text { Resultado } \\
3^{e r} \text { Seminograma } \\
\text { Fecha } \\
\text { Resultado }\end{array}\end{array}$ \\
\hline $\begin{array}{l}\text { 9. Complicaciones: } \\
\text { No } \\
\text { Si (tipo) }\end{array}$ \\
\hline 10. Posibles factores de riesgo \\
\hline
\end{tabular}


El procesamiento de los datos se ha realizado mediante el programa estadístico SPSS + base, y el programa gráfico Harvard Graphics rodados en un ordenador IBM PS/2.

\section{RESULTADOS}

La demanda de vasectomía en el área 12 de la Comunidad Valenciana es elevada, constituyendo la $8^{\mathrm{a}}$ causa de motivo de consulta urológica en nuestro hospital (Tabla II), y la $4^{\text {a }}$ causa de cirugía local ambulatoria (Tabla III).
Se ha estudiado un total de 300 pacientes sometidos a esterilización por vasectomía bilateral en el Hospital Marina Alta.

La edad de los pacientes osciló entre 23 y 51 años, con una edad media de 37,5 años, y moda de 36 años.

El número de hijos de las esposas de los pacientes varió entre 1 y un máximo de 7 , con un promedio de 2,41 hijos por paciente y moda de 2 hijos.

Respecto a la indicación de vasectomía, ésta fue por planificación familiar voluntaria en 258

TABLA II

DEMANDA DE CONSULTA PARA VASECTOMÍA EN EL HOSPITAL MARINA ALTA DENIA. ÁREA 12 COMUNIDAD VALENCIANA. DESCRIPCIÓN NUMÉRICA Y PORCENTUAL DE LOS 8 MOTIVOS MÁS FRECUENTES DE CONSULTA EN PRIMERA VISITA UROLÓGICA AÑOS 1994-2002. TASA DE FRECUENTACION

\begin{tabular}{|c|c|c|c|c|c|c|c|c|c|c|c|c|c|c|c|c|c|c|}
\hline \multirow{3}{*}{ Motivos de consulta } & \multicolumn{18}{|c|}{ AÑOS } \\
\hline & \multicolumn{2}{|c|}{1994} & \multicolumn{2}{|l|}{1995} & \multicolumn{2}{|c|}{1996} & \multicolumn{2}{|c|}{1997} & \multicolumn{2}{|l|}{1998} & \multicolumn{2}{|c|}{1999} & \multicolumn{2}{|c|}{2000} & \multicolumn{2}{|l|}{2001} & \multicolumn{2}{|c|}{2002} \\
\hline & № $\operatorname{cas} 0 \mathrm{~s}$ & $\%$ & № $\operatorname{cas} 0 \mathrm{~s}$ & $\%$ & № $\operatorname{cas} 0 \mathrm{~s}$ & $\%$ & № $\operatorname{cas} 0 \mathrm{~s}$ & $\%$ & № casos & $\%$ & № $\operatorname{casos}$ & $\%$ & № $\operatorname{cas} 0 \mathrm{~s}$ & $\%$ & № $\operatorname{cas} 0 \mathrm{~s}$ & $\%$ & № casos & $\%$ \\
\hline 1. Patología prostática & 259 & 22 & 307 & 26 & 524 & 30,6 & 456 & 31 & 360 & 33 & 441 & 25 & 283 & 21,5 & 309 & 19,3 & 303 & 19,2 \\
\hline $\begin{array}{l}\text { 2. Litiasis urinaria- } \\
\text { Cólico nefritico }\end{array}$ & 120 & 10 & 133 & 11 & 247 & 14,4 & 267 & 18 & 218 & 18 & 258 & 14,7 & 209 & 15,9 & 231 & 14,4 & 253 & 16,1 \\
\hline 3. Hematuria & 84 & 7 & 108 & 9 & 175 & 10,2 & 122 & 8,2 & 63 & 5,7 & 140 & 7,9 & 114 & 8,6 & 154 & 9,6 & 137 & 8,7 \\
\hline 4. Patología prepucial & 71 & 6 & 99 & 8 & 155 & 9 & 128 & 8,6 & 90 & 8,1 & 137 & 7,8 & 88 & 6,6 & 134 & 8,3 & 91 & 5,7 \\
\hline $\begin{array}{l}\text { 5. Escroto, testículo, } \\
\text { epididimo }\end{array}$ & 58 & 5 & 55 & 4,5 & 150 & 8,7 & 118 & 7,9 & 63 & 5,7 & 139 & 7,9 & 97 & 7,3 & 132 & 8,2 & 163 & 10,3 \\
\hline 6. Infecciones urinarias & 45 & 4 & 56 & 5 & 110 & 6,4 & 66 & 4,4 & 49 & 4,4 & 132 & 7,5 & 94 & 7,1 & 116 & 7,2 & 125 & 7,9 \\
\hline 7. Incontinencia & 38 & 3 & 71 & 6 & 32 & 1,8 & 62 & 4,1 & 48 & 4,3 & 130 & 7,4 & 83 & 6,3 & 108 & 6,7 & 88 & 5,6 \\
\hline 8. Vasectomía & 36 & 3 & 54 & 4,5 & 57 & 3,3 & 46 & 3,1 & 47 & 4,2 & 84 & 4,7 & 58 & 4,4 & 65 & 4 & 63 & 4 \\
\hline $\begin{array}{l}1^{\underline{a}} \text { Visitas } \\
\text { estudiadas }\end{array}$ & 1167 & & 1189 & & 1710 & & 1481 & & 1103 & & 1755 & & 1314 & & 1601 & & 1575 & \\
\hline Total 1av visitas & 1492 & & 1702 & & 1710 & & 1481 & & 1103 & & 1755 & & 1341 & & 1601 & & 1575 & \\
\hline
\end{tabular}

TABLA III

LA VASECTOMÍA RESPECTO A LAS CIRUGÍAS AMBULATORIAS MÁS FRECUENTES. PERIODO 1994-2002

\begin{tabular}{|c|c|c|c|c|c|c|c|c|c|}
\hline \multirow[b]{2}{*}{$\begin{array}{l}\text { Tipo intervención } \\
\text { cirugía local }\end{array}$} & \multicolumn{9}{|c|}{ AÑOS } \\
\hline & 1994 & 1995 & 1996 & 1997 & 1998 & 1999 & 2000 & 2001 & 2002 \\
\hline 1 a. Cistoscopia & 115 & 186 & 174 & 215 & 171 & 218 & 224 & 220 & 256 \\
\hline $2^{\mathrm{a}}$. Circuncisión & 26 & 49 & 61 & 93 & 51 & 72 & 50 & 61 & 92 \\
\hline $3^{\text {a }}$. Frenillo & 4 & 5 & 12 & 25 & 11 & 17 & 7 & 19 & 20 \\
\hline $4^{a}$. Vasectomia & 20 & 59 & 33 & 79 & 46 & 79 & 46 & 69 & 86 \\
\hline 5․ Biopsia próstata & 21 & 59 & 59 & 81 & 78 & 90 & 60 & 75 & 73 \\
\hline Total & 186 & 358 & 339 & 493 & 357 & 476 & 387 & 444 & 527 \\
\hline
\end{tabular}


pacientes (86\%), por enfermedades de la esposa que contraindicaban la gestación en 27 pacientes (9\%), por consejo genético en 13 (4,33\%), y por problema socio-sanitario de la pareja en 2 casos $(0,66 \%)$ (Tabla IV).

\section{TABLA IV}

INDICACIONES DE LA VASECTOMÍA

\begin{tabular}{|l|c|c|}
\hline Tipo de indicación & $\begin{array}{c}\text { Número } \\
\text { pacientes }\end{array}$ & Porcentaje \\
\hline $\begin{array}{l}\text { Planificación familiar } \\
\text { voluntaria }\end{array}$ & 258 & $86 \%$ \\
\hline $\begin{array}{l}\text { Enfermedades de la } \\
\text { esposa que contraindican } \\
\text { la gestación }\end{array}$ & 27 & $9 \%$ \\
\hline Consejo genético & 13 & $4,33 \%$ \\
\hline Problema socio-familiar & 2 & $0,66 \%$ \\
\hline
\end{tabular}

Las 27 causas de enfermedad de la mujer que contraindicaban la gestación se muestran en la Tabla V.

Las 13 causas de consejo genético son las referidas en la Tabla VI.

Tuvimos 2 casos especiales de planificación familiar de "indicación social". El primero se trataba de un paciente de 40 años con 4 hijos a su cuidado, sin medios económicos ni trabajo y que nos fue remitido a través de los Servicios Sociales de su Ayuntamiento para la práctica de la vasectomía, contando con su consentimiento. El segundo, se trataba de un paciente de 23 años con alteración de la personalidad y 3 hijos que estaban a cargo del Ayuntamiento, siendo recomendada la vasectomía desde el propio Ayuntamiento.

Conocemos los métodos contraceptivos previos utilizados por 197 parejas (65,66\%) (Tabla VII), siendo por orden de frecuencia: DIU en 98 (49,74\%), preservativo en $51(25,88 \%)$, anticonceptivos hormonales en $26(13,19 \%)$, anticonceptivos hormonales + DIU en $16(8,12 \%)$ y coitus interruptus en 6 (3,04\%).

La vasectomía fue bilateral en los 300 pacientes, no hallando ningún caso de agenesia deferencial en la serie estudiada, aunque recientemente hemos tenido un caso de agenesia de deferente izquierdo. La vasectomía se realizó bajo anestesia local el día de la programación en 299
TABLA V

INDICACIONES DE VASECTOMÍA POR ENFERMEDADES DE LA MUJER QUE DESACONSEJABAN LA GESTACIÓN

\begin{tabular}{|l|c|c|}
\hline Enfermedad & № pacientes & Porcentaje \\
\hline Enf. Parkinson juvenil & 1 & $0,33 \%$ \\
\hline Embarazo extrauterino & 1 & \\
\hline 2 partos prematuros & 1 & \\
\hline Patologia pelvis ósea (3 cesáreas) & & \\
\hline 4 abortos de repetición & 1 & \\
\hline Miomas uterinos (gestación riesgo) & 1 & \\
\hline Enf. de Hodgkin & 1 & \\
\hline Gran "mal” & 1 & \\
\hline Cáncer mama & 1 & \\
\hline Obesidad mórbida & 1 & \\
\hline 2 prematuros + 1 cesárea & 1 & \\
\hline CIN III + cerclaje anterior gestación & 1 & \\
\hline $\begin{array}{l}\text { Embarazo } \\
\text { extrauterino+salpingectomía izda }\end{array}$ & 1 & \\
\hline Embarazo gemelar & 1 & \\
\hline Crioglobulinemia con nefropatía & 1 & \\
\hline TEP en anterior gestación & 1 & \\
\hline VHB + VHC (+) & 1 & \\
\hline 2 abortos sucesivos & 1 & \\
\hline 3 abortos + hipermenorrea & 1 & \\
\hline ADVP & 1 & \\
\hline Asma y epilepsia & 1 & \\
\hline Obesidad mórbida y varices & 1 & \\
\hline Patologia del raquis & 1 & \\
\hline Esclerosis múltiple & 1 & \\
\hline Psicosis maniaco-depresiva & 1 & \\
\hline Hepatitis crónica activa B & 1 & \\
\hline Total & 1 & \\
\hline
\end{tabular}

pacientes. En 1 paciente fue unilateral, ya que no se identificó el deferente izquierdo en la primera cirugía debido a la coexistencia con hernia inguino-escrotal ipsilateral, por lo que se sometió a posteriori con carácter diferido a herniorrafia y vasectomía izquierda bajo anestesia loco-regional (raquídea).

Respecto a la intervención de vasectomía en sí, en 290 pacientes $(99,66 \%)$, la vasectomía se practicó como intervención única. En 10 (3,33\%) se simultaneó con otras cirugías locales: 3 casos 
TABLA VI

INDICACIONES DE VASECTOMÍA POR CONSEJO GENÉTICO

\begin{tabular}{|c|c|c|c|}
\hline & № pacientes & № hijos afectos & Porcentaje \\
\hline \multicolumn{4}{|l|}{ Enfermedad genética } \\
\hline $\begin{array}{l}7 \text { hijos, } 4 \text { de ellos con malformaciones congénitas } \\
\text { óseas y craneales }\end{array}$ & 1 & 4 & \\
\hline \multicolumn{4}{|l|}{$\begin{array}{l}\text { - } 2 \text { hijos con agenesia parcial bilateral de metatarso y dedos } \\
\text { (oligodactilia y sindactilia) }\end{array}$} \\
\hline \multicolumn{4}{|l|}{ - 1 hija con displasia craneotelencefálica } \\
\hline \multicolumn{4}{|l|}{$\begin{array}{l}\text { - } 1 \text { hija con deficiencia mental media secundaria a } \\
\text { encefalopatía connatal }\end{array}$} \\
\hline 2 hijos con alteración desarrollo sistema arteriovenoso & 1 & 2 & \\
\hline \multicolumn{4}{|l|}{$\begin{array}{l}\text { - } 1 \text { hijo con CIV, estenosis valvular pulmonar, arco aórtico } \\
\text { derecho y subclavia izda aberrante }\end{array}$} \\
\hline \multicolumn{4}{|l|}{$\begin{array}{l}\text { - } 1 \text { hijo con síndrome de Klippel- Trennaunay e } \\
\text { hemihipertrofia izquierda }\end{array}$} \\
\hline 1 muerte fetal de origen desconocido por cesárea & 1 & 1 & \\
\hline Epidermolisis ampollosa (bullosa). Enfermedad de Koebner & 2 & 2 & \\
\hline 14 familiares con síndrome de Down & 1 & 0 & \\
\hline 2 hijos con estenosis hipertrófica del píloro & 1 & 2 & \\
\hline 1 hijo con síndrome de Down & 2 & 1 & \\
\hline 6 abortos de repetición & 1 & 6 & \\
\hline Mongolismo familiar & 1 & 1 & \\
\hline Madre epiléptica y 1 hijo epiléptico & 1 & 1 & \\
\hline Síndrome de Evans (anemia hemolítica + trombopenia) & 1 & 1 & \\
\hline Total & 13 & & $4,33 \%$ \\
\hline
\end{tabular}

TABLA VII

\section{MÉTODOS CONTRACEPTIVOS PRE-VASECTOMÍA}

№ vasectomías 300

Métodos contraceptivos previos

Conocidos en 197 (65,66\%)

DIU 98 (49,74\%)

Condón $51(25,88 \%)$

ACHO 26 (13,19\%)

$\mathrm{ACHO}+\mathrm{DIU} 16(8,12 \%)$

Coitus interruptus $6(3,04 \%)$

de circuncisión (1\%), 1 de evacuación de hidrocele $(0,33 \%), 1$ de punción quiste cordón bilateral $(0,33 \%), 1$ de exéresis de verrugas escrotales $(0,33 \%), 1$ de exéresis quiste de prepucio $(0,33 \%)$, 1 de exéresis quistes sebáceos escroto $(0,33 \%), 1$ de cistoscopia (0,33\%) o bajo anestesia general (un único caso): 1 herniorrafia+vasectomía $(0,33 \%)$ (Tabla VIII).
El tipo de anestesia fue local en 299 pacientes y en 1 que no se logró identificar el deferente izquierdo por coexistir con hernia, precisó otro acto quirúrgico diferido bajo anestesia raquídea para efectuar simultáneamente herniorrafia $\mathrm{y}$ vasectomía de ese lado.

Se produjeron complicaciones en 30 pacientes (10\%), que incluían 11 tipos de complicaciones diferentes: 12 casos de orquiepididimitis (4\%), 5 granulomas espermáticos $(1,66 \%), 3$ orquialgias crónicas (1\%), 2 hematomas de escroto $(0,66 \%), 2$ hemorragias de herida $(0,66 \%), 1$ disminución transitoria de la líbido $(0,33 \%), 1$ anorgasmia temporal $(0,33 \%), 1$ prostatitis crónica $(0,33 \%), 1$ intolerancia a la sutura cutánea/ infección herida $(0,33 \%), 1$ infección seminal $(0,33 \%)$ y 1 impétigo escrotal estafilocócico con posterior sepsis $(0,33 \%)$. Todas se muestran en la Tabla IX. La gravedad de las complicaciones osciló desde leve en 29 pacien- 
TABLA VIII

VASECTOMÍA: TIPO ANESTESIA Y CIRUGIAS ASOCIADAS

\begin{tabular}{|c|c|c|c|}
\hline Tipo anestesia & \multicolumn{1}{|c|}{ Intervención } & No pacientes & Porcentaje \\
\hline Local & \multicolumn{1}{|c|}{ Única } & 290 & $99,66 \%$ \\
\hline Local & Cirugías asociadas & 10 & $3,33 \%$ \\
\hline & Circuncisión & 3 & $1 \%$ \\
\hline & Punción hidrocele & 1 & $0,33 \%$ \\
\hline & $\begin{array}{l}\text { Punción quiste cordón } \\
\text { bilateral }\end{array}$ & 1 & $0,33 \%$ \\
\hline & Exéresis verrugas escroto & 1 & $0,33 \%$ \\
\hline & Exéresis quiste prepucio & 1 & $0,33 \%$ \\
\hline Loco-regional (raquídea) & $\begin{array}{l}\text { Exéresis quistes sebáceos } \\
\text { escroto }\end{array}$ & 1 & $0,33 \%$ \\
\hline & Cistoscopia & 1 & $0,33 \%$ \\
\hline
\end{tabular}

\section{TABLA IX}

COMPLICACIONES VASECTOMÍA EN NUESTRA SERIE

\begin{tabular}{|c|c|c|}
\hline Tipo complicación & № pacientes & Porcentaje \\
\hline 1. Orquiepididimitis aguda & 12 & $4 \%$ \\
\hline 2. Granuloma espermático & 5 & $1,66 \%$ \\
\hline 3. Orquialgia crónica & 3 & $1 \%$ \\
\hline 4. Hematoma escrotal & 2 & $0,66 \%$ \\
\hline 5. Hemorragia de herida & 2 & $0,66 \%$ \\
\hline 6. Disminución transitoria de la líbido & 1 & $0,33 \%$ \\
\hline 7. Anorgasmia temporal & 1 & $0,33 \%$ \\
\hline 8. Prostatitis crónica & 1 & $0,33 \%$ \\
\hline $\begin{array}{l}\text { 9. Intolerancia a la sutura cutánea/ } \\
\text { infección herida }\end{array}$ & 1 & $0,33 \%$ \\
\hline 10. Infección seminal & 1 & $0,33 \%$ \\
\hline $\begin{array}{l}\text { 11. Impétigo escrotal estafilocócico/ } \\
\text { sepsis/Sindr. Stevens-Johnson }\end{array}$ & 1 & $0,33 \%$ \\
\hline Total no complicaciones: 11 & 30 & $10 \%$ \\
\hline
\end{tabular}

№ vasectomías 300

№ pacientes con complicaciones $30(10 \%)$

tes $(96,66 \%)$ a grave en $1(3,33 \%)$. Todas curaron con tratamiento médico sintomático o antibiótico y carácter ambulatorio salvo 1 caso de granuloma espermático $(0,33 \%)$ que requirió cirugía. El impétigo escrotal, precisó ingreso hospitalario para su curación, primero en planta hospitalaria y después en UCI por posterior sepsis estafilocócica y desarrollo de un síndrome de Stevens-
Johnson cuya etiología pudo estar condicionada al tratamiento i.v. con metamizol (Nolotil) o amoxicilina-clavulánico (Augmentine). Fue una complicación aleccionadora, que duda cabe.

Entre los posibles factores de riesgo que pueden favorecer el desarrollo de complicaciones tenemos: el alargamiento del tiempo quirúrgico, una excesiva manipulación escrotal por deferente ilocalizable, las enfermedades infecciosas locales "dermatitis y dermatosis escrotales" tales como (micosis, foliculitis, psoriasis, etc.) por gran riesgo de infectar la herida, el varicocele por riesgo de hematoma escrotal o hematocele, la patología neurológica como el temblor esencial por impedir la cirugía y la patología psiquiátrica (claustrofobia) por impedir la cirugía con anestesia local (Tabla X).

\section{TABLA X}

FACTORES DE RIESGO PARA DESARROLLO DE COMPLICACIONES
1. Alargamiento del tiempo quirúrgico.
2. Excesiva manipulación escrotal.
3. Enfermedades infecciosas locales (dermatosis $y$ dermatitis escrotales): micosis, foliculitis, psoriasis.
4. Varicocele.
5. Alteraciones de la hemostasia/Hemofilia.
6. Patología neurológica que impida la cirugía con anestesia local: temblor esencial, claustrofobia, fobia a las agujas y epilepsia.


Disponemos de estudio anatomopatológico en 285 pacientes (95\%), en los 15 restantes (5\%) no se enviaron los deferentes al patólogo, desconociéndose los motivos.

Seminogramas documentados de control post-vasectomía disponemos en 255 pacientes (85\%), en los restantes 45 pacientes (15\%) o no consta el seminograma en la historia clínica, o se perdieron de control, desconociendo si se controlaron en Atención Primaria o en el CPF (Centro Planificación Familiar) (Tabla XI).

\section{TABLA XI}

SEMINOGRAMAS DE CONTROL POST-VASECTOMÍA

\begin{tabular}{||l|c|c|}
\hline & № pacientes & Porcentaje \\
\hline № vasectomías & 300 & $100 \%$ \\
\hline $\begin{array}{l}\text { № pacientes sin seminograma/ } \\
\text { perdidos de control }\end{array}$ & 45 & $15 \%$ \\
\hline № pacientes con seminograma & 255 & $85 \%$ \\
\hline $\begin{array}{l}\text { № altas con azoospermia en } \\
1 \text { ó 2 seminogramas }\end{array}$ & 243 & $81 \%$ \\
\hline $\begin{array}{l}\text { № altas con “algún espermios } \\
\text { aislado” en seminogramas }\end{array}$ & 12 & $4 \%$ \\
\hline
\end{tabular}

De los 255 pacientes con seminograma, en 243 (81\%) el alta se produjo con azoospermia "ausencia de espermatozoides en uno o dos seminogramas, en este último caso con una diferencia de tiempo mayor de 15 días (habitualmente 1 mes). A 12 pacientes (4\%) se les cursó el alta con algún espermatozoide en el seminograma.

El número de seminogramas por paciente queda reflejado en la Tabla XII: 0 seminogramas en 45 pacientes, todos ellos operados (15\%); 1 seminograma en 189 pacientes (63\%), de ellos 183 eran azoospérmicos y 6 eran positivos, "contenían espermatozoides"; 2 seminogramas en 48 pacientes (16\%), (todos con seminogramas negativos); 3 o más seminogramas en 18 pacientes (12 con seminogramas negativos y 6 con seminogramas positivos equivalentes a un informe con "algún espermatozoide aislado").

El tiempo en alcanzarse la azoospermia osciló entre un mínimo de 10 días y un máximo de 350 días, con una media de 82,41 días, y con una desviación estándar de 47,12 días. En 204 pacientes (68\%) la azoospermia ya se constató en el primer seminograma, media de 86,81 días, desviación estándar de 47,30 días y mediana de 76 días (Tabla XIII).

TABLA XII

NÚMERO DE SEMINOGRAMAS POR PACIENTE

\begin{tabular}{||l|c|c|c|c||}
\hline № seminogramas & No pacientes & Controlados & Perdidos control & Porcentaje \\
\hline 0 & 45 & No & Sí & $15 \%$ \\
\hline 1 & $\begin{array}{c}189: \\
183 \text { azoospérmicos } \\
6 \text { no azoospérmicos } \\
\text { "con espermatozoides" }\end{array}$ & Sí & & $63 \%$ \\
\hline 2 & $\begin{array}{c}18 \text { Só más } \\
12 \text { azoospérmicos } \\
6 \text { algún espermatozoide } \\
\text { aislado }\end{array}$ & Sí & No & $16 \%$ \\
\hline
\end{tabular}

TABLA XIII

TIEMPO EN ALCANZARSE LA AZOOSPERMIA

\begin{tabular}{|l|l|}
\hline To mínimo & 10 días \\
\hline To máximo & 350 días \\
\hline To medio & 82,41 días (desviación estándar 47,12 días) \\
\hline $\begin{array}{l}204 \text { pacientes (68\%) Azoospermia en el primer seminograma: } \\
\text { Media de } 86,81 \text { días } \\
\text { Desviación estándar 47,30 días }\end{array}$ & \\
\hline
\end{tabular}


Respecto al alta de los pacientes, ésta se produjo en 183 pacientes (61\%), tras un primer espermiograma azoospérmico. En 23 pacientes $(7,66 \%)$ el alta se produjo con dos seminogramas negativos consecutivos o no consecutivos $\left(1^{\circ}\right.$ y $2^{\circ}$ seminogramas azoospérmicos en 18 pacientes, $2^{\circ}$ y $3^{\circ}$ seminogramas negativos en 3 pacientes y $1^{\circ}$ y $3^{\circ}$ seminogramas negativos en 2 pacientes). En 12 pacientes (4\%), se precisaron 3 seminogramas para confirmar la esterilidad ( 5 de ellos cursaron alta tras 2 seminogramas negativos y 7 tras un solo seminograma negativo).

\section{DISCUSIÓN}

La vasectomía es una intervención bien conocida en la sociedad actual, y si bien muchos de sus efectos a largo plazo son hoy día aún desconocidos, los estudios al respecto son cada vez más frecuentes.

Una referencia temprana de la oclusión de los conductos deferentes es la realizada por el cirujano y anatómico inglés John Hunter en 1775 y posteriormente en 1830 por su discípulo Astley Cooper que inicia un trabajo experimental sobre la vasectomía. Ligaba arteria y vena del cordón espermático de un lado en perros, dejando intacto el conducto deferente, mientras en el lado opuesto si ligaba el conducto deferente. En el lado donde ligaba los vasos, el testículo se gangrenaba, mientras que en el lado que sólo obstruía el deferente, el tejido testicular permanecía sano. El líquido espermático sobrevivía en el conducto situado delante del punto de ligadura y el epidídimo se dilataba para adaptarse al acúmulo espermático ${ }^{11}$.

Las primeras referencias bien documentadas respecto a la práctica de la vasectomía datan del siglo XIX, aunque su finalidad no era la esterilización masculina, sino comprobar sus efectos sobre la próstata, para prevenir epididimitis postadenomectomía prostática, y era de práctica común para los pacientes adenomectomizados hasta la década de los 60-70, así como para paliar estados de hipersexualidadad.

En 1883, el cirujano francés Guyón afirmaba que el bloqueo del conducto deferente conducía a la atrofia de la próstata. A partir de ahí, se realizó la vasectomía durante mucho tiempo a la vez que se practicaba la adenomectomía prostática, con el fin de disminuir el tamaño de la glándula verda- dera y evitar las referidas epididimitis post-operatorias. Esta práctica se ha realizado en España hasta los años 60-70 e incluso más tarde.

Harry Sharp, en Indiana (USA) en 1909 refiere haber realizado una vasectomía en 1899 a un enfermo mental que presentaba excesiva masturbación. El paciente consintió pensando que se acabaría su obsesión. El resultado fue favorable, quizá por efecto psicológico, naturalmente. Este mismo autor en años siguientes de primeros de siglo, realizó la vasectomía a 456 voluntarios sanos con el fin de obtener su esterilización ${ }^{11}$.

Estas reseñas históricas tienen su importancia, ya que hoy día la vasectomía es un método popular de anticoncepción en nuestra sociedad moderna, por ser el recurso más simple, seguro, barato, mínimamente invasivo y con mucha más baja morbilidad que la ligadura tubárica en la mujer.

La vasectomía es el procedimiento quirúrgico contraceptivo más utilizado en el hombre cuando se pretende la esterilización definitiva con fines de planificación familiar o personal. En planificación familiar se utiliza como método para evitar el embarazo en parejas estables, pero también, como método de esterilización personal en hombres sin pareja o con pareja inestable (separados, divorciados, o viudos) que siguen manteniendo relaciones sexuales o que aún conviviendo con otra pareja, no desean más hijos.

Sin embargo, a pesar de ser el método de control de la fertilidad masculina más divulgado y aceptado en todos los foros sanitarios mundiales, ciertos factores, como pueden ser: 1) actitudes éticas de sectores socio-sanitarios; 2) la postura crítica de algunos urólogos para su práctica a cargo del dinero público del SNS a pesar de no constituir per se una enfermedad; y 3) su relativa facilidad técnica, han condicionado que este procedimiento urológico que debiera ser realizado por el urólogo (facultativo especializado, bien preparado y que ofrece las mejores garantías quirúrgicas), se haya desplazado a otros ambientes quirúrgicos como son los Centros de Planificación Familiar o por el propio intrusismo de facultativos de otras especialidades quirúrgicas, en las que sin ánimos de herir sensibilidades, los pacientes no están respaldados con iguales garantías quirúrgicas ni de control ${ }^{25}$. 
Se añade a ésto el problema del seguimiento, en lo referente al inconstante control evolutivo que se hace a los pacientes vasectomizados, en lo que coinciden varios autores españoles ${ }^{1,6,11,14,25}$. Controles de seguimiento que por otro lado y afortunadamente no son muy necesarios ni requeridos en un elevado porcentaje de pacientes, pero que al ser insuficientes nos dan una falsa idea del procedimiento en lo referente a esas infrecuentes pero reales complicaciones del método, y al control evolutivo tardío del vasectomizado sobre todo en lo concerniente al impacto socio-sanitario de la presunta relación entre vasectomía y cáncer de próstata, lo que motivó notas informativas de la AUA y más tarde de la AEU, recomendando controles de tacto rectal y PSA a varones mayores de 50 años cuya vasectomía se realizó hace más de 15 años, y aunque no se disponía aún de estudios concluyentes por esas fechas, la polémica existió ${ }^{12,18,26-28}$. Últimamente ha salido un estudio en el JAMA, que definitivamente indica la no-relación de la vasectomía con el cáncer de próstata. Aspectos del seguimiento que se discutirán más tarde.

La vasectomía es un método contraceptivo eficaz ya que prácticamente en el $100 \%$ de casos esteriliza a todos los pacientes, sin embargo existe una pequeña proporción de casos en los que podría producirse una recanalización espontánea entre ambos extremos del deferente en un $\%$ que oscila entre un $0,16 \%^{17}, 0,2-1 \%^{1,11}$ y un $2 \%^{2,19}$.

La cifra de vasectomías que se realizan hoy en el mundo, al año, es millonaria. Unos 50 millones de parejas han adoptado este método de control de su fertilidad ${ }^{18,26}$, y hoy en día se sobrepasa la cifra de 100 millones de hombres vasectomizados en el mundo ${ }^{26}$.

En España, la primera encuesta nacional sobre la vasectomía, se presentó en una Mesa Redonda en el LXV Congreso Nacional de Urolo- gía de Madrid 2000 por los Dres Valero Millán y Pinsach Elías ${ }^{10}$ e indicaba que la vasectomía es la intervención quirúrgica urológica más practicada en España. Estimándose que anualmente 100.000 varones se someten voluntariamente a esta intervención, de las cuales 70.000 son practicadas por urólogos y 30.000 por otros especialistas "no urólogos" ${ }^{\circ}$.

El auge de esta intervención quirúrgica ha motivado, incluso que los urólogos se muestren más sensibilizados ante esta creciente demanda, exigiendo cierta coherencia a la hora de optar por esta intervención con una actitud mucho más crítica. La selección adecuada de los pacientes y el desarrollo de campañas de información son algunas de las soluciones propuestas para frenar/detener esta creciente moda, donde la "indicación old standard" es un varón de 37,5 años con pareja estable y 2 hijos. Una incoherencia si revisamos los índices de natalidad española en la prensa nacional o regional ${ }^{29}$, donde se sitúa a España entre los países con población más envejecida y con menor tasa de natalidad del mundo, con 1,13 hijos por mujer, sólo por encima de los 1,10 hijos de 5 países: Letonia, Armenia, Bulgaria, Macao, y Ucrania, donde las condiciones de vida y nivel socio-sanitario dista mucho del de los países desarrollados donde se encuentra España.

En nuestra área sanitaria (área 12 de la CV), con 154.438 habitantes censados + una población flotante de 80.000 , la demanda de vasectomía es también cada vez más creciente a nivel de consultas externas, lo que se traduce también en un aumento de la ocupación del quirófano local programado semanal. Así para estos últimos 9 años 1994-2002, los datos comparativos de solicitudes de vasectomía en Consultas Externas y las vasectomías realizadas se muestran en la Tabla XIV.

\section{TABLA XIV}

FLUJO DE PACIENTES DE VASECTOMÍA. DINÁMICA DE LA LISTA DE ESPERA QUIRÚRGICA AÑOS $1994-2002$

\begin{tabular}{||l|c|c|c|c|c|c|c|c|c||}
\hline & $\mathbf{1 9 9 4}$ & $\mathbf{1 9 9 5}$ & $\mathbf{1 9 9 6}$ & $\mathbf{1 9 9 7}$ & $\mathbf{1 9 9 8}$ & $\mathbf{1 9 9 9}$ & $\mathbf{2 0 0 0}$ & $\mathbf{2 0 0 1}$ & $\mathbf{2 0 0 2}$ \\
\hline $\begin{array}{l}\text { Lista espera } \\
\text { quirúrgica }\end{array}$ & & & & & & & & & \\
\hline Incluidos & 36 & 54 & 57 & 46 & 47 & 84 & 58 & 66 & 63 \\
\hline Operados & 20 & 59 & 33 & 79 & 46 & 79 & 46 & 69 & 86 \\
\hline
\end{tabular}


Conocemos perfectamente los datos puesto que en nuestro servicio se realiza un estudio estadístico mensual de los motivos de consulta de todas las primeras visitas y sucesivas visitas. Es a partir de ahí, y de las memorias anuales del servicio por donde se llega a conocer con un pequeño margen de error el número de solicitudes de vasectomía que son remitidas desde los CPF o desde APS. Del mismo modo, a partir de nuestro sistema informático, podemos conocer el número de intervenciones de vasectomía que se realizan cada año, la fecha de intervención, el facultativo, etc.

Se enumera el flujo de pacientes que entran en LEQL y el número de pacientes que salen operados o no, durante los años 1994 a 2002, que nos dan fiel idea de su demanda (Tabla XIV).

Por tanto, es una cirugía que ocupa una parcela importante de nuestra actividad quirúrgica programada local; así como en el resto de Servicios de Urología de España, de tal manera que en palabras del Dr. Jiménez Cruz, se podría llegar a colapsar los quirófanos si no se detiene esta tendencia ${ }^{6}$.

Al tiempo que esta demanda creciente es motivo de retraso en la atención quirúrgica de enfermedades urológicas que requieren intervención más urgente, por lo que hay quien considera que esta cirugía voluntaria o satisfactiva / estética o no curativa, debería ser más restrictiva ${ }^{9}$. Se deberían redefinir los casos en los que el SNS debe financiar las vasectomías. No olvidemos que el Seguro Obligatorio de Enfermedad (SOE) se creó para tratar enfermedades y financiar operaciones a pacientes y en el caso de la vasectomía, el "paciente" habitualmente no es un enfermo (paciente), sino un cliente, pero ¿quién es el valiente que pone el cascabel al gato?

Por otra parte, en la vasectomía al quedar supeditada la intervención por la existencia o no de otras patologías más prioritarias, habitualmente se retrasan, con el riesgo de aumentar la demora media de las listas de espera ya que siempre se prioriza a otras intervenciones de local como fimosis, biopsias, cistoscopias, etc.

A diferencia del estudio nacional ${ }^{6}$, donde el mayor número de solicitudes procede de varones de entre 30-40 años con una media de 1,2 hijos, en nuestra área, la edad es similar, 37,5 años, pero el número de hijos es mayor: 2,41 hijos por pareja (muy por encima del índice de natalidad nacional de 1,13 hijos por pareja), por lo que nuestras indicaciones responden a un mejor criterio de práctica clínica. Sin embargo, cada vez es mayor la tendencia a solicitarla por varones $<$ de 30 años.

Las indicaciones y contraindicaciones de la vasectomía son también tema de controversia, al no tratarse de una enfermedad. Existen indicaciones personales (voluntarias), médicas (consejo genético o riesgo para la madre), sociales e incluso excepcionalmente, podrían existir las judiciales.

Habitualmente es una decisión conyugal. En estos casos de indicación personal, la vasectomía es solicitada por parejas estables que han optado por no tener mas hijos, con la $1^{\underline{a}}$ ó $2^{\text {a }}$ cónyuge $^{5}$.

Otras veces la indicación es médica cuando existen enfermedades de la mujer que contraindican la gestación, por parto de alto riesgo (para el feto o la madre): alteraciones de la pelvis, obesidad, eclampsia previa, hipertensión arterial severa, cesáreas previas, etc. En menos ocasiones por consejo genético a la pareja ante el riesgo de transmisión de patologías hereditarias a la descendencia: mongolismo, malformaciones óseas hereditarias, malformaciones cardiopulmonares, etc.

Algunas raras veces el paciente viene remitido desde los servicios sociales de su ayuntamiento, debido a matrimonios con muchos hijos y escasos recursos, para orientación familiar y cirugía, como ocurrió en 2 casos de nuestra serie.

Las indicaciones judiciales son raras en España, aunque podrían ajustarse a derecho, en casos de hipersexualidad, síndrome de Down, etc., aquí con las repercusiones bioéticas pertinentes ${ }^{30}$.

No hay contraindicaciones absolutas (permanentes) para la práctica de la vasectomía, pero no se debería realizar en presencia de infección local, infección sistémica aguda, signos o síntomas de ETS, filariasis, elefantiasis genital, masa intraescrotal, alergia a los anestésicos locales, alteraciones de la coagulación y hemofilia. También estaría cuestionada -"contraindicada"en caso de disfunciones sexuales (impotencia) por riesgo de empeoramiento ${ }^{31}$.

Existen condiciones del paciente que aumentan el riesgo operatorio, como son los antecedentes de trauma escrotal, varicocele, hidrocele voluminoso, hernia inguinal, cirugía previa por criptorquidia, alteraciones de la coagulación y hemofilia. 
Estas condiciones se deberían de informar a los pacientes porque incrementan el riesgo de complicaciones.

Respecto al consentimiento informado es importante que se especifique individual y personalmente a los pacientes que no es una intervención banal y que deben conocer todos los puntos clave del proceso: cirugía ambulatoria bajo anestesia local, salvo imposibilidad, que la intervención puede tener complicaciones menores en un 8$10 \%$, que la esterilidad no es inmediata tras la vasectomía, debiendo seguir utilizando el método anticonceptivo previo hasta confirmar la esterilidad: ausencia de espermios en el eyaculado (azoospermia) en 2 análisis de semen con un intervalo entre ellos de 15-30 días. Asímismo se ha de dar a conocer a los pacientes y cónyuges que existe un porcentaje de fallos en la vasectomía, por lo que se denomina recanalización espontánea, que oscilan entre un $0,36-1 \%$ para la recanalización precoz (23 meses post-vasectomía) y un $0,03 \%$ para la recanalización tardía (>3-6 meses) ${ }^{11,32}$.

Conocido ésto, se ofrece la vasectomía como un método de contracepción definitivo, perpetuo, pero con posibilidades de reconstitución o restauración de la vía seminal del deferente en determinadas circunstancias y sin totales garantías de éxito, respecto a la futura recuperación de la fertilidad por problemas técnicos, inmunológicos, etc.

En estos términos los pacientes deben firmar el consentimiento informado. Nosotros en el momento de la consulta, entregamos las normas preoperatorias a realizar horas antes el mismo día de la operación (Tabla XV).

En la actualidad estamos usando los formularios de consentimiento informado en urología de la Asociación Española de Urología, CD-Rom para PC (Edimsa 2000).

El circuito asistencial de la vasectomía es el de la cirugía ambulatoria a través de la U.C.S.I. (Unidad Cirugía Sin Ingreso), (Tabla XVI). Respecto al preoperatorio, no realizamos determinaciones de hemostasia, salvo en pacientes con antecedentes de alteraciones de la coagulación o pacientes anticoagulados. En los pacientes anticoagulados por lo general suspendemos el Sintrom y pasamos a Clexane 5-7 días antes y en los pacientes antiagregados suspendemos el antiagregante 3-5 días antes. Tampoco realiza- mos ECG salvo que el paciente padezca previamente del corazón. La Rx de tórax tampoco es imprescindible, salvo si hay patología pulmonar que la justifique.

El tipo de anestesia utilizado es la local tanto en España como en el resto de Europa y EE.UU, aunque también ha sido realizada con anestesia cutánea tópica con crema anestésica EMLA, principios activos lidocaína y prilocaína ${ }^{33}$. No obstante pueden existir pacientes que requieran anestesia loco-regional o general como:

- Solicitud expresa del paciente.

- Aprovechamiento de la misma anestesia para realizar otra cirugía simultánea.

- Obesidad mórbida.

- Escroto dismórfico, deferentes difíciles, o hernia asociada.

- Patología neuro-psiquiátrica como epilepsia, temblor esencial o claustrofobia.

Las técnicas quirúrgicas de vasectomía son múltiples, pero fundamentalmente existen 2 tipos de técnicas que a su vez derivan de 2 principios técnicos:

1. Técnicas quirúrgicas: técnicas de resección + ligadura (oclusión): vasectomía convencional.

2. Técnicas mínimamente invasivas: técnicas de oclusión deferencial.

Ahora bien, también se podría hablar dentro de estas 2 técnicas de:

- Vasectomía abierta.

- Vasectomía percutánea.

- Vasectomía endoscópica.

1. Técnicas de vasectomía convencional por resección + oclusión (ligadura):

a) Técnica con 2 incisiones o tipo Schmidt ${ }^{34,35}$.

b) Técnica con incisión media única o tipo Tilak $^{36}$.

\section{Técnicas de oclusión deferencial:}

a) Vasectomía sin bisturí o vasectomía tipo $\mathrm{Li}^{37,38}$.

b) Obstrucción deferencial por inyección percutánea (vasectomía percutánea).

- Elastomero de silicona,

- Tapón siliconado inyectado en la luz deferencial

c) Oclusión mecánica abierta.

- Microválvulas

- Clip de tántalo

- Hilo intradeferencial (cobre, silicona, prolene)

- Otros métodos con balones 


\section{NORMAS PREOPERATORIAS Y CONSENTIMIENTO INFORMADO DE VASECTOMÍA}

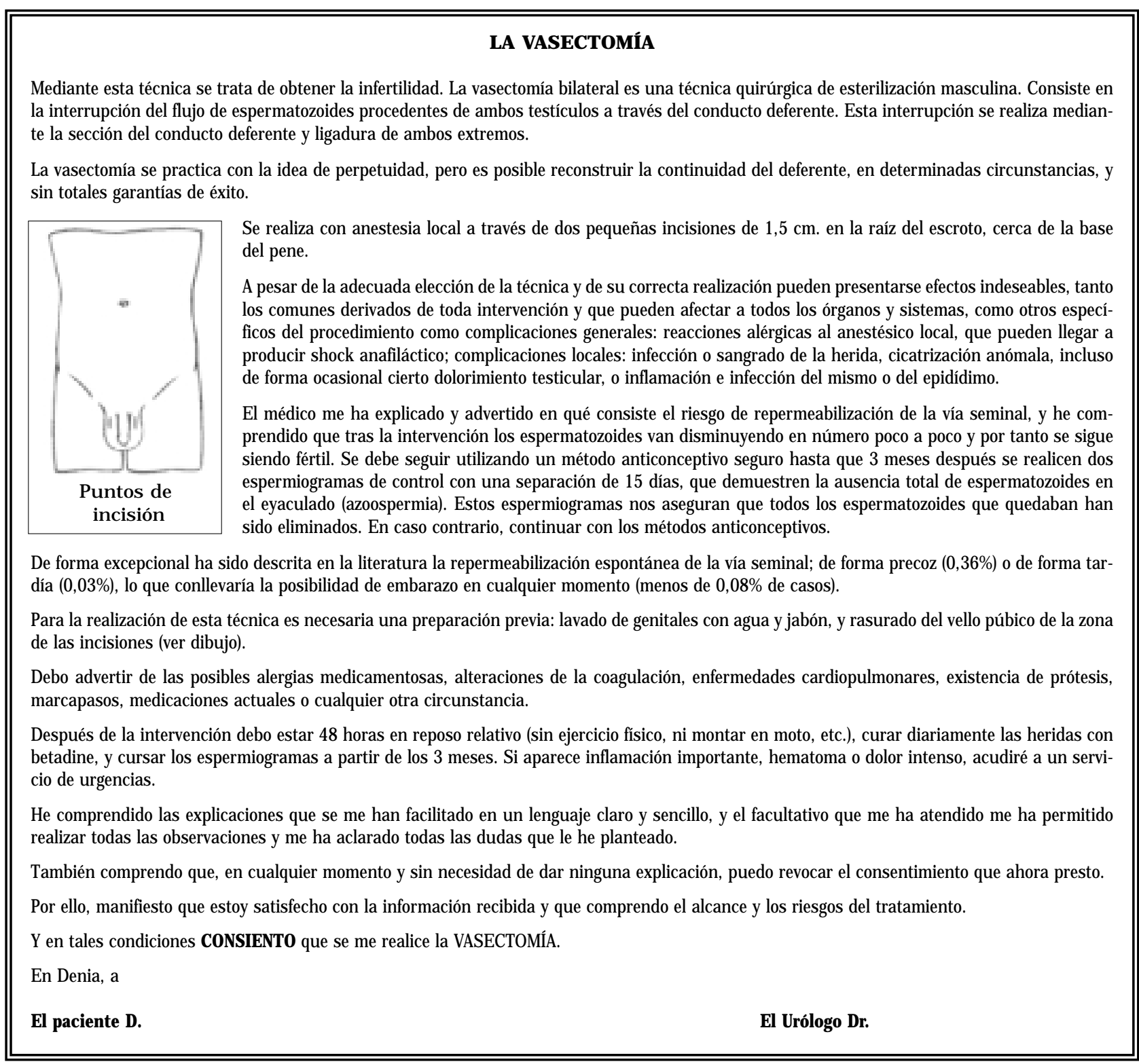

d) Oclusión química o esclerosis deferencial.

e) Oclusión endoscópica de la vía espermática en uretra prostática (uretroscopia).

f) Otros métodos oclusivos.

\section{Técnicas de vasectomía convencional por resección y oclusión (ligadura defe- rencial) (técnicas de Schmidt y Tilak)}

Son las más realizadas en España, Europa y EE.UU. Las consideraciones preoperatorias de esta cirugia son la existencia de historia clínica donde figuren número de hijos y las prácticas contracep- tivas previas. Es importante conocer si el paciente padece enfermedades sistémicas como la diabetes, ya que estos enfermos deben incluirse los primeros del parte para prevenir crisis de hipoglucemia por el ayuno excesivo, o alteraciones de la coagulación o toma de anticoagulantes como el Sintrom (acecumarol), que debemos suspender 5 días antes y pautar heparinas de bajo peso molecular tipo Clexane subcutáneo (enoxaparina), o de antiagregantes en cuyo caso hay que suspenderlos al menos de 3-7 días antes de la cirugía. Interesa conocer si existen 
TABLA XVI

CIRCUITO ASISTENCIAL DE LA VASECTOMÍA

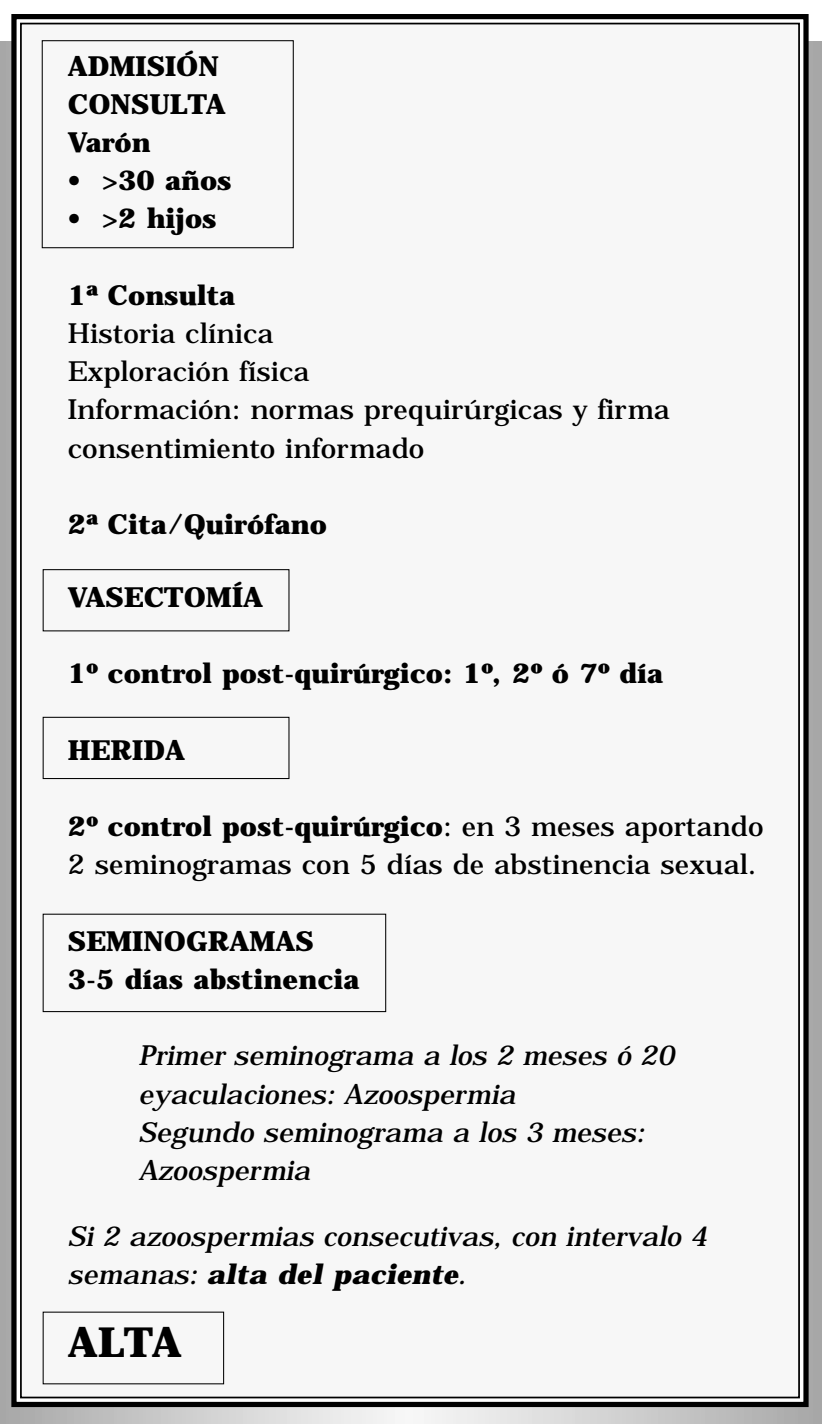

alteraciones genitales que puedan dificultar la cirugía (hernias, hidrocele, varicocele, etc.), tener clara la causa por la que se opera y la firma del paciente en la hoja de consentimiento informado.

En nuestro hospital se entrega siempre una hoja explicativa sobre la intervención, en la que figura también el consentimiento informado (Tabla XV).

En la técnica de Schmidt o de 2 incisiones y en la de Tilak o de 1 incisión en rafe medio el procedimiento es casi el mismo (Figs. 1, 2 y 3).

Técnica de Schmidt (Fig. 1).

Paciente en decúbito supino, con los genitales rasurados en las caras laterales del escroto, y vía

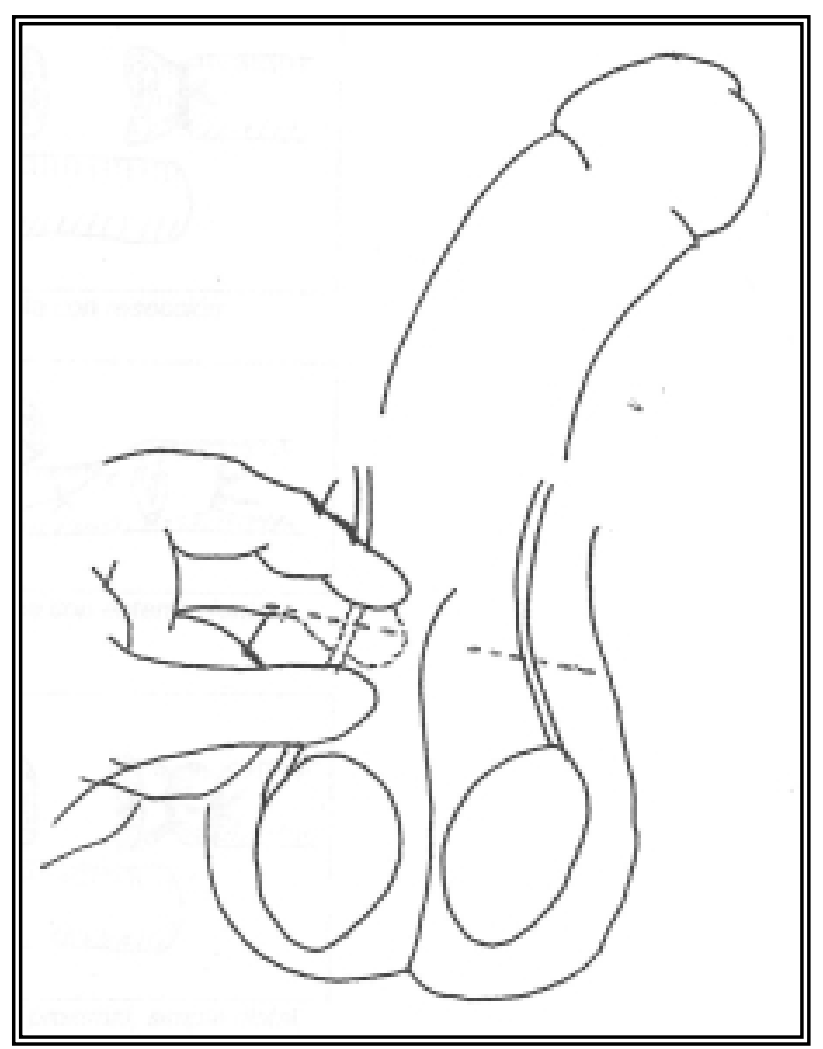

FIGURA 1. Esquema de la vasectomia según técnica de Schmidt o de "2 incisiones". Modificado de Álvarez González $1993^{11}$.

venosa periférica canalizada, en prevención de hipotensiones y bradicardias por el dolor o la tracción del cordón. Desinfección del escroto con betadine (povidona iodada al 10\%) y colocación de campos estériles. Localización y fijación del conducto deferente en la raíz lateral del escroto mediante la técnica de los 3 dedos de Goldstein ${ }^{39}$ : pulgar e indice por arriba y medio por abajo, situándolo lo más superficial posible con los mismos, también se puede hacer con 2 dedos pulgar e índice solamente.

Se practica un habón anestésico subcutáneo con aguja fina de insulina de $25 \mathrm{G}$ y Scandinibsa al $2 \%$ sin vasoconstrictor (mepivacaína $2 \%$ ) diluida en $2 \mathrm{ml}$ de bicarbonato $1 / 6 \mathrm{M}$ para evitar el desagradable picor que produce la infiltración.

Apertura de la piel con bisturí, disección con mosquito curvo de las capas del escroto e identificación del deferente, se infiltra en sus fascias y se fija con pinza de anillo tipo Allis y por tracción se exterioriza. Con bisturí se secciona longitudinalmente la fascia espermática y se ve el deferente de color blanco y mediante una pinza de 
dientes se tracciona y se desliza hacia fuera en una longitud de $2-3 \mathrm{~cm}$. Se colocan pinzas de mosquito en ambos lados con una distancia de 2 $\mathrm{cm}$ y se resecciona el segmento de $2-3 \mathrm{~cm}$ transversalmente. El método oclusivo de los cabos deferenciales puede ser variado y la incidencia de recanalización está determinada por la longitud del deferente extirpado y por la técnica utilizada para el sellado luminal del deferente. Si se extirpan segmentos largos se reducen las posibilidades de reconstrucción microquirúrgica posterior. Muchos urólogos envian el deferente a estudio anatomopatológico, más por arma legal que por verdadera necesidad, ya que si bien la confirmación de que lo extirpado es el deferente puede ofrecer poca protección frente a una demanda legal, si que confirma que se realizó la vasectomía y no otra intervención (por ejemplo la ligadura de una vena, una arteria u otra estructura anatómica que no corresponde al deferente).

De todos modos el procedimiento más utilizado como método oclusivo es la ligadura con suturas no reabsorbibles de seda de $2 / 0$ de los dos cabos deferenciales, si bien este recurso puede originar necrosis del extremo distal a la ligadura, y aumentar las posibilidades de recanalización espontánea por aparición de un granuloma espermático. La frecuencia de recanalización si se utilizan suturas para la oclusión varía entre $0,2-1,5 \%$.

La utilización de hemoclips pequeños en ambos extremos provoca menos necrosis al estar disminuida la presión parietal por ser mayor la superficie de contacto que en el caso de las suturas de hilo, con este método los índices de recanalización o fracaso son $<1 \% 40$.

La electrocoagulación de la luz deferencial (termocauterización) en los cabos distales del segmento reseccionado con un electrobisturí con extremo de aguja fina, es capaz de destruir la mucosa sin afectar al resto de las capas del deferente y es un método efectivo que posee un índice de fracasos de $<0,5 \%{ }^{41}$.

Nosotros realizamos resección de 1-2 $\mathrm{cm}$ de deferente, ligadura doble proximal con seda $2 / 0$, ligadura simple distal con seda $2 / 0$ y coagulación de la luz de ambos extremos deferenciales.

Esta técnica convencional puede tener ciertas variaciones respecto a si se realiza ligadura sin resección o con resección, así cabrían las 5 posibilidades siguientes (Fig. 2):

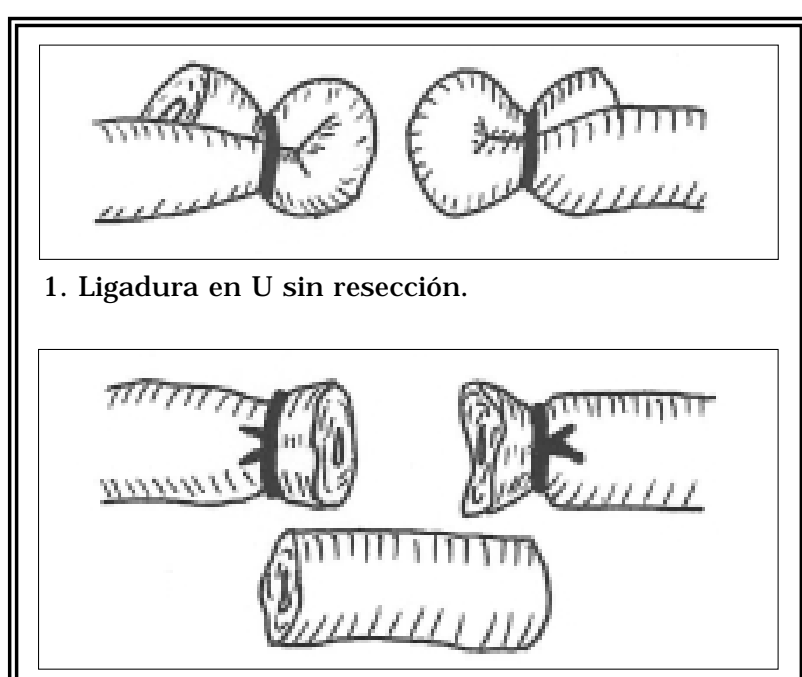

2. Ligadura simple con resección.

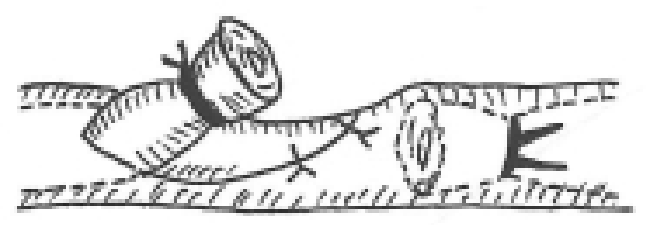

3. Ligadura simple con enterramiento cabo proximal.

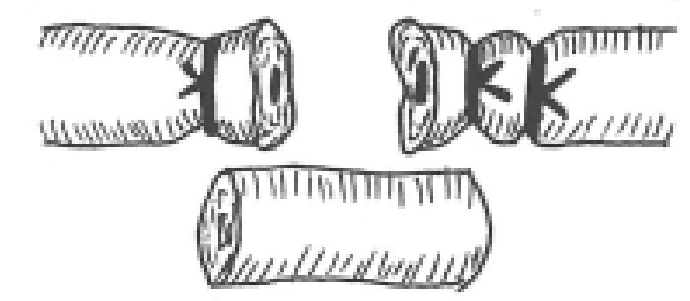

4. Doble ligadura proximal, simple distal, resección y coagulación de la luz.

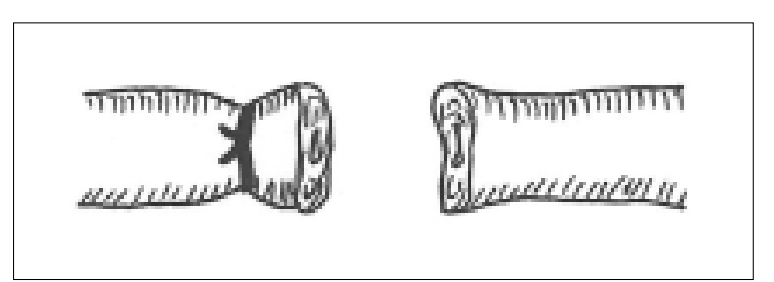

5. Ligadura distal sin ligadura proximal.

FIGURA 2. Técnicas de vasectomía por "ligadura y resección". Modificado de Weiske $2001^{26}$.

1. Ligadura en $U$, reversión sin resección.

2. Ligadura simple proximal y distal con resección.

3. Ligadura simple proximal y distal, enterrando extremo proximal e interponiendo fascia espermática.

4. Doble ligadura proximal, ligadura simple distal, resección y electrocoagulación de la luz (nuestra técnica).

5. Ligadura distal sin ligadura proximal (epididimaria). 
1‥ Ligadura en $U$ con reversión de ambos deferentes pero sin resección.

$2^{a}$. Ligadura proximal y distal con resección.

3a . Ligadura proximal y distal, enterrando el extremo proximal interponiendo fascia espermática.

4⿳⺈. Doble ligadura proximal al testículo, ligadura simple distal, resección y coagulación de la luz (nosotros).

5a . Ligadura distal (arriba) sin ligadura proximal (epididimo).

Nosotros realizamos como variante la doble ligadura proximal y la simple distal con coagulación luminal, con buenos resultados. Sin embargo, otras escuelas dejan el extremo proximal o epididimario sin ligadura, lo que se llama vasectomía con extremo proximal abierto, y al no ser ocluido el deferente, se favorecería la formación de un granuloma espermático que sirve como mecanismo descompresivo de la vía espermática y evita el daño epididimario. Esta vasectomía sin oclusión proximal la hacen quienes piensan que la filtración del fluido seminal testicular en el lugar de la vasectomía evita la presión retrógrada en el extremo proximal y por consiguiente, el peligro de rotura del tubo epididimario que podría dar lugar a obstrucciones epididimarias que en caso de vaso-vasostomía posterior la harían fracasar $^{12}$.

Realizada cualquiera de estas 5 técnicas el paso siguiente es una buena hemostasia y la sutura del dartos cutáneo con material reabsorbible (antes catgut), ahora abandonado por riesgo de transmisión de "priones" o enfermedad de las vacas locas. El procedimiento se repite en el lado contralateral. El apósito y el suspensorio protegen la herida y evitan el dolor y la aparición de hematomas.

Técnica de Tilak (Fig. 3).

Hay autores que utilizan 1 incisión escrotal única y trasladan digitalmente el deferente hasta la incisión. La incisión se hace el rafe medio escrotal. Los defensores de esta técnica dicen que es más fácil de ejecutar, acorta el tiempo quirúrgico y tiene menos complicaciones. Personalmente la he realizado en caso de deferentes anteriores o cuando existe varicocele, hernia o dificultad en el abordaje lateral ${ }^{36}$.

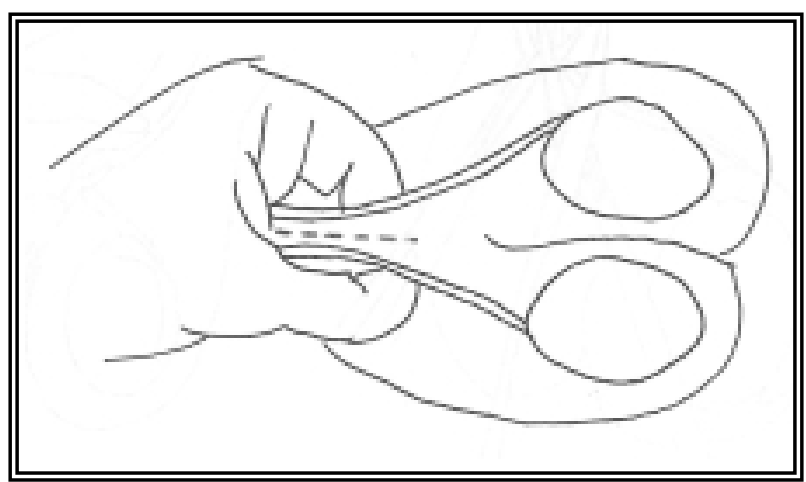

FIGURA 3. Esquema de la vasectomía según técnica de Tilak o de "1 incisión rafe medio". Modificado de Álvarez González $1993^{11}$.

\section{Técnicas de oclusión deferencial}

Nacen por razones culturales y/o religiosas. Son técnicas mínimamente invasivas que ocluyen el conducto deferente sin utilizar incisión cutánea ni bisturí1 ${ }^{12,36}$.

a) Vasectomía o vasotomía sin bisturí, vasectomía tipo $\mathrm{Li}$

Técnica desarrollada en 1974 por LI en China ${ }^{37}$ y más tarde introducida en EE.UU ${ }^{38}$, donde ha ganado popularidad, pero no en Europa. Precisa material específico (pinza hemostática, y pinza de anillo). No es preciso bisturí, la cicatriz es más pequeña y provoca menos complicaciones que los métodos convencionales (Fig. 4).

Se realiza mediante fijación del conducto deferente, sección o resección del fragmento deferencial, sin apertura cutánea (punción cutánea mínima). La preparación y la anestesia local son las mismas que en los métodos convencionales. La técnica se realiza con una sola punción en el rafe medio hasta donde se desplazan digitalmente los deferentes. Una vez el deferente en la línea media es aprehendido con la pinza clamp de punta anular a través de la piel, que no es lesionada al poseer la pinza una apertura en la base del anillo.

Con una rama de la pinza de punta aguda se realiza una punción mínima que interesa la piel, vaina y pared deferencial. Se introduce toda la punta cerrada y a través de ese mínimo orificio se abre y dilata la piel y todas las capas hasta verse denudado el deferente. Se atraviesa oblicuamente la pared del conducto con una rama de la pinza y ésta se rota $180^{\circ}$ exteriorizándose el defe- 


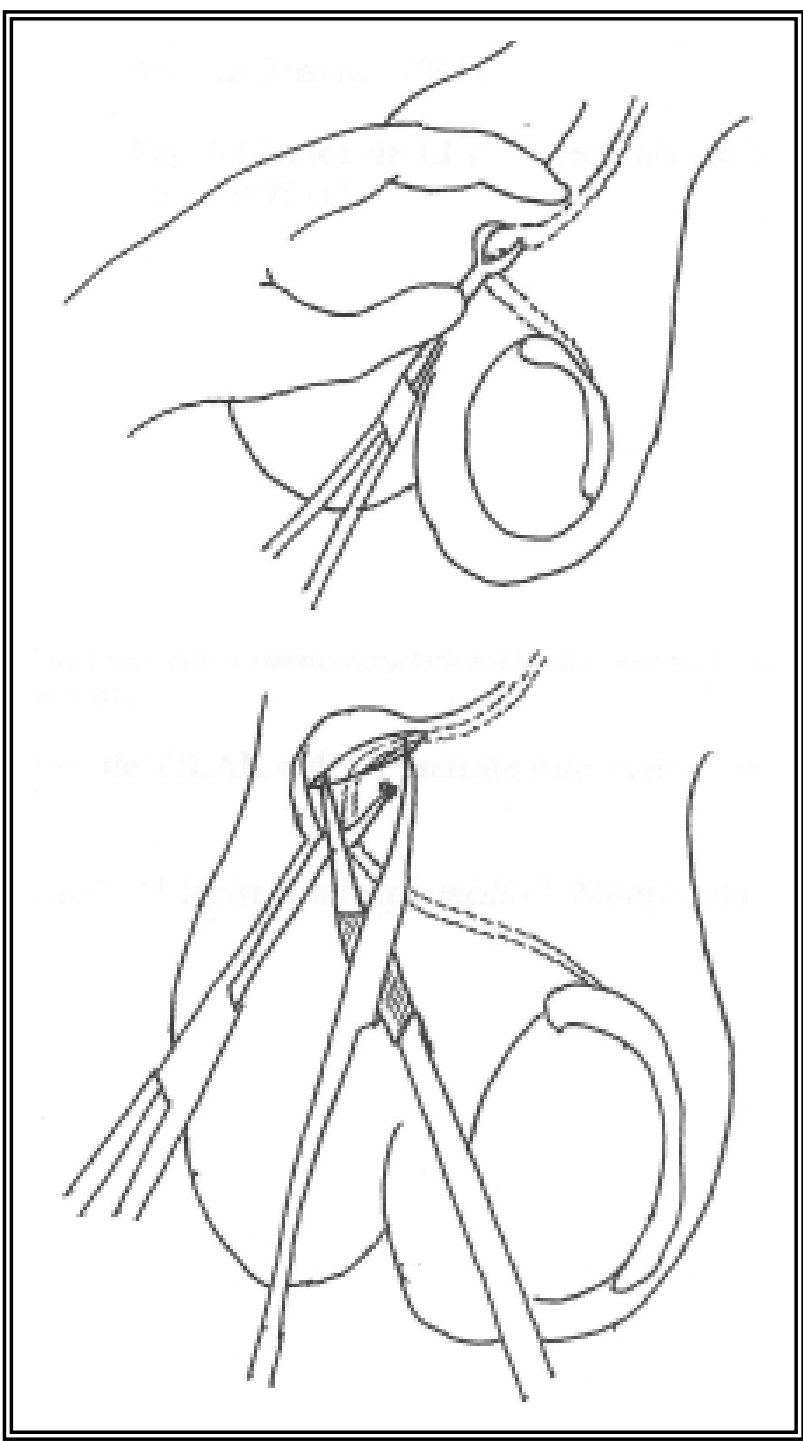

FIGURA 4. Técnica de LI o "vasectomia sin bisturi" "I incisión en rafe medio". Modificado de Artiles y Chesa $1998^{12}$.

rente, que ahora es tomado de nuevo con la pinza anular para finalizar la disección de unos centímetros del conducto deferente. Después se secciona el deferente y se procede a la oclusión luminal utilizando los procedimientos de ligadura con seda o los métodos que referimos a continuación. Posteriormente se devuelve a la bolsa escrotal, se comprime unos 2 minutos, y se comprueba la ausencia de sangrado. No suele precisarse sutura de la piel.

La técnica se acompaña de menos hematomas, infecciones o dolor y además el tiempo quirúrgico es mucho menor. Sin embargo su apren- dizaje es más difícil que la vasectomía convencional y el material ha de comprarse en EE.UU o China.

b) Obstrucción deferencial por inyección percutánea (vasectomía percutánea)

Se han buscado procedimientos fáciles, bien tolerados y eficaces que logren una oclusión deferencial menos destructiva que la conseguida con las técnicas convencionales, y además son reversibles en su gran mayoría.

En China se han realizado más de medio millón de sellados deferenciales percutáneos inyectando productos químicos a través de agujas de 24G. Estos agentes químicos no han sido autorizados en Europa ni en USA.

- Tapón de elastomero de poliuretano.

Se realizó en China en 12.000 varones, con 56 complicaciones menores. En 500 que se siguieron 3 años el \% de azoospermia era del 98\%. En cuanto a su reversibilidad, se realizó la extracción de los tapones de poliuretano en 86 pacientes y 51 lograron descendencia.

- Tapón siliconado inyectado en la luz deferencial.

Se introduce también percutáneo y se libera en una longitud de 1-2 cm.

\section{c) Oclusión mecánica abierta}

Son varias técnicas que mediante apertura quirúrgica mínima del escroto, persiguen la oclusión deferencial reversible, por medio de válvulas, clips, filamentos, etc., que se extraerán en el momento que se quiera hacer reversible.

- Microválvulas metálicas o de material sintético, con mecanismo de apertura y cierre a voluntad del paciente.

Estos métodos buscan el menor traumatismo, respetando la continuidad espermática y una fácil repermeabilización voluntaria. Hay numerosos estudios en busca de procedimientos reversibles de oclusión valvular de la vía espermática como la válvula deferencial sintética de Brueschke $1976^{12}$.

- Clip de tántalo colocado exteriormente sobre un tutor deferencial. Es un anillo metálico abierto que se cierra pinzando externamente el conducto deferente (seccionado o no). Es biológicamente inerte y bien tolerado. Se colocan 2-3 clips sobre cada extremidad seccionada. $\mathrm{Si}$ 
se quiere restablecer la continuidad del deferente la intervención de retirada de clips no siempre es fácil en el seno de la reacción esclerosa.

- Hilo intradeferencial (cobre, silicona, nylon, prolene, propileno, cilindro de acero-titanio).

Un hilo de nylon o de algodón siliconado se introduce en la luz deferencial mediante una pequeña incisión deferencial o mediante una aguja especial. De uno de los extremos sale un hilo de algodón negro de unos $8 \mathrm{~cm}$ que impide la emigración y que permite recuperar la permeabilidad al retirarlo mediante tracción. Se ha usado en voluntarios pero sin resultados prácticos, con más del $6 \%$ de fracasos.

- Otros métodos con balones cerrados mediante clips de plata y otros dispositivos valvulares. $\mathrm{Su}$ finalidad es la reversibilidad, pero aún están en fase experimental.

d) Oclusión química o esclerosis deferencial

Oclusión reversible del deferente mediante inyección de sustancias químicas esclerosantes como etanol al 90\% + formaldehído al 3,6\% ${ }^{12}$.

e) Oclusión endoscópica (uretroscopia).

Requiere cirugía endoscópica por vía uretral bajo anestesia loco-regional o local tópica mucosa. Dolorosa. Se electrocoagula la vía espermática en el punto de desembocadura de los 2 conductos eyaculadores en la uretra posterior, realizado a través de un uretroscopio dotado de 1 electrodo que se introduce por los orificios de los 2 conductos eyaculadores. La secuela más frecuente de la técnica es la estenosis de uretra, "un alto precio", eso sin contar que la oclusión de los conductos eyaculadores sea eficaz.

f) Otros métodos oclusivos han sido investigados o están en vías de investigación, con el empleo de electricidad, láser, ultrasonidos, o criocirugía. Sólo a nivel experimental.

\section{Cambios en las vías espermáticas post- vasectomía}

Hasta aquí se han descrito las diferentes técnicas de vasectomía; a continuación veremos qué cambios se producen en el paciente y en las vías espermáticas tras la vasectomía.
En el paciente, la potencia eréctil y el apetito sexual no se modifican tras la operación. La fertilidad, capacidad fecundativa o reproductiva no se ve alterada inicialmente. Se sigue siendo fértil 23 meses e incluso 5 meses, por lo que se seguirá con el método anticonceptivo utilizado previo a la vasectomía (preservativo, DIU, ACHO, coitus interruptus, etc.). No se sale del quirófano estéril, como ocurre cuando se realiza la ligadura de trompas en la mujer.

La eyaculación sí que presenta volúmenes inferiores en un 10-15\% a los que se tenía previa a la operación. La viscosidad y filancia se modifican, siendo el semen un líquido de aspecto más seroso.

Las secreciones hormonales de FSH, LH, testosterona y estradiol no se modifican ${ }^{12}$.

En las vías espermáticas, a nivel de epididimo y conos eferentes se aprecia la presencia de espermiófagos (macrófagos) que fagocitan los espermatozoides.

La espermatogénesis no se modifica cualitativamente, presentando a nivel del epidídimo espermatozoides normales en estudios realizados, ocurriendo lo mismo que en los pacientes con agenesia bilateral de vía espermática (deferentes y vesículas seminales) común en la fibrosis quística del páncreas o mucoviscidosis, donde también hay espermios en sus epidídimos hasta la $4^{\text {a }}$ década de la vida.

Los espermatozoides pues, se siguen produciendo y la oclusión deferencial aguda que representa la vasectomía, hace que estos espermatozoides se acumulen en el epidídimo, que aparece tenso y distendido, hasta que la producción y destrucción de los mismos se equilibra.

Los cambios post-quirúrgicos en el eyaculado y su control son tema de gran importancia y de posibles implicaciones legales, ya que a consecuencia de los mismos muchos de nosotros "nos podemos ver sentados en el banquillo de los acusados".

\section{Controles seminales post-vasectomía}

Ya que el tiempo necesario para la eliminación total de los espermatozoides presentes en el tramo distal de la vía seminal es variable en cada individuo, se precisa un control posterior del eyaculado mediante seminograma o espermiograma. 
La mayoría de autores coincide en hacer un primer seminograma pasados 2 meses de la vasectomía o tras 15-20 eyaculaciones, presentando azoospermia en ese momento el 95\% de los pacientes ${ }^{16}$.

El control seminal debe hacerse en fresco. La ausencia de espermatozoides en el estudio en fresco, requerirá el estudio del sedimento previa centrifugación, y si se confirma azoospermia, es necesario solicitar otra muestra del semen separada 4-6 semanas y sólo si se confirma también azoospermia, podrán entonces normalizarse las relaciones sexuales sin método anticonceptivo, aunque conviene informar a la pareja por escrito de una probabilidad remota pero existente de recanalización espontánea tardía, cifrada en un $0,03 \%$, en vistas a litigios legales ${ }^{12,42-44}$.

La persistencia en el tiempo de espermatozoides en el eyaculado ${ }^{45-47}$ o la aparición de formas móviles debe hacernos pensar en un fracaso de la técnica por algunos de los siguientes motivos:

- Recanalización espontánea.

- Persistencia de la continuidad de la vía espermática.

- Vía espermática supernumeraria.

- Que el semen del eyaculado no corresponda al paciente (error de laboratorio o mala fe del paciente).

$\mathrm{Si}$ persiste mucho tiempo la presencia de espermios en el eyaculado y se demora la azoospermia, preguntar si hay relaciones sexuales y en qué frecuencia ya que si no existen es difícil eliminar los espermatozoides residuales de la vía espermática.

La recanalización espontánea se produce en el $0,36 \%$ al $1 \%$ de los pacientes y suele ser precoz, apareciendo a los 2-3 meses de la cirugía. La recanalización tardía tiene una incidencia del $0,03 \%$ en una revisión de 16.796 vasectomías $^{32}$.

¿Es necesario el estudio histológico del deferente extirpado? . Este es un procedimiento común que realizamos en España la mayoría de los urólogos, con el fin de demostrar que la intervención se ha llevado a cabo correctamente. Se realiza para asegurarse de que se ha extirpado el deferente y no otro tejido o vaso. Pero es una medida de seguridad para quién, ¿para el pacien- te?, ¿para el cirujano?, ¿o para ninguno?. En España este estudio no es legalmente necesario. Además es un procedimiento que causa un gasto innecesario sin proveernos de beneficios significativos.

Desde el punto de vista legal no es necesario, ya que demuestra que el vaso resecado es el deferente, pero no aporta información sobre si el procedimiento quirúrgico se efectuó bien o mal.

En caso de no cortar el deferente por error de identificación, el primer seminograma mostrará numerosos espermatozoides móviles que persistirán en sucesivos análisis seminales posteriores.

Esta práctica, es costosa para el paciente o para la Seguridad Social y no protege al paciente de recanalizaciones espontáneas posteriores, ni al urólogo de litigios judiciales.

Aunque en raras ocasiones puede mostrar las alteraciones específicas que ocurren en el deferente en caso de enfermedades sistémicas, como por ejemplo la calcificación de los conductos deferentes en la diabetes ${ }^{48}$.

Hay autores como de los Ríos y Castro con amplia experiencia en la práctica de vasectomías que lo han abandonado. En un estudio recientemente publicado de 5.000 vasectomías ${ }^{23}$ sólo han realizado el estudio anatomopatológico del deferente en 430 pacientes, es decir en un 8,6\%. Hoy día ya no lo realizan. Que cada uno obre en consecuencia a este respecto.

\section{Morbilidad post-operatoria y complicaciones}

Respecto a la morbilidad post-operatoria y complicaciones de la vasectomía cabe decir que la vasectomía como toda intervención quirúrgica está sujeta a una serie de complicaciones, cuya tasa oscila entre $0-18 \%^{11}$. La mayoría de complicaciones son leves y ceden con reposo, hielo local, antiinflamatorios o antibióticos, nos referimos a equimosis, seromas, hematomas, o infección cutánea. Más raras veces la complicación es grave y pone en peligro los órganos genitales o la propia vida del paciente por sepsis ${ }^{13,14}$, gangrena ${ }^{22,49,50}$, endocarditis bacteriana ${ }^{51}$ o incluso por muerte ${ }^{24}$.

Existen una serie de factores de riesgo para el desarrollo de complicaciones o comorbilidades. Estos factores de riesgo pueden derivar del propio acto quirúrgico (experiencia del cirujano, 
alargamiento del acto quirúrgico, no-localización del deferente, etc...), así como de las condiciones generales del paciente (obesidad mórbida con escroto difícil, alergia a los anestésicos locales, infección sistémica, alteraciones de la hemostasia, hemofilia, etc...), alteraciones psicológico/psiquiátricas (claustrofobia, temblor esencial), y sobre todo por alteraciones locales del escroto: infecciones cutáneas o dermatitis (foliculitis o micosis), escrotomegalias (varicocele, hidrocele, hernia inguinoescrotal), escrotos hipoplásicos, cirugía previa (criptorquidia o hernia), atrofia testicular, o deferente ilocalizable (agenesia, deferente fino, obesidad, binomio escroto hipoplásico-cordón corto), (Tabla XVII). Estos hallazgos pueden en determinados casos predisponer a complicaciones o comorbilidades, y como mínimo a un alargamiento del tiempo quirúrgico.

En nuestra experiencia hemos tenido 2 casos de incidencias/complicaciones debidas a las condiciones locales del escroto. Un caso por hernia inguinoescrotal que dificultó localizar el deferente bajo anestesia local, por lo que se intervino a pos- teriori con anestesia raquídea en el mismo acto que la herniorrafia. Otro caso de foliculitis escrotal desarrolló un impétigo estafilocócico y posteriormente una sepsis por autocontaminación cutánea.

Las complicaciones publicadas en la literatura científica, las dividiremos en complicaciones generales peroperatorias, precoces (leves y severas), tardías y problemas e incógnitas a largo plazo (Tabla XVIII), aunque en el meta-análisis veremos la gran diversidad de complicaciones referidas en la literatura. Analizaremos estas complicaciones por separado:

\section{Complicaciones generales intraoperatorias}

- Reacción alérgica a los anestésicos locales, desde el eritema al shock anafiláctico de graves consecuencias, incluida la muerte.

- Reacciones vagales. Se han descrito algunas con colapso vascular que han precisado reanimación cardiorrespiratoria. Lo frecuente es la reacción vagal con sudoración, bradicardia, o vómitos, provocada por dolor secundario a la tracción del cordón insuficientemente anestesiado. Ceden

\section{TABLA XVII}

DEPENDENCIA DE LOS FACTORES DE RIESGO PARA DESARROLLAR COMPLICACIONES O CO-MORBILIDADES EN LA INTERVENCIÓN DE VASECTOMÍA

\begin{tabular}{|c|c|}
\hline 1. Propio acto quirúrgico & $\begin{array}{l}\text { Experiencia del cirujano } \\
\text { Alargamiento del acto quirúrgico } \\
\text { La no localización del deferente }\end{array}$ \\
\hline 2. Condiciones generales del paciente & $\begin{array}{l}\text { Obesidad mórbida } \\
\text { Alergia a anestésicos locales } \\
\text { Infección sistémica } \\
\text { Metabolopatías } \\
\text { Discrasias sanguíneas / Hemofilia }\end{array}$ \\
\hline 3. Patología neuro-psiquiátrica & $\begin{array}{l}\text { Temblor esencial } \\
\text { Claustrofobia } \\
\text { Fobia a las agujas } \\
\text { Epilepsia }\end{array}$ \\
\hline 4. Patología local del escroto & $\begin{array}{l}\text { Infecciones cutáneas: dermatitis: foliculitis, micosis. } \\
\text { Escrotomegalias: varicocele, hidrocele, hernia, linfedema, } \\
\text { elefantiasis, deferentitis / orquiepididimitis. } \\
\text { Escrotos dismórficos e hipoplásicos. } \\
\text { Cirugía previa: herniorrafia, hidrocelectomía, varicocelectomía, } \\
\text { criptorquidia. } \\
\text { Historia de traumatismos escrotales: atrofia testicular, luxación } \\
\text { crónica testicular. } \\
\text { Deferente ilocalizable: agenesia (fibrosis quística), fino, obesidad, } \\
\text { binomio escroto alto-cordón corto. }\end{array}$ \\
\hline
\end{tabular}


TABLA XVIII

COMPLICACIONES DE LA VASECTOMÍA REFERIDAS EN LA LITERATURA

\begin{tabular}{|c|c|c|}
\hline \multicolumn{3}{|l|}{ PRECOCES } \\
\hline & Tipos de complicaciones & $\%$ \\
\hline Leves & $\begin{array}{l}\text { Reacciones vagales intraoperatorias } \\
\text { Hallazgo de } 1 \text { solo deferente } \\
\text { Cicatrización por } 2^{\text {a }} \text { intención } \\
\text { Epididimitis y deferentitis } \\
\text { Absceso cutáneo }\end{array}$ & $\begin{array}{c}? \\
0,1 \% \\
0,2-1 \% \\
0,2-6,1 \% \\
6 \%\end{array}$ \\
\hline Graves o severas & $\begin{array}{l}\text { Alteraciones psico-sexuales } \\
\text { Fístulas deferento-cutáneas } \\
\text { Absceso escrotal } \\
\text { Abscesos profundos } \\
\text { Hematomas } \\
\text { Granulomas espermáticos } \\
\text { Hidrocele } \\
\text { Gangrena escrotal } \\
\text { Fracasos: persistencia/recanalización }\end{array}$ & $\begin{array}{c}1-21 \% \\
<1 \% \\
3-5,5 \% \\
3 \% \\
0-18,2 \% \\
5-70 \% \\
0-4 \% \\
? \\
0-6 \%\end{array}$ \\
\hline \multicolumn{3}{|l|}{ TARDÍAS } \\
\hline & $\begin{array}{l}\text { Alteración función testicular } \\
\text { Dolor testicular crónico } \\
\text { Deferentitis nodosa } \\
\text { Obstrucción epididimaria } \\
\text { Ac. antiespermáticos inmovilizantes } \\
\text { Ac. antiespermáticos aglutinantes }\end{array}$ & $\begin{array}{c}30 \% 1^{\mathrm{er}} \text { año } \\
62 \% \text { al } 2^{\circ} \text { año }\end{array}$ \\
\hline \multicolumn{3}{|c|}{ INCÓGNITAS LARGO PLAZO } \\
\hline & $\begin{array}{l}\text { Efectos inmunológicos } \\
\text { Arteriosclerosis } \\
\text { Metabolismo hormonal } \\
\text { Alteraciones psicológicas } \\
\text { Cáncer testículo } \\
\text { Cáncer de próstata } \\
\text { Conociendo estos antecedentes: } \\
\text { ¿es beneficiosa a largo plazo? }\end{array}$ & \\
\hline
\end{tabular}

con atropina i.v. y $\mathrm{O}_{2}$ en gafas nasales, e interrumpiendo unos segundos o minutos el acto quirúrgico y anestesiando mejor. Por ello y dado que se utiliza anestesia local, la operación ha de realizarse en medio hospitalario correctamente dotado y el paciente con vía venosa periférica canalizada.

- Hallazgo incidental de un solo conducto deferente. Es raro si se explora previamente al acto quirúrgico en la $1^{\mathrm{a}}$ consulta como realizamos nosotros. No obstante se ha descrito en un $0,1 \%$ de los pacientes operados. Nosotros tenemos un caso de agenesia unilateral de deferente que no está recogido para este estudio por ser posterior al mismo. La vasectomía unilateral logró la azoospermia.

\section{Complicaciones precoces}

\subsection{Leves}

- Hemorragia de la herida, equimosis, hematoma subcutáneo, etc. Son de aparición precoz y curan con medidas generales.

- Cicatrización por segunda intención. Se suele producir en caso de infección de la herida o absceso cutáneo, ya que suele haber deshiscencia de sutura. Su frecuencia es de 0,2-1\%.

- Epididimitis y deferentitis son secundarias a la manipulación quirúrgica, su frecuencia oscila entre 0,2-6,1\%.

- Absceso cutáneo. Es raro. Sin embargo hay autores que dan frecuencias del $6 \% 12$.

Hay quien considera que la aparición de anticuerpos antiespermatozoides inmovilizantes des- 
pués de 1 año en alrededor del 30\% de pacientes es una complicación leve. Igualmente que la aparición de anticuerpos antiespermatozoides aglutinantes, que a los 2 años es positiva en el $62 \%$ de los pacientes.

\subsection{Graves o severas}

- Alteraciones psico-sexuales. Son generalmente leves. Referidas con frecuencia dispar entre $1-21 \%$, pero que en ocasiones representan un problema severo. La potencia sexual no tiene por que alterarse tras la vasectomía, pero no se aconseja realizar la vasectomía en pacientes afectos de disfunción eréctil, porque es obvio que la vasectomía no la va a resolver y al contrario fácilmente la podrá agravar. Lo habitual es que esta operación se realice con una finalidad diferente, en numerosas ocasiones, tratando de evitar el efecto negativo que el riesgo de un embarazo no deseado origina sobre la función eréctil, la realidad es que la vasectomía puede ser el detonante que hace saltar un conflicto de pareja en situaciones de problemas psicológicos previos.

La confusión entre virilidad y esterilidad surge cuando el paciente relaciona la vasectomía con la castración o la pérdida de su masculinidad.

- Fístulas deferento-cutáneas (vasocutáneas). Aparecen entre la $3^{\mathrm{a}}$ y $11^{\mathrm{a}}$ semanas, con una frecuencia $<1 \%$. Se deben a infección y necrosis del extremo proximal del deferente, ante la presencia de un cuerpo extraño como es el material de ligadura quirúrgica (seda). La operación puede ser necesaria para retirar la sutura, pero a veces excepcionalmente cierran espontáneamente al expulsarse el material. También ha sido descrito un caso de fístula uretro-deferento-cutánea ${ }^{52}$.

- Abscesos cutáneos escrotales y abscesos profundos también han sido referidos en la literatura con una frecuencia de $3-5,5 \%$ para los escrotales y del 3\% para los profundos.

- Granulomas espermáticos. Ocurren con una frecuencia muy dispar entre el 5-70\% según Weiske $^{26}$. Pueden formarse en el punto de ruptura del conducto deferente debido a la hiperpresión, con ellos se origina una obstrucción. Se produce, como efecto natural y no como complicación en las técnicas de vasectomía que no ligan el cabo proximal (inferior). Está justificada su resección cuando produce dolor crónico o fistuliza a piel, hecho éste infrecuente ${ }^{12}$.
- Gangrena de Fournier. Es rara. Aunque se ha descrito en España ${ }^{22}$. Es de graves consecuencias para los pacientes ya que pueden perder parte de sus genitales ${ }^{49,50}$, o incluso la vida ${ }^{24}$.

\section{Complicaciones tardías}

- Alteraciones de la función testicular. La oclusión deferencial provoca un aumento de presión en la porción ductal cercana al testículo, que se trasmite al tubo seminífero, lo que ocasiona cambios histológicos detectados en biopsias realizadas hasta 15 años más tarde.

- Síndrome de dolor testicular crónico post-vasectomía. Es un dolor crónico testicular o epididimario. Afecta al 0,05\% de los pacientes. El dolor se acompaña de induración epididimaria y es refractario al tratamiento médico por lo que precisará epididectomía y vasectomía parcial. La sintomatología desaparece a las 24 horas postreintervención en el 95\% de pacientes.

- Deferentitis nodosa (vasitis nodosa). Se observa en $2 / 3$ de los pacientes sometidos a repermeabilizaciones o reversiones tipo vasovasostomía tras la vasectomía (66\% de casos). Es un proceso benigno del conducto deferente que ocasiona una pequeña tumoración que a veces se puede confundir con un tumor benigno ${ }^{53}$. Kiser y cols., revisan 30 pacientes a los que se les extrae una masa deferencial durante la vaso-vasostomía, apreciando esta patología en 20 casos. Su importancia viene dada porque su existencia puede hacer posible la recanalización espontánea de los extremos deferenciales tras la vasectomía ${ }^{19}$. Su tratamiento es quirúrgico: resección del tumor benigno que representa la vasitis nodosa y nueva vasectomía de ese lado.

- Obstrucción epididimaria. Es una lesión epididimaria similar a deferentitis nodosa, descrita en pacientes sometidos a epididectomía por dolor tras la vasectomía. En más del 70\% de casos una respuesta inmunológica profunda ha sido implicada como la responsable de estas continuas complicaciones tardías. Cuando la oclusión aguda da lugar a rotura de la vía espermática por sobredistensión, los macrófagos fagocitan los espermatozoides, contribuyendo a la autosensibilización ante los propios antígenos espermáticos. La vasectomía produciría la "rotura de la barrera hematotesticular", creando altos valores 
de anticuerpos séricos antiespermáticos en el 68$80 \%$ de pacientes vasectomizados, sin que se haya asociado a enfermedades inmunitarias o autoinmunes en animales ni en el hombre.

- Anticuerpos antiespermatozoides inmovilizantes aparecen después de un año en el 30\% de los pacientes vasectomizados.

- Anticuerpos antiespermatozoides aglutinantes aparecen a los 2 años en el $62 \%$ de pacientes.

- Controversia vasectomía y cáncer de próstata. La publicación de algunos artículos en EE.UU sobre el posible aumento del riesgo de padecer cáncer de próstata en la población vasectomizada ${ }^{54,55}$, abrió una controversia no aclarada hasta hace poco $^{56}$.

En 1993 un panel multidisciplinario de los Institutos Nacionales de Salud de EE.UU. concluyó que la asociación entre cáncer de próstata y vasectomía carecía de solidez, recomendando no hacer diferencias para la indicación de screening en la población vasectomizada ${ }^{57,58}$.

No obstante la Sociedad Americana de Urología recomienda la realización de tacto rectal y determinación de PSA anual a los pacientes que llevan más de 20 años vasectomizados y a todos aquellos sometidos a la vasectomía por encima de los 40 años.

La Asociación Española de Urología emitió una nota informativa en abril de 1993 donde recomendaba la realización de examen digital prostático y PSA en los individuos que lleven 20 años o más vasectomizados, así como la inclusión de información sobre el resultado de los estudios citados en el consentimiento informado previo a la intervención.

Recientemente el pasado año 2002, un estudio del Instituto Nacional de Salud Estadounidense ha demostrado, en contra de lo concluido por ensayos previos, que los hombres vasectomizados no tienen mayor riesgo de padecer cáncer de próstata. Según se publica en el último número del JAMA el equipo de Brian Cox, del Instituto Nacional de la Salud Infantil y Desarrollo Humano, entrevistó a 2.150 varones neozelandeses de entre 40 y 74 años, la mitad de los cuales tenían cáncer de próstata diagnosticado. Tras los ajustes oportunos se determinó que la vasectomía no aumentaba el riesgo de padecer carcinoma de próstata. Este artículo del JAMA ${ }^{56}$ des- miente por tanto definitivamente toda relación entre cáncer de próstata y vasectomía.

Los científicos eligieron Nueva Zelanda por dos razones: el país tiene una de las más altas prevalencias de vasectomía y el cáncer debe declararse en un Registro Nacional de Enfermedad ${ }^{56}$.

\section{Efectos e incógnitas de la vasectomía a largo plazo \\ - Efectos inmunológicos}

El $70 \%$ de los pacientes vasectomizados desarrolla anticuerpos séricos antiespermáticos ${ }^{59}$, con un máximo a las 6-8 semanas 60 .

Es una respuesta inmune clásica a los antígenos (espermatozoides). Los espermatozoides son antígenos a causa de la barrera hemato-testicular (en condiciones normales no la atraviesan) y por el hecho de que ellos se forman después del desarrollo del sistema inmune. Al romperse la barrera hemato-testicular por la extravasación de espermios secundaria a la obstrucción deferencial aguda, se ponen en contacto con el sistema inmune, sin que se haya evidenciado enfermedades inmunitarias ni autoinmunes por dichos anticuerpos. En la mayoría de los pacientes los anticuerpos descienden a valores moderados.

Weiske en el 2001 publica que en 500 vasectomizados sometidos a reversión de la vasectomía, detecta anticuerpos antiespermáticos en el $13 \%{ }^{26}$.

Se conoce que dichos anticuerpos son de 2 tipos:

- Anticuerpos antiespermáticos inmovilizantes, presentes en el 30\% de pacientes a partir del primer año.

- Anticuerpos antiespermáticos aglutinantes, que aparecen a los 2 años en el $62 \%$ de los pacientes $^{61}$.

- Alteraciones bioquímicas, patologías que precisan hospitalización o enfermedades cardiovasculares.

No se ha podido demostrar que los pacientes vasectomizados tengan mayor riesgo, comparados con grupos control ${ }^{62}$.

\section{- Arteriosclerosis}

En España Puyol y cols. en $1997^{20}$ no encontraron cambios significativos sobre los factores de riesgo conocidos en la patología arteriosclerótica en 103 pacientes vasectomizados. 
Un estudio anterior más amplio de Massey y cols. en $1984^{63}$ sobre 10.590 pacientes vasectomizados, se comparó con el mismo número de pacientes no vasectomizados, de la misma edad y raza, y examinados para 54 enfermedades de órganos importantes. La media de tiempo post-vasectomía era de 7,9 años. Los resultados del estudio mostraron un nivel similar o más bajo de enfermedades cardiovasculares, neoplasia y enfermedades autoinmunes, en el grupo de los vasectomizados. La diabetes mellitus y la morbilidad general era más baja en el grupo de los vasectomizados.

Manson en $1999^{64}$, en 22.071 vasectomizados, evidenció que la vasectomía no aumentaba el riesgo cardiovascular incluso 15 años después de ser vasectomizado.

Se puede establecer hoy, que la vasectomía no se asocia con un aumento de riesgo de arteriosclerosis o enfermedades autoinmunes. Sin embargo, un grado más alto de morbilidad se apreció para los vasectomizados en epididimitis y orquitis (lo cual es lógico).

\section{- Litiasis urinaria}

Un estudio reciente con pacientes vasectomizados y controles encontró un incremento de riesgo duplicado para litiasis urinaria en vasectomizados menores de 46 años, dicho factor de riesgo persiste 14 años post-vasectomía ${ }^{65}$.

\section{- Metabolismo hormonal}

La testosterona producida por las células de Leydig no se ve afectada por la vasectomía ${ }^{66}$. Un estudio multicéntrico reveló concentraciones más bajas en suero de la globulina fijadora de hormona sexual (SHBG) y un ratio más alto de DHT/T en los vasectomizados que en los controles. Resultados similares con elevación de la DHT en los vasectomizados se vieron en el estudio de Mo y cols. en $1995^{67}$. Este perfil endocrino alterado en pacientes vasectomizados necesita evaluación posterior en estudios longitudinales. A fecha de hoy no hay motivo biológico de por qué la vasectomía influiría en la conversión de testosterona en dihidrotestosterona.

\section{- Alteraciones psicológicas}

Los pacientes con alteraciones psicológicas previas, no se deben de intervenir de vasectomía sin una amplia discusión preoperatoria para aclarar los problemas psicológicos, y consecuentemente llegar a la consideración de si la vasec- tomía debería realizarse más tarde o no hacer$1 a^{26}$. En España, y más concretamente en nuestro medio, la fuerte demanda en consultas externas no ofrece muchas oportunidades para extenderse con los pacientes problemáticos, debiendo citarles en otra ocasión o incluso fuera del horario de consultas para aclarar estas dudas.

\section{- Vasectomía y cáncer testicular}

La asociación de vasectomía y cáncer de testículo ha sido discutida, sin que hasta la actualidad los datos epidemiológicos publicados hayan aportado alguna relación etiopatogénica con esta neoplasia ${ }^{68,69}$.

Los estudios relacionados con el cáncer de testículo son controvertidos. En todas las investigaciones donde se demostró una relación positiva entre el cáncer testicular y la vasectomía, ésta estaba relacionada con causas epidemiológicas. Estadísticamente es muy difícil establecer una correlación positiva, particularmente porque la incidencia de carcinoma testicular en la población es de 2-8/100.000 varones. En un importante estudio de cohortes con más de 73.000 hombres, no se observó riesgo aumentado de cáncer testicular después de la vasectomía ${ }^{68}$.

El cáncer testicular se origina a partir de un carcinoma in situ (CIS). Se cree que el CIS es un gonocito maligno formado durante la embriogénesis. La vasectomía podría precipitar el desarrollo de cáncer testicular pero a partir de una lesión preinvasiva de $\mathrm{CIS}^{70}$.

- Vasectomía y cáncer de próstata, ¿el por qué de la controversia?

Tema controvertido por haber 2 opiniones contradictorias, unos opinan que la vasectomía sí aumenta el riesgo de cáncer de próstata y otros que no.

Entre los estudios que opinan que la vasectomía aumenta el riesgo de cáncer de próstata tenemos 2 estudios de cohortes de Giovannucci en $1993 a^{54}$ y $1993 b^{71}$ y 2 investigaciones de Mettlin en $1990^{72}$ y Rosenberg en $1990^{73}$ que dicen que los vasectomizados tienen un aumento de riesgo de cáncer de próstata, sobre todo los que están más de 20 años operados. Sin embargo, la diferencia de mortalidad no es significativa.

Otros autores como Lesko y cols. en 199974, en un estudio realizado en Massachusetts, no 
confirman la hipótesis de que la vasectomía aumente el riesgo de cáncer en hombres mayores de 55 años.

Bernal Delgado y cols. en $1998^{27}$ realizaron un meta-análisis de todos los estudios importantes sobre vasectomía y cáncer de próstata en la literatura, concluyendo que no hay relación causal entre vasectomía y cáncer de próstata.

Más recientemente un artículo publicado en JAMA de Brian Cox y cols. en $2002^{56}$ desmiente toda relación entre vasectomía y cáncer de próstata y aclara definitivamente que la vasectomía no aumenta el riesgo de cáncer de próstata.

Nosotros éramos partidarios de no recomendar la vasectomía a pacientes con antecedentes familiares de cáncer de próstata (padres/hermanos), ahora tenemos dudas de si debemos aconsejarla o no, incluso existiendo estos antecedentes, en vistas al trabajo de Cox y cols. ${ }^{56}$.

¿Pero por qué se obtienen estos diferentes resultados en un tema tan importante?

Las diferencias podrían deberse a sesgos en la selección de los participantes en el estudio y en los controles, y también en la forma en la que se ha obtenido la información de los pacientes incluidos en el estudio (cuestionarios, entrevistas telefónicas, etc.) y a la confusión existente en la relación entre vasectomía y cáncer de próstata.

En USA y Europa Occidental, la vasectomía es realizada por urólogos. Por lo tanto es más fácil pensar que un porcentaje de pacientes tengan un examen preoperatorio rectal y un chequeo de su PSA a diferencia de los pacientes que no son operados por urólogos ${ }^{26}$.

En un meta-análisis Bernal Delgado y cols. en $1998^{27}$ hallan un riesgo significativo más elevado de cáncer de próstata, después de la vasectomía en los estudios hospitalarios (riesgo relativo $=1,98$; $95 \%$ intervalo confianza entre $1,37-2,86)$ y no hallan riesgo aumentado en los estudios basados en población general no hospitalaria (riesgo relativo 1,$12 ; 95 \%$ intervalo confianza entre $0,96-1,32$ ).

Los hombres vasectomizados son sexualmente más activos, tienen mejor salud y viven más tiempo, por ello se ven con menos frecuencia en los hospitales que los no vasectomizados ${ }^{75}$.

Sin embargo una vida prolongada se asocia con el riesgo de desarrollar cáncer de próstata en la vejez, tanto en vasectomizados como en no vasectomizados.
En 1998 Peterson y Howards ${ }^{28}$ del Centro Nacional de Atlanta para la Prevención de Enfermedades Crónicas y Promoción de la Salud, llegaron a la conclusión de que los estudios de relación entre vasectomía/cáncer de próstata son inconsistentes y que las asociaciones observadas entre los estudios más positivos son débiles epidemiológicamente.

No debe causar sorpresa esta supuesta relación entre vasectomía y cáncer de próstata, ya que se tardó 10 años en refutar la idea de que la vasectomía incrementaba el riesgo de arteriosclerosis en el varón.

Por lo tanto en EE.UU como en Europa, las parejas siguen usando la vasectomía como un método seguro de anticoncepción ${ }^{76}$, la población general no está nada preocupada por esta posible asociación.

La American Urological Association, en un informe apoyado por la German Society of Urology, recomienda que se debería realizar exámenes preventivos a partir de los 40 años a los vasectomizados, con tacto rectal y PSA anuales.

En este momento no hay razones para que los hombres vasectomizados se sometan a reversión de su vasectomía por riesgo de cáncer de próstata. Previo a la vasectomía a los pacientes se les debe informar de que deben someterse a estudios posteriores pertinentes, dejando la decisión final para él.

Un análisis del factor de riesgo de cáncer de próstata en más de 500.000 varones en un estudio nacional de PSA fue insuficiente para demostrar relación entre vasectomía y cáncer de próstata $^{77}$.

\section{5. ¿Es la vasectomía beneficiosa a la larga?}

Alrededor de un $5 \%$ de varones vasectomizados consideran someterse a la reversión de la vasectomía. El 90\% de estos casos se deben a un nuevo matrimonio con una mujer más joven y el deseo de tener hijos. Considerando un grado de divorcio por encima del $50 \%$ en los países occidentales, este \% de reconversiones es bastante bajo, lo que hace pensar que los hombres que se someten a la vasectomía tienen parejas estables y la decisión la tenían clara ${ }^{78}$.

Al haber tantos divorcios, se debería esperar un \% más alto para la vaso-vasostomía. La vaso- 
vasostomía tiene un éxito quirúrgico del 75-95\% y ofrece un \% de embarazos del $40-75 \%^{79}$. El coste de la operación de reconversión es más bajo que si se hubiesen adoptado métodos anticonceptivos durante $7-9$ años ${ }^{80}$.

En opinión de Weiske $2001^{26}$ no se justifica la criopreservación de semen preoperatoria en general, ya que el 95\% de los vasectomizados no desearán nunca hacerse la reconversión. Además podría sobrepasar el coste de la propia reconversión si se deja el semen congelado entre 7-9 años.

La vasectomía debe realizarse a quien esté seguro al $100 \%$ de que la quiere, es decir que sea opinión definitiva. La criopreservación ¿debe ofrecerse a los pacientes con dudas? ¿o por el contrario no debe hacerse la vasectomía?. La criopreservación no debe ofrecerse a los pacientes ya que disminuye la seriedad de la decisión por la vasectomía.

\section{6. ¿Es necesario el estudio histológico del segmento de deferente extirpado?}

Es un procedimiento común que realizamos para demostrar que se ha llevado a cabo la intervención de vasectomía. Se realiza para asegurarnos de que lo que se extirpa es el deferente y es una seguridad para el paciente y para el cirujano. Sin embargo esta medida no es requerida legalmente.

Es un procedimiento costoso, y quizá innecesario, que causa gasto adicional sin proveer beneficios significativos. Hay autores como De los Ríos y Castro con amplia experiencia en esta cirugía que han abandonado la práctica del estudio histológico del deferente resecado ${ }^{23}$.

Desde el punto de vista legal no es necesario, y no es necesario legalmente ya que demuestra que el vaso resecado es el deferente, pero no aporta información sobre si el procedimiento quirúrgico se llevó a cabo correctamente.

En caso de no cortar el deferente por error de identificación, el primer espermiograma mostrará numerosos espermatozoides móviles que persistirán en sucesivos análisis de semen posteriores.

En resumen, es una práctica costosa que no protege al paciente de recanalizaciones posteriores. Aunque en raras ocasiones puede informar incidentalmente de la repercusión de las enfer- medades generales o metabólicas en el deferente, como por ejemplo la diabetes y la calcificación deferencial $^{48}$.

\section{La vasectomía en los Congresos Nacionales de Urología y publicaciones nacionales}

Hemos revisado los abstracts de todos los libros de resúmenes de los Congresos Nacionales de Urología (CNU) desde el año 1993 al 2003 (11 años), y hemos reseñado las citas referentes a la vasectomía que quedan reflejadas en la Tabla XIX. En estos 11 años se han presentado en los CNU un total de 11 trabajos relacionados con la vasectomía. La mayoría de los cuales no eran realmente sobre esta técnica sino sobre su reconversión o vaso-vasostomía. Así, había 7 comunicaciones sobre vasovasostomía, 3 sobre la vasectomía o su morbilidad y 1 sobre agenesia deferentes. La media de comunicaciones anuales sobre vasectomía en nuestros CNU es de 1 por año, ¿es una patología olvidada?, o ¿carece de interés urológico?.

Quizá se trate más en los Congresos Nacionales de Andrología, a este respecto sólo dispongo de datos del $\mathrm{X}$ Congreso de Alicante 2001 con un total de 5 comunicaciones en 1 año: Romero Pérez y cols. ${ }^{14}$, Romero Maroto y cols. ${ }^{91}$, Lertxundi $^{92}$, Llopis ${ }^{93}$, Canovas y cols. ${ }^{94}$.

La vasectomía tampoco ha recibido en general especial trato en las publicaciones científicas nacionales, injusto diría yo, si tenemos en cuenta que es la cirugía urológica más frecuente que se realiza en España. Impresiona que no sea tema de interés general, salvo excepciones, que recogemos y deseamos haberlas recogido todas y si hemos omitido alguna ha sido involuntariamente.

Hemos realizado una extensa revisión de la literatura nacional en las 2 revistas nacionales más prestigiosas Actas Urológicas Españolas y Archivos Españoles de Urología así como en otras revistas también de la especialidad e incluso de libros. Tenemos documentadas 30 publicaciones sobre la vasectomía o relacionadas con ella, de otros tantos autores, en las que hemos incidido sobre todo en el estudio de sus complicaciones, y en las que se reseña autor, revista/libro año, número de casos y \% de complicaciones (Tabla XX). 
COMUNICACIONES SOBRE LA VASECTOMÍA EN LOS CONGRESOS NACIONALES DE UROLOGÍA PERIODO 1993-2003 (11 AÑOS)

\begin{tabular}{|c|c|c|c|c|c|}
\hline Años & № congreso AEU & Ciudad & № comunicaciones & Autores & Temática \\
\hline 1993 & LVIII CNU & Málaga & 0 & & \\
\hline 1994 & LIX CNU & Sitges & $\begin{array}{c}1 \\
\text { (+ }+5 \text { experimentales) }\end{array}$ & $\begin{array}{l}\text { Hernáez Manrique } \\
\text { y cols. }{ }^{81}\end{array}$ & $\begin{array}{l}\text { Vaso-vasostomía } \\
\text { post-vasectomía }\end{array}$ \\
\hline 1995 & LX CNU & Santiago Compostela & 0 & & \\
\hline 1996 & LXI CNU & Santander & 2 & $\begin{array}{l}\text { Martín y cols. }{ }^{82} \\
\text { Pomerol y cols. }{ }^{83}\end{array}$ & $\begin{array}{c}\text { Morbilidad } \\
\text { vasectomia } \\
\text { Vaso-vasostomia }\end{array}$ \\
\hline 1997 & LXII CNU & Valladolid & 0 & & \\
\hline 1998 & LXIII CNU & Cádiz & 1 & Delgado Martín y cols. ${ }^{84}$ & Vaso-vasostomía \\
\hline 1999 & LXIV CNU & Zaragoza & 1 & Valero Millán y cols. ${ }^{85}$ & Vaso-vasostomía \\
\hline 2000 & LXV CNU & Madrid & 3 & $\begin{array}{l}\text { Valero Millán y cols. } .^{10,86} \\
\text { Clemente y cols. }{ }^{87}\end{array}$ & $\begin{array}{c}\text { Mesa redonda: } \\
\text { vasectomia* } \\
\text { Vaso-vasostomia } \\
\text { Agenesia deferentes }\end{array}$ \\
\hline 2001 & LXVI CNU & Granada & 2 & $\begin{array}{l}\text { Jiménez Aristu y cols. }{ }^{88} \\
\text { Gómez de Vicente y cols. }{ }^{89}\end{array}$ & $\begin{array}{l}\text { Vaso-vasostomía } \\
\text { Espermiograma } \\
\text { post-vasectomia* }\end{array}$ \\
\hline 2002 & LXVII CNU & Murcia & 1 & Cos Calvet y cols. ${ }^{90}$ & Vaso-vasostomía \\
\hline 2003 & LXVIII CNU & $\begin{array}{l}\text { Las Palmas de } \\
\text { Gran Canaria }\end{array}$ & 0 & & \\
\hline \multicolumn{6}{|l|}{ Total } \\
\hline 11 años & 11 congresos & & 11 referencias & 9 autores & $\begin{array}{l}3 \text { referencias } \\
\text { específicas } \\
\text { vasectomía }\end{array}$ \\
\hline
\end{tabular}

Las referencias específicas sobre vasectomía son las marcadas con * y negrita.

\section{Revisión de las complicaciones de la vasectomía}

La vasectomía es una intervención urológica técnicamente sencilla, pero no por ello exenta de complicaciones y como tal acto quirúrgico (manual) está sujeta a una serie de comorbilidades que detallaremos tanto a nivel nacional como internacional, en respectivas tablas.

La tasa de complicaciones derivadas de la propia intervención oscila entre un $0-18 \%{ }^{11}$. Su gravedad y naturaleza puede ser sumamente variable, desde una leve equimosis hasta una grave gangrena genital ${ }^{22,49,50}$, una endocarditis bacteriana ${ }^{51}$ o incluso la muerte ${ }^{24}$.

Otra complicación, quizá la más desagradable para facultativos y pacientes, es la derivada de la recanalización espontánea temprana, cuya tasa es de $0,36 \%$ o tardía cuya tasa es del 0,03\%, con el fallo de la vasectomía y el embarazo de la esposa y/o nacimiento de un nuevo hijo ${ }^{3,32}$.
- Tipo de complicaciones referidas en la literatura nacional española (Tablas XXI y XXII).

A nivel nacional español existen también referencias acerca de las complicaciones de la vasectomía, entre las que destacan las series de numerosos autores como Arango y cols. en $1988^{16}$, Arango y cols. en $1993^{3}$, Romero y cols. en $2001^{14}$, Castillo y cols. en 1992 ${ }^{17}$, González y cols. en $1992^{105}$, entre otros.

Hemos estudiado a 20 autores nacionales entre 1987 y 2002 con aportación de 30 complicaciones diferentes. Estos 16 años, los hemos dividido en dos periodos, uno de 10 años (19871996) con 10 autores (Tabla XXI) y otro de 6 años (1997-2002) con 10 autores (Tabla XXII).

Es de esperar que estas complicaciones referidas en la literatura se vean disminuidas en el futuro, a partir de los trabajos que se siguen llevando a cabo sobre los efectos de la vasectomía sobre el tracto genital masculino, en especial 
TABLA XX

PUBLICACIONES NACIONALES SOBRE LA VASECTOMÍA Y SUS COMPLICACIONES. PERIODO 1986-2002

\begin{tabular}{|c|c|c|c|c|}
\hline Autores & Año & Publicación & № casos & $\%$ complicaciones \\
\hline 1. Núñez y cols. ${ }^{95}$ & 1986 & Actas Urol Esp 10: 55 & Trabajo experimental ratas & \\
\hline 2. Mayor y cols. ${ }^{15}$ & 1987 & Actas Urol Esp 9: 481 & 140 & 35 (25\%) \\
\hline 3. Arango y cols. ${ }^{16}$ & 1988 & Actas Urol Esp 12: 430 & 500 & $12(2,4 \%)$ \\
\hline 4. Álvarez González ${ }^{1}$ & 1989 & $\begin{array}{l}\text { Andrología. Teoría y } \\
\text { práctica (LIBRO) }\end{array}$ & $\begin{array}{l}\text { Revisa anticoncepción } \\
\text { masculina }\end{array}$ & $4,3-9,6 \%$ \\
\hline 5. McDonald ${ }^{96}$ & 1991 & $\begin{array}{l}\text { BMJ Internacional (edición } \\
\text { español) 3: } 8\end{array}$ & $\begin{array}{l}\text { Vasectomía y testículos } \\
\text { humanos }\end{array}$ & \\
\hline 6. Castillo y cols. ${ }^{17}$ & 1992 & Arch Esp Urol 45: 63 & 1800 & $108(6 \%)$ \\
\hline 7. Álvarez González ${ }^{11}$ & 1993 & Cuadernos de Urología 11: 3-9 & Revisión vasectomía & $0-18 \%$ \\
\hline 8. Arango y cols. ${ }^{3}$ & 1993 & Arch Esp Urol 46: 29-34 & $\begin{array}{l}\text { Seminograma post- } \\
\text { vasectomía } 313 \text { casos }\end{array}$ & \\
\hline 9. Ruiz y Leva ${ }^{97}$ & 1993 & $\begin{array}{l}\text { Tratado Urología Jiménez } \\
\text { Cruz-Rioja Sanz voll, cap. 56: } 913\end{array}$ & Anticoncepción masculina & $\begin{array}{l}6,4 \% \text { inmediatas } \\
3,2 \% \text { tardias }\end{array}$ \\
\hline 10. Ruiz y Pomerol ${ }^{98}$ & 1994 & $\begin{array}{l}\text { Práctica Andrológica. } \\
\text { Pomerol-Arrondo. LIBRO } \\
\text { cap. 73: } 609\end{array}$ & Contracepción quirúrgica & No se especifica $\%$ \\
\hline 11. Viladoms y $\mathrm{Li}^{4}$ & 1994 & Arch Esp Urol 47: 695 & Vasectomía sin bisturí & \\
\hline 12. Saiz y cols. ${ }^{18}$ & 1994 & Actas Urol Esp 18: 552-554 & Vasectomía y cáncer próstata & \\
\hline 13. Saladié y cols. ${ }^{99}$ & 1996 & Arch Urol Esp 49: 507-510 & Vaso-vasostomía & \\
\hline 14. Cozcolluela y cols. ${ }^{100}$ & 1996 & Actas Urol Esp 20: 750 & Espermatocele & \\
\hline 15. Pellicé y cols. ${ }^{2}$ & 1996 & $\begin{array}{l}\text { I }{ }^{a} \text { S Jornadas Técnicas de } \\
\text { Atención Primaria ICS-CERVERA }\end{array}$ & Revisión vasectomía & \\
\hline 16. Sánchez y cols. ${ }^{101}$ & 1996 & Actas Urol Esp 20: 403 & Trabajo experimental ratas & \\
\hline 17. Pujol y cols. ${ }^{20}$ & 1997 & Actas Urol Esp 21: 609-613 & Vasectomía y arteriosclerosis & \\
\hline 18. Llarena y cols. ${ }^{19}$ & 1997 & Arch Esp Urol 50: 534-536 & Vasitis nodosa & \\
\hline 19. Bates ${ }^{102}$ & 1997 & $\begin{array}{l}\text { Br J Urol (edición española) } \\
\text { 80: 691-697 }\end{array}$ & $\begin{array}{l}\text { Anticuerpos antiespermatozoides } \\
\text { e infertilidad }\end{array}$ & \\
\hline 20. Pellicé y cols. ${ }^{21}$ & 1998 & $\begin{array}{l}\text { Urologia i Comarques 7: 1-3 } \\
\text { V Jornada de L'ACUC }\end{array}$ & $\begin{array}{l}\text { Consideraciones sobre } \\
\text { vasectomía }\end{array}$ & \\
\hline 21. Artiles y Chesa ${ }^{12}$ & 1998 & $\begin{array}{l}\text { Actualización en } \\
\text { Andrología (LIBRO) 11: 1-15 }\end{array}$ & Contracepción masculina & \\
\hline 22. Mora y Jiménez ${ }^{8}$ & 1998 & $\begin{array}{l}\text { Colección Jurisprudencia } \\
\text { Práctica (LIBRO 147) }\end{array}$ & $\begin{array}{l}\text { Complicaciones jurídicas } \\
\text { vasectomía }\end{array}$ & $\begin{array}{l}\text { Recanalización espontánea } \\
0,3-1 \%\end{array}$ \\
\hline 23. Pellicé 5 & 1998 & Actas Urol Esp 22: 547-551 & Revisión vasectomia & $6 \%$ \\
\hline 24. Romero Pérez y cols. ${ }^{13}$ & 1999 & $\begin{array}{l}\text { XXXIII Congreso Urología } \\
\text { Asociaciones Valenciana y } \\
\text { Murciana. LIBRO } \\
\text { RESÚMENES, pág. } 40\end{array}$ & $\begin{array}{l}\text { Impétigo escrotal } \\
\text { estafilocócico y shock } \\
\text { séptico post-vasectomia }\end{array}$ & \\
\hline 25. De Diego y cols. ${ }^{22}$ & 2000 & Arch Esp Urol 53: 275-278 & $\begin{array}{l}\text { Gangrena de Fournier tras } \\
\text { vasectomía }\end{array}$ & \\
\hline 26. Dominguez y López ${ }^{103}$ & 2001 & Actas Urol Esp 25: 770-773 & Agenesia de deferente & \\
\hline 27. Romero Pérez y cols. ${ }^{14}$ & 2001 & $\begin{array}{l}\text { X Congreso Nacional } \\
\text { Andrología. LIBRO } \\
\text { RESÚMENES, pág. } 61\end{array}$ & $\begin{array}{l}\text { Complicaciones en } 273 \\
\text { vasectomías }\end{array}$ & $10,98 \%$ \\
\hline 28. Merenciano y cols. ${ }^{44}$ & 2002 & $\begin{array}{l}\text { IV Congreso Sociedad } \\
\text { Española Contracepción. } \\
\text { LIBRO RESÚMENES, pág. } 178\end{array}$ & $\begin{array}{l}\text { Espermiograma post- } \\
\text { vasectomía }\end{array}$ & \\
\hline 29. Pellicé104 & 2002 & Actas Urol Esp 26: 310 & Agenesia unilateral de deferente & \\
\hline 30. Romero Pérez ${ }^{48}$ & 2002 & Actas Urol Esp 26: 380 & $\begin{array}{l}\text { Calcificación de conducto } \\
\text { deferente }\end{array}$ & \\
\hline Total 30 referencias & 17 años & & & \\
\hline
\end{tabular}


TABLA XXI

REVISIÓN DE LAS COMPLICACIONES DE LA VASECTOMÍA EN LAS SERIES NACIONALES. TIPO DE COMPLICACIONES REFERIDAS EN LA LITERATURA NACIONAL ESPAÑOLA. PERIODO 1987-1996 (10 AUTORES)

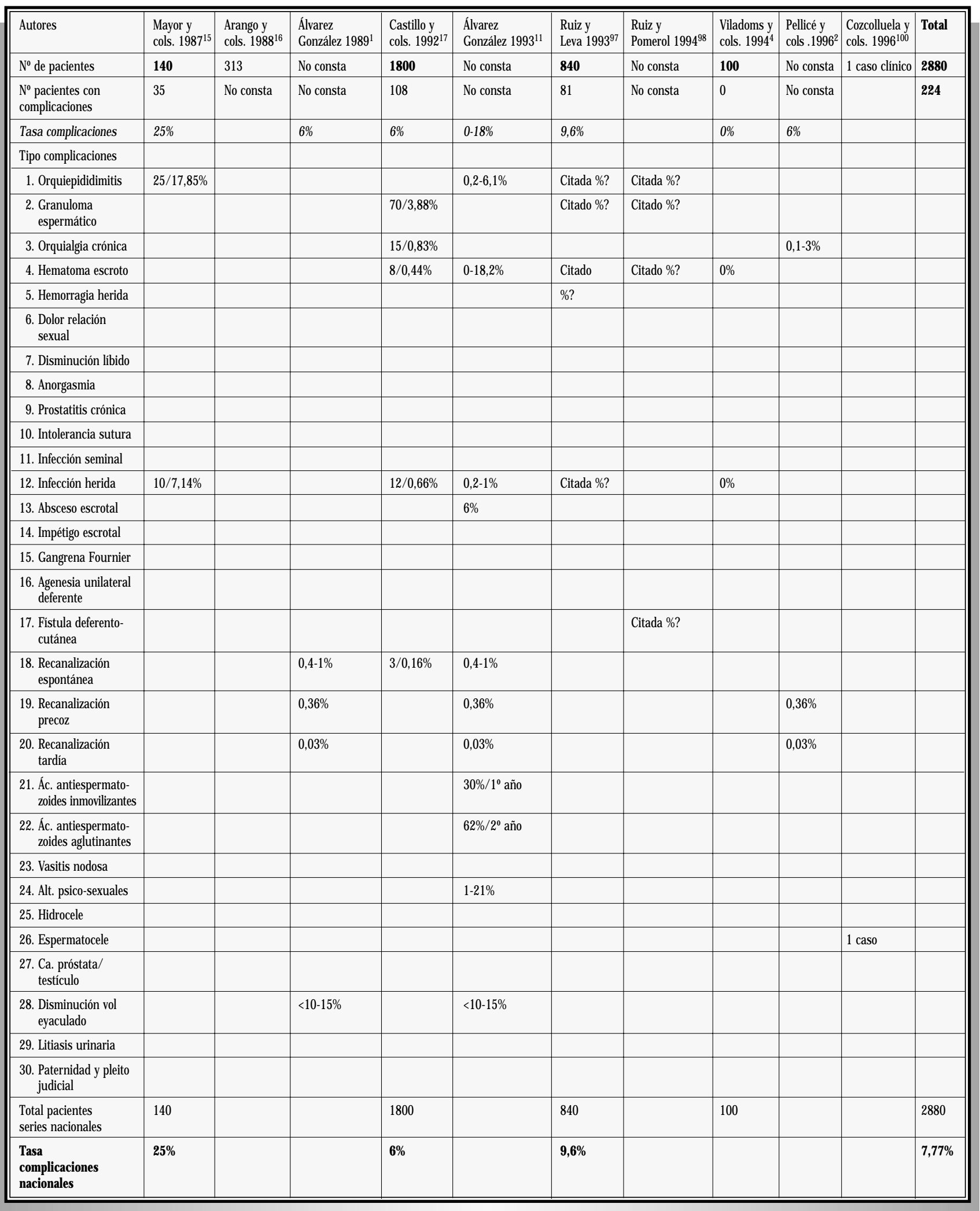

*Sólo hemos encontrado 4 series con datos fiables en el periodo 1987-1996 (marcadas en negrita). 
TABLA XXII

REVISIÓN DE LAS COMPLICACIONES DE LA VASECTOMÍA EN LAS SERIES NACIONALES. TIPO DE COMPLICACIONES REFERIDAS EN LA LITERATURA NACIONAL ESPAÑOLA. PERIODO 1997-2002 (10 AUTORES)

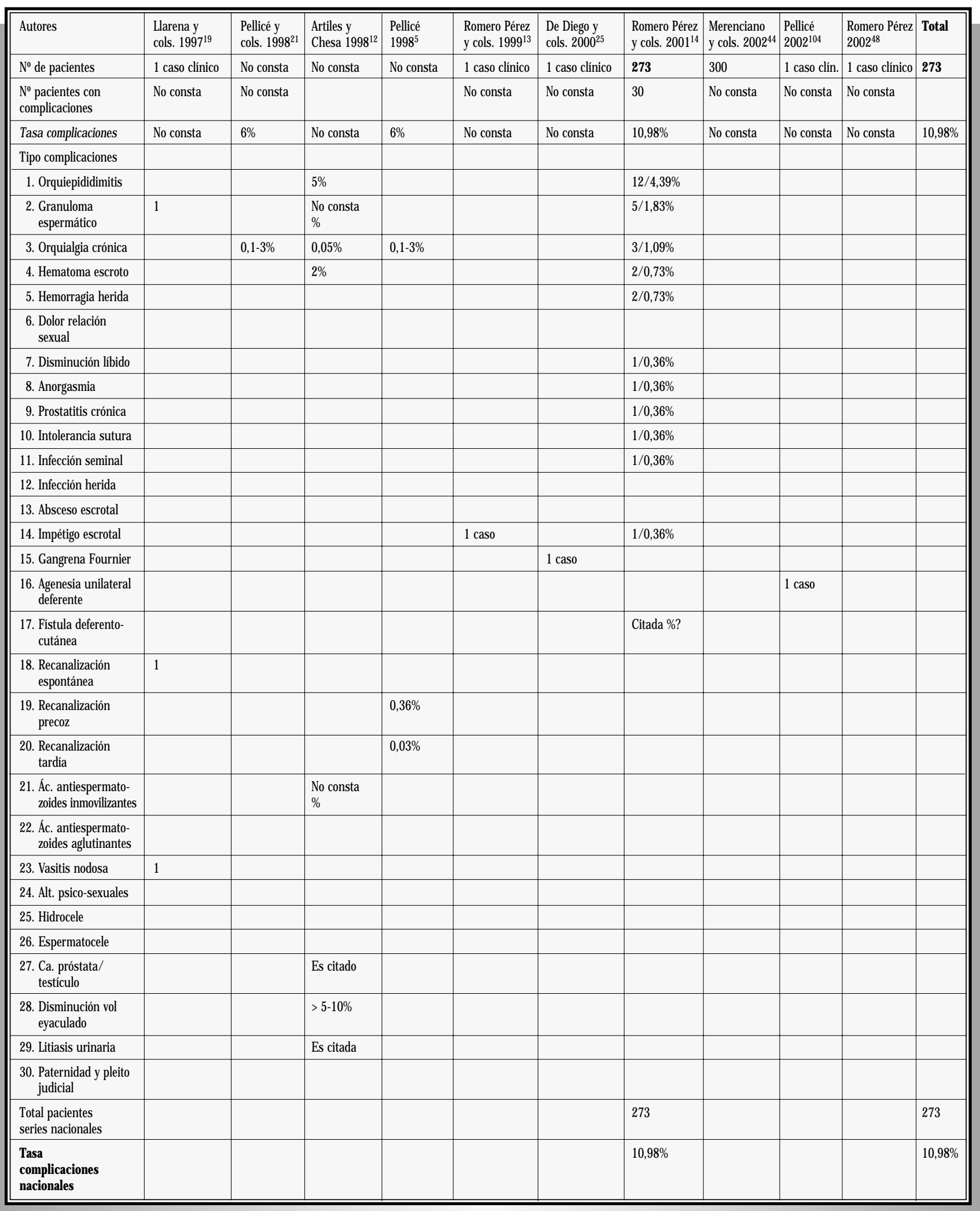

*Sólo hemos encontrado 1 serie con datos fiables en el periodo 1997-2002 (marcada en negrita). 
sobre el testículo. Estos estudios merecen nuestro interés porque buscan distintas modalidades técnicas de vasectomía con el fin de encontrar el método oclusivo más eficaz del deferente, más fácil de realizar, con menos complicaciones, y que mejore el pronóstico para una posterior vasovasostomía ${ }^{106-113}$

- Tipo de complicaciones referidas en la literatura internacional (Tablas XXIII y XXIV).

Uno de los trabajos pioneros que las aborda en especificidad es el de Philp y cols. de $1984^{32}$ y el de Raspa de $1993^{114}$, aunque existen muchos más que se detallan en las Tablas XXIII y XXIV. Hemos revisado 22 autores internacionales entre 1984 y 2002 recogiendo un total de 42 distintas complicaciones de gravedad variable.

Hemos dividido estos 19 años, en dos periodos: uno de 1984-1998 con estudio de series de 11 autores (Tabla XXIII) y otro de 1998-2002 con series de otros 11 autores (Tabla XXIV).

Estas variadas y posibles complicaciones que se presentan en la vasectomía, nos han de poner en aviso sobre como está la situación legal de la vasectomía en España, tema que abordaremos a continuación.

\section{Encuadramiento de la vasectomía en la clá- sica medicina curativa y en la moderna medi- cina satisfactiva}

En materia sanitaria y antes de analizar los requisitos que han de concurrir para que prospere la reclamación de daños y perjuicios, es preciso conocer una dualidad en la naturaleza jurídica del acto médico que los Tribunales han establecido por su evidente distancia entre ambos. Nos referimos a las diferencias existentes entre la clásica "cirugía o medicina curativa" y la menos clásica "cirugía o medicina satisfactiva". Médicamente, se diferencian en que la primera de ellas tiene como objetivo la curación del paciente, y la segunda, en cambio, persigue como finalidad un beneficio estético o funcional que no supone de por sí una curación del paciente, es decir, que no es una necesidad la que lleva a someterse a este tipo de medicina o cirugía.

Jurídicamente, la diferencia esencial radica en que, al perseguirse en la cirugía satisfactiva normalmente un resultado, se acentúa la obligación del facultativo de obtener el resultado y de informar al paciente de los riesgos y pormenores de la intervención a que va a ser sometido. En cambio, en la cirugía curativa prevalece la obligación de medios del facultativo, sin que esté sometido a la obligación de resultados, consistiendo la diligencia del médico en emplear todos los medios a su alcance para conseguir, si es posible, la curación del paciente, siempre teniendo en cuenta la situación peculiar de éste $\mathrm{y}$, por supuesto, el medio en el que se actúa y las circunstancias concurrentes en el caso concreto.

Desde el punto de vista procesal, la importancia de la distinción entre ambos tipos de medicina radica en que cuando prevalezca la obligación de medios, concretamente en la cirugía curativa, se descarta cualquier tipo de responsabilidad objetiva, no procediendo tampoco la aplicación de la inversión de la carga de la prueba, correspondiendo siempre a la parte actora, como necesario deber procesal, demostrar en juicio que concurren los requisitos exigidos en el artículo 1902 y en su relación con el 1903 del Código Civil, para el éxito en la demanda planteada. Así se ha pronunciado el Tribunal Supremo en temas de una supuesta responsabilidad médica en sentencias como las de 7 de febrero de 1990, 16 de noviembre de 1991 y 8 de mayo de 1991, 8 de octubre de 1992, 2 de febrero y 4 y 15 de marzo de 1993, entre otras muchas.

La vasectomía, se viene considerando como una intervención de naturaleza jurídica intermedia o híbrida entre ambos tipos de medicina. Dentro de la habitual información a la que todo usuario de la sanidad tiene derecho al someterse a cualquier acto médico, en la vasectomía se hace preciso que el paciente conozca que la operación, pese a estar correctamente practicada y por motivos ajenos a la conducta del cirujano, puede que no de el resultado perseguido, con lo que el sujeto vasectomizado, como antes vimos, recupera su fertilidad con las consecuencias que dicha situación comporta. Por tanto, cobra especial relevancia la información al paciente de la probabilidad de que acontezca esta complicación ya definida.

La operación de vasectomía, sin perder el carácter de arrendamiento de servicios $\mathrm{y}$, por tanto, sujeto el facultativo a la obligación de medios, se aproxima de forma notoria al arrendamiento de obra, con la consiguiente exigencia de una mayor garantía del resultado perseguido. 
TABLA XXIII

TIPO DE COMPLICACIONES REFERIDAS EN LA LITERATURA INTERNACIONAL. PERIODO 1984-1998 (11 AUTORES)

\begin{tabular}{|c|c|c|c|c|c|c|c|c|c|c|c|}
\hline Autores & $\begin{array}{l}\text { Philp } \\
1984^{32}\end{array}$ & $\begin{array}{l}\text { Viddeleer } \\
1992^{24}\end{array}$ & $\begin{array}{l}\text { O'Brian } \\
1995^{45}\end{array}$ & $\begin{array}{l}\text { Benger } \\
1995^{46}\end{array}$ & $\begin{array}{l}\text { Ekman } \\
1995^{115}\end{array}$ & $\begin{array}{l}\text { Schmidt } \\
1995^{35}\end{array}$ & $\begin{array}{l}\text { Choe } \\
1996^{116}\end{array}$ & $\begin{array}{l}\text { Lessing } \\
1996^{117}\end{array}$ & $\begin{array}{l}\text { Kronmal } \\
1997^{65}\end{array}$ & $\begin{array}{l}\text { Lebrecque } \\
1998^{118}\end{array}$ & $\begin{array}{l}\text { Peterson } \\
1998^{28}\end{array}$ \\
\hline № $\operatorname{cas} 0 \mathrm{~s}$ & 16.796 & 1 caso & 1.000 & 633 & 107 & 6.248 & 182 & 1 caso & Revisión & 1.223 & Revisión \\
\hline № complicaciones & $72 / 534$ & ¿? & 6 & 61 & $33 / 91$ & 517 & 34 & & & 94 & No consta \\
\hline$\%$ complicaciones & $13,48 \%$ & ¿? & $0,60 \%$ & $9,63 \%$ & $36,26 \%$ & $8,27 \%$ & $18,68 \%$ & & & $7,68 \%$ & No consta \\
\hline \multicolumn{12}{|l|}{ Tipo complicaciones } \\
\hline 1. Orquiepididimitis congestiva & $41 / 7,7 \%$ & & & & & $300 / 4,8 \%$ & & & & & \\
\hline 2. Granuloma deferencial & & & & & & $90 / 1,44 \%$ & & & & & \\
\hline 3. Orquialgia crónica & & & & & & $6 / 0,90 \%$ & $34 / 18,68 \%$ & & & & \\
\hline 4. Hematoma escrotal & $5 / 0,92 \%$ & & & & & $17 / 0,3 \%$ & & & & & \\
\hline 5. Hemorragia herida & $19 / 3,6 \%$ & & & & $24 / 28 \%$ & & & & & & \\
\hline \multicolumn{12}{|l|}{ 6. Dolor relación sexual } \\
\hline \multicolumn{12}{|l|}{ 7. Disminución líbido } \\
\hline \multicolumn{12}{|l|}{ 8. Anorgasmia } \\
\hline \multicolumn{12}{|l|}{ 9. Prostatitis crónica } \\
\hline 10. Intolerancia sutura & & & & $1 / 0,15 \%$ & & & & & & & \\
\hline \multicolumn{12}{|l|}{ 11. Infección seminal } \\
\hline \multicolumn{12}{|l|}{$\begin{array}{l}\text { 12. Endocarditis bacteriana } \\
\text { Sthaphylococcus hominis }\end{array}$} \\
\hline $\begin{array}{l}\text { 13. Endocarditis bacteriana } \\
\text { Sthaphylococcus lugdunensis }\end{array}$ & & & & & & & & 1 caso & & & \\
\hline \multicolumn{12}{|l|}{ 14. Paternidad y pleito judicial } \\
\hline \multicolumn{12}{|l|}{ 15. Paternidad sin pleito judicial } \\
\hline \multicolumn{12}{|l|}{ 16. Impétigo escrotal-sepsis } \\
\hline 17. Recanalización espontánea & $\begin{array}{l}57 / 16796 \\
0,34 \%\end{array}$ & & & & & & & & & & \\
\hline \multicolumn{12}{|l|}{ 18. Recanalización precoz } \\
\hline 19. Recanalización tardía & & & & $1 / 0,15 \%$ & & & & & & & \\
\hline $\begin{array}{l}\text { 20. Persistencia espermios } \\
\text { eyaculado }\end{array}$ & & & $6 / 0,6 \%$ & $27 / 4,2 \%$ & & & & & & & \\
\hline 21. Infección herida & $7 / 1,3 \%$ & & & & $9 / 10 \%$ & & & & & & \\
\hline \multicolumn{12}{|l|}{ 22. Ác. aglutinantes } \\
\hline \multicolumn{12}{|l|}{ 23. Ác. inmovilizantes } \\
\hline \multicolumn{12}{|l|}{ 24. Absceso escrotal } \\
\hline \multicolumn{12}{|l|}{ 25. Vasitis nodosa } \\
\hline \multicolumn{12}{|l|}{ 26. Alt. psico-sexuales } \\
\hline \multicolumn{12}{|l|}{ 27. Hidrocele } \\
\hline 28. Gangrena Fournier & & 1 caso & & & & & & & & & \\
\hline 29. Cáncer próstata & & & & & & & & & & & No $>$ riesgo \\
\hline \multicolumn{12}{|l|}{ 30. Cáncer testículo } \\
\hline \multicolumn{12}{|l|}{ 31. Disminución eyaculado } \\
\hline 32. Litiasis urinaria & & & & & & & & & Riesgo x2 & & \\
\hline $\begin{array}{l}\text { 33. Fallo vasectomía. } \\
\text { Reoperación }\end{array}$ & & & & $31 / 4,9 \%$ & & & & & & & \\
\hline \multicolumn{12}{|l|}{ 34. Perforación hidrocele } \\
\hline 35. Arteriosclerosis & & & & & & & & & & & \\
\hline 36. Granuloma epididimario & & & & & & $56 / 0,9 \%$ & & & & & \\
\hline 37. Funiculitis & & & & & & $8 / 0,13 \%$ & & & & & \\
\hline 38. Disfunción sexual & & & & & & $39 / 0,62 \%$ & & & & & \\
\hline 39. Fistula deferento-cutánea & & & & $1 / 0,15 \%$ & & $1 / 0,01 \%$ & & & & & \\
\hline $\begin{array}{l}\text { 40. Agenesia deferencial } \\
\text { (hallazgo) }\end{array}$ & & & & & & & & & & & \\
\hline $\begin{array}{l}\text { 41. Fascitis necrotizante } \\
\text { Streptococo piógenes grupo A }\end{array}$ & & & & & & & & & & & \\
\hline 42. Muerte & & $\begin{array}{l}1 \text { caso } \\
\text { (mismo) }\end{array}$ & & & & & & & & & \\
\hline
\end{tabular}

*5 series "fiables" en el periodo 1984-1998 (en negrita). Total de pacientes de este periodo: 24.966 . 
TABLA XXIV

TIPO DE COMPLICACIONES REFERIDAS EN LA LITERATURA INTERNACIONAL. PERIODO 1998-2003 (11 AUTORES)

\begin{tabular}{|c|c|c|c|c|c|c|c|c|c|c|c|}
\hline Autores & $\begin{array}{l}\text { Kessler } \\
1998^{119}\end{array}$ & $\begin{array}{l}\text { Verhulst } \\
1999^{47}\end{array}$ & $\begin{array}{l}\text { Seidi } \\
2000^{120}\end{array}$ & $\begin{array}{l}\text { Nangia y } \\
\text { cols. } 2000^{121}\end{array}$ & $\begin{array}{l}\text { Fervenza y } \\
\text { cols. } 2000^{122}\end{array}$ & $\begin{array}{l}\text { Badrakumar } \\
2000^{42}\end{array}$ & $\begin{array}{l}\text { West } \\
2000^{123}\end{array}$ & $\begin{array}{l}\text { Schwingl } \\
2000^{31}\end{array}$ & $\begin{array}{l}\text { Christensen } \\
2002^{124}\end{array}$ & $\begin{array}{l}\text { Nielsen } \\
2002^{125}\end{array}$ & $\begin{array}{l}\text { De Los Rios } \\
2003^{23}\end{array}$ \\
\hline № $\operatorname{casos}$ & 1 caso & Revisión & 150 & 4 casos & 1 caso & 1321 & 60 & Revisión & 99 & 2563 & 5000 \\
\hline № complicaciones & & No consta & 7 & & & $34 / 1104$ & 13 & No consta & 36 & 36 & 502 \\
\hline$\%$ complicaciones & & No consta & $4,66 \%$ & & & $3,07 \%$ & $21,66 \%$ & No consta & $36,36 \%$ & $1,40 \%$ & $10,04 \%$ \\
\hline \multicolumn{12}{|l|}{ Tipo complicaciones } \\
\hline 1. Orquiepididimitis congestiva & & & & & & & & $0,4-6 \%$ & & & $22 / 0,44 \%$ \\
\hline 2. Granuloma deferencial & & & & & & & & $15-40 \%$ & & & $6 / 0,12 \%$ \\
\hline 3. Orquialgia crónica & & & & & & & $13 / 21,66 \%$ & & $9,9 \%$ & & $10 / 0,20 \%$ \\
\hline 4. Hematoma escrotal & & & & & & & & $1-4,6 \%$ & $13 / 13 \%$ & & $41 / 0,82 \%$ \\
\hline \multicolumn{12}{|l|}{ 5. Hemorragia herida } \\
\hline \multicolumn{12}{|l|}{ 6. Dolor relación sexual } \\
\hline \multicolumn{12}{|l|}{ 7. Disminución libido } \\
\hline \multicolumn{12}{|l|}{ 8. Anorgasmia } \\
\hline \multicolumn{12}{|l|}{ 9. Prostatitis crónica } \\
\hline 10. Intolerancia sutura & & & & & & & & & & & $15 / 0,30 \%$ \\
\hline \multicolumn{12}{|l|}{ 11. Infección seminal } \\
\hline $\begin{array}{l}\text { 12. Endocarditis bacteriana } \\
\text { Sthaphylococcus hominis }\end{array}$ & 1 caso & & & & & & & & & & \\
\hline $\begin{array}{l}\text { 13. Endocarditis bacteriana } \\
\text { Sthaphylococcus lugdunensis }\end{array}$ & & & & 4 casos/ & 1 caso & & & & & & \\
\hline 14. Paternidad y pleito judicial & & 6 casos/ & & & & & & & & & \\
\hline 15. Paternidad sin pleito judicial & & 32 casos/ & & & & & & & & & $47 / 0,94 \%$ \\
\hline \multicolumn{12}{|l|}{ 16. Impétigo escrotal-Sepsis } \\
\hline 17. Recanalización espontánea & & & & & & & & & & & $181 / 3,62 \%$ \\
\hline \multicolumn{12}{|l|}{ 18. Recanalización precoz } \\
\hline \multicolumn{12}{|l|}{ 19. Recanalización tardia } \\
\hline $\begin{array}{l}\text { 20. Persistencia espermios } \\
\text { eyaculado }\end{array}$ & & & & & & $27 / 2 \%$ & & & & & \\
\hline 21. Infección herida & & $\% ?$ & & & & & & $3,5 \%$ & $9 / 13 \%$ & & $18 / 0,36 \%$ \\
\hline 22. Ác. aglutinantes & & & & & & & & $52-68 \%$ & & & \\
\hline 23. Ác. inmovilizantes & & & & & & & & $52-60 \%$ & & & \\
\hline 24. Absceso escrotal & & & & & & & & & & & $11 / 0,22 \%$ \\
\hline 25. Vasitis nodosa & & & & & & & & No da $\%$ & & & $11 / 0,22 \%$ \\
\hline 26. Alt. psico-sexuales & & & & & & & & Menciona & & & \\
\hline \multicolumn{12}{|l|}{ 27. Hidrocele } \\
\hline \multicolumn{12}{|l|}{ 28. Gangrena Fournier } \\
\hline 29. Cáncer próstata & & & & & & & & No riesgo & & & No $>$ riesgo \\
\hline 30. Cáncer testículo & & & & & & & & No riesgo & & & \\
\hline \multicolumn{12}{|l|}{ 31. Disminución eyaculado } \\
\hline \multicolumn{12}{|l|}{ 32. Litiasis urinaria } \\
\hline $\begin{array}{l}\text { 33. Fallo vasectomía. } \\
\text { Reoperación }\end{array}$ & & 21 casos/ & & & & & & & $5 / 5 \%$ & $36 / 1,4 \%$ & $115 / 2,3 \%$ \\
\hline 34. Perforación hidrocele & & & $7 / 4,66 \%$ & & & & & & & & \\
\hline \multicolumn{12}{|l|}{ 35. Arteriosclerosis } \\
\hline \multicolumn{12}{|l|}{ 36. Granuloma epididimario } \\
\hline 37. Funiculitis & & & & & & & & & & & $17 / 0,34 \%$ \\
\hline 38. Disfunción sexual & & & & & & & & & & & $8 / 0,16 \%$ \\
\hline \multicolumn{12}{|l|}{ 39. Fístula deferento-cutánea } \\
\hline $\begin{array}{l}\text { 40. Agenesia deferencial } \\
\text { (hallazgo) }\end{array}$ & & & & & & & & & & & $7 / 0,14 \%$ \\
\hline \multicolumn{12}{|l|}{$\begin{array}{l}\text { 41. Fascitis necrotizante } \\
\text { Streptococo piógenes grupo A }\end{array}$} \\
\hline 42. Muerte & & & & & & & & & & & \\
\hline
\end{tabular}

*5 series "fiables" en el periodo 1998-2003 (en negrita). Total de pacientes de este periodo: 9.193.

Total pacientes "bien controlados": $1104+60+99+2563+5000=8826$.

Control de complicaciones: Cuestionario postal o encuesta telefónica complicaciones en: $34+13+36+36+502=621(7,03 \%)$.

Para ambas series: $7.688+8826=16.514$ pacientes.

Hallamos complicaciones en $717+621=1338(8,10 \%)$. 
Pero hemos analizado que el resultado no siempre se consigue pese a que la conducta seguida por el cirujano haya sido la correcta. La diligencia del médico se completará siempre y cuando se haya advertido e informado al paciente de que, pese a la corrección del acto médico, existe la posibilidad de la anteriormente estudiada recanalización espontánea entre ambos extremos del deferente ${ }^{8}$.

\section{Complicaciones jurídico-médicas en la intervención de vasectomía}

Reclamación de daños y perjuicios: resultado, negligencia y relación de causalidad.

Los tres anteriores son los requisitos que nuestra jurisprudencia ha ido delimitando en reclamaciones contra facultativos, para declarar el derecho de los perjudicados a obtener una indemnización por parte del médico. Como vimos antes, se descarta en estos casos cualquier tipo de responsabilidad objetiva en clara diferencia con otras reclamaciones como las de "tráfico" debiendo concurrir, por tanto, un acto negligente o contrario a la denominada "lex artis ad hoc" ${ }^{26}$, como se contempla en la Sentencia del Tribunal Supremo de 25 de abril de 1994, que inicia la posterior "selección de jurisprudencia”.

En la intervención de vasectomía, puede producirse un triple resultado dañoso: por un lado, la recanalización, que requerirá para subsanarla una reintervención; por otro lado, la posibilidad de que el vasectomizado engendre un hijo con las consecuencias en el plano económico que el "nacimiento de un hijo no deseado" supone y que más adelante se analizan; y, además, no puede descartase absolutamente algún otro daño en el orden fisico del paciente, como consecuencia de la intervención, como se verá en la Sentencia del Tribunal Supremo de 31 de enero de 1996, que condenó a abonar una indemnización de 100.000 ptas, cuantía que se correspondía con las secuelas sufridas por el paciente, consistentes en supuraciones y fístula en testículo derecho.

Ciñéndonos al daño consistente en el nacimiento de un hijo tras la recanalización, para que este daño genere una indemnización, es necesario que exista negligencia en la conducta del facultativo $y$, por ende, relación causa-efecto entre dicha negligencia y el resultado dañoso producido. De este tema de actualidad un excelente trabajo sobre embarazos post-vasectomía es el publicado por Lertxundi en $2001^{127}$.

La negligencia, consistirá en la ausencia o defectuosa información, que va a recibir el paciente de las complicaciones de la operación. Es preciso que el mismo conozca la existencia de posibilidades, (remotas pero existentes), de que la vasectomía no surta efectos pese a estar correctamente practicada.

La suficiente o insuficiente información es un tema que nuestros Tribunales se han encargado de delimitar no sólo en las vasectomías, sino en la totalidad de intervenciones quirúrgicas y actos médicos de las distintas especialidades sanitarias. El punto de partida que ha servido para considerar si ha existido una adecuada información lo tenemos en la Ley General de Sanidad, con algunas referencias, cada vez más comunes, al deber de información que se contiene en el artículo 13 de la Ley General para la Defensa de Consumidores y Usuarios ${ }^{128}$.

La norma sanitaria, aprobada mediante Ley 14/1986, de 25 de abril, en su artículo 10.5 establece el derecho de todo paciente a que se le de en términos comprensibles, a él y a sus familiares o allegados, información completa y continuada, verbal y escrita sobre su proceso, incluyendo diagnóstico, pronóstico y alternativas de tratamiento.

Esta información ha de ser en términos comprensivos para el paciente, de manera que sean los datos que se faciliten sobre el acto médico los que hagan al sujeto consentir la realización de la misma.

En esta combinación de información al paciente y de consentimiento prestado, surge la figura unánimemente extendida hoy día entre los facultativos del "consentimiento informado" (CI).

Además, hoy día con la reciente aprobación por las Cortes Generales de la Ley 41/2002 de 14 de noviembre de 2002, Ley de Autonomía del paciente, Información y Documentación Clínica, en vigor desde 16 de mayo de 2003, el consentimiento informado (CI) adquiere una relevancia y fuerza especial en las relaciones clínico-asistenciales con los pacientes y es de uso obligatorio para todos los actos médicos ${ }^{129}$. Ley que tiene su homóloga en la Comunidad Valenciana en la Ley $1 / 2003$ de 28 de enero ${ }^{130}$. 
Por estas razones y leyes, el tema del CI se ha convertido en los últimos años en uno de los más debatidos dentro del Derecho Sanitario, ya que presenta aún numerosas dudas sobre su alcance, el sujeto pasivo del mismo, quién ha de redactarlo, etc ${ }^{131}$.

Una vez señalada la indudable importancia de la información al paciente, para que la actuación facultativa genere una indemnización de daños y perjuicios, es preciso que exista relación causaefecto entre la insuficiente información y el resultado dañoso. En este supuesto, la relación de causalidad entre el daño y la insuficiente información es clara, ya que resulta obvio que el paciente, de conocer la posibilidad de que es fértil pondría los medios oportunos (controles periódicos y otras medidas anticonceptivas) para evitar el nacimiento de un hijo ${ }^{8}$.

En cuanto al daño, y centrándonos en el nacimiento de un menor, siempre ha surgido un debate ético en torno a si puede ser considerado un "daño" la venida al mundo de una persona. Ese "daño" se fundamentará en el hecho de que el vasectomizado optó por limitar su facultad procreadora, no considerándose económicamente capacitado para soportar el "coste" que conlleva la crianza y desarrollo en el ámbito familiar de una persona más. En el Derecho norteamericano, este nacimiento no deseado es la figura jurídica del denominado "wrongful birth" o nacimiento no deseado o indebido ${ }^{12,132}$.

Pero cuando hablamos de daños y éste se traduce en el nacimiento de una persona, hemos de valorar con suma cautela las repercusiones que en la esfera familiar pueden tener un suceso como el "fallo de la vasectomía" y posterior nacimiento de un hijo, como se comprueba en algunos pronunciamientos de Juzgados menores, como la Sentencia del Juzgado de Primera Instancia número 8 de Huelva, de fecha 5 de junio de 1997, y la del Juzgado de Primera Instancia número 4 de Gijón, de 29 de mayo de 1996. En ambos casos parecía dejarse entrever, sin haberse practicado pruebas de paternidad, que los menores no habían sido engendrados por los demandantes vasectomizados ${ }^{126}$.

Sobre este particular, al poder existir terceros implicados en el embarazo de una mujer, y aunque esto sólo sea una remota posibilidad, no cabe descartarse que en ocasiones, bajo la apariencia de lo que hemos venido considerando resultado dañoso tras fallo en la vasectomía, se enmascare una situación de infidelidad de la pareja con una consecuencia para el vasectomizado más indeseada que si se tratase de un hijo por el engendrado. Por ello, es sumamente delicada la situación, máxime cuando la existencia de espermatozoides aislados en el semen no implican la fertilidad del hombre, sino que, es necesaria una cantidad millonaria de aquellos, para considerar a alguien fértil ${ }^{3}$.

Las especiales connotaciones del tema han hecho que procesalmente se importen, de las acciones para determinar la filiación, las pruebas biológicas de investigación de la paternidad (pruebas del ADN) para poder asegurar técnicamente que la criatura engendrada lo ha sido por el previamente vasectomizado. En este sentido, creemos que se ha seguido por el Tribunal Supremo, en su Sentencia de 28 de enero de 1997, un sendero adecuado al permitir la realización de las pruebas de la paternidad en un procedimiento como el de reclamación de indemnización de daños y perjuicios tras el nacimiento de un supuesto hijo de la pareja reclamante, y no cabe duda de que, de no permitirse esos medios probatorios, en ocasiones se situaría al facultativo en una clara situación de indefensión, por las presunciones de inocencia de nuestro Código Civil que han de ceder frente a la posible equivocación del reclamante ${ }^{8,133}$.

En conclusión, hoy en día no es tan noticiable como antaño que un juzgado condene a un facultativo a indemnizar a un paciente en una llamativa cantidad. Día a día, a los profesionales sanitarios nos van acostumbrando a las idas y venidas de los Juzgados para que sean estos los que revisen y supervisen si obramos o no conforme a la lex artis ad hoc, como concepto que determina la idoneidad jurídica de la conducta del facultativo.

Pero sin duda, seguirá siendo la vasectomía uno de los temas estrella del Derecho Sanitario pues difícilmente una específica intervención o acto médico podrá tener tantas repercusiones jurídicas. Este estrellato se cimentó en la celebre Sentencia antes citada de 25 de abril de 1994, que ha servido, por su amplia argumentación, como base de los posteriores pronun- 
ciamientos de Tribunales y Juzgados, al mismo tiempo que cita obligada en todo procedimiento judicial de reclamación tras defectuosa atención sanitaria, no sólo por intervención de vasectomía.

En aquella ocasión, el hecho que dio lugar a la demanda fue un parto gemelar de mujer con marido vasectomizado. La resolución judicial contenía un auténtico tratado de Derecho Sanitario. La indemnización se fijó en sentencia en la cantidad de 9 millones de pesetas ${ }^{133}$.

Los comentarios en los foros de debate de Derecho Sanitario, no pudieron ser más acertados ante la novedad que suponía un pronunciamiento tan curioso por las circunstancias concurrentes en el mismo: "nacidos con un pan bajo del brazo...., un pan de cuatro kilos y medio" (en clara referencia a los hermanos gemelos) $^{8}$.

En referencia a estos hechos, coincidimos con Thon y cols. en $1992^{134}$ y con Gingell y cols. en $2001^{135}$ en su afirmación sobre la vasectomía: "la vasectomía, intervención menor pero de graves secuelas".

Ante este real y peligroso tema que nos acecha a todos los urólogos, recomendamos seguir las normas del Dr. Pérez-Castro, acerca de cómo evitar ser demandado o "Los Diez Mandamientos de la Urología"136.

\section{CONCLUSIONES}

1. La vasectomía es la intervención quirúrgica urológica más practicada en España.

2. No existe un verdadero seguimiento de los pacientes tanto en España como en el resto de Europa, ya que al ser una intervención menor, su seguimiento posterior es inconstante y muchas veces incorrecto, a veces éste ni se realiza o se lleva a cabo en Atención Primaria, lo que dificulta el conocimiento exacto de sus posibles complicaciones.

3. Muchos de los estudios sobre morbilidad y complicaciones son realizados por cuestionarios postales, lo que ofrece poca seriedad y fiabilidad sobre sus resultados, siendo su morbilidad y complicaciones mal conocidas.

4. Estas complicaciones son escasas pero existentes en alrededor de un $10 \%$ de casos, siendo graves en un $1 \%$.
5. En el consentimiento informado, lo más importante es informar de las complicaciones y también de que la técnica no es segura al $100 \%$, existiendo la posibilidad remotísima pero real de recanalización espontánea y nuevo embarazo, sin olvidar que por este motivo nos citan en los Juzgados.

\section{REFERENCIAS}

1. ÁLVAREZ GONZÁLEZ E.: Anticoncepción masculina. En: “Andrología. Teoría y práctica. E. Álvarez González". Ediciones Díaz de Santos S.A, Madrid 1989; 18: 236-248.

2. PELLICÉ C, MARTÍNEZ B, PARÉS E.: Vasectomía: técniques, controls i complicacions. 11 Jornades Técniques d'Atenció Primária. Intercanvi d'Experiencies (ICS Cervera 1996).

3. ARANGO TORO O, ANDOLZ PEITIVI P, LLADÓ CARBONELL C, BIELSA GALI O, BIELSA CARRIÓN MA, GELABERT MAS A.: Estudio del semen post-vasectomía en 313 varones. Análisis estadístico, aspectos médicos e implicaciones legales. Arch Esp Urol 1993; 46 (1): 29-34.

4. VILADOMS FUSTER JM, SHIHUA LI PH.: Vasectomía sin bisturí. Arch Esp Urol 1994; 47 (7): 695-701.

5. PELLICÉ VILALTA C.: Algunos comentarios y consideraciones referidos a la práctica de la vasectomía. Actas Urol Esp 1998; 22 (7): 547-551.

6. VALERO MILLÁN J, PINSACH ELIAS L, BLASCO CASARES FJ.: Vasectomía ¿cuál es nuestra realidad?. Mesa Redonda. LXV Congreso Nacional de Urologia. Madrid, 28-31 mayo 2000. Forum 2000; 410: 20-21.

7. MARTÍNEZ CALCERRADA L.: Responsabilidad civil del médico: la profecía del Doctor Marañón. Calidad y Riesgo 2001; 1 (1): 7595.

8. MORA GARCÍA JM, JIMÉNEZ SUÁREZ O.: Complicaciones jurídico-médicas en la intervención de vasectomía. Colección Jurisprudencia Práctica, $\mathrm{n}$ - 147, Editorial Tecnos, Madrid 1998.

9. VALERO MILLÁN J.: Vasectomías, ¿un problema de salud?. En: "Bioética y Urología: una nueva perspectiva". Coordinador José Jara Rascón. Luzán-5, S.A. de Ediciones, Madrid 2001; 8: 145158. Yamanouchi Pharma, S.A.

10. VALERO MILLÁN J, PINSACH ELIAS L, BLASCO CASARES FJ.: Vasectomía ¿cuál es nuestra realidad?. Mesa Redonda (Presidencia Dr. O. Leiva Galvis). Lunes 29 mayo 2000. LXV Congreso Nacional de Urologia. Madrid 2000. Actas Urol Esp (supl). 2000; 24 (5): 10.

11. ÁLVAREZ GONZÁLEZ E.: La vasectomía y sus problemas. Cuadernos de Urología 1993; 11: 3-9.

12. ARTILES JL, CHESA N.: Contracepción masculina. En: "Luis Rodríguez Vela y Luis Ángel Rioja Sanz. I Curso de Actualización en Andrología 1998; (11-12): 1-15.

13. ROMERO PÉREZ P, AMORES VALENCIANO P, MUÑOZ BALLESTER P, SERRAT PÉREZ C, AMAT CECILIA M.: Infecciones quirúrgicas post-vasectomia infrecuentes y graves. A propósito de un caso. XXXIII Congreso de Urología de las Asociaciones de la Comunidad Valenciana y Comunidad Murciana. Libro de resúmenes C-47, pág. 40. Denia 26,27 de febrero de 1999.

14. ROMERO PÉREZ P, MERENCIANO FJ, AMAT CECILIA M, RAFIE MAZKETLI W.: Complicaciones en 273 vasectomías. Comunicación al X Congreso Nacional de Andrología. Libro de resúmenes. Alicante 30 de marzo de 2001: 61.

15. MAYOR J, GONZÁLEZ ANDRÉS JF, MEJIAS J, ATANCE JC.: Vasectomía: experiencia en nuestra provincia. Actas Urol Esp 1987; 9 (5): 481-484. 
16. ARANGO TORO O, PEYRÍ J, ROSALES A, GELABERT A. Vasectomía por incisión única escrotal. Revisión de 500 casos. Nota técnica. Actas Urol Esp 1988; 12: 430.

17. CASTILLO JIMENO J M, SANTIAGO GONZÁLEZ A, RODRÍGUEZ PÉREZ MJ, QUEL ALZUETA N, RUIZ RUBIO J L, ANTÓN LÓPEZ MJ, MARTÍNEZ MORILLAS M.: Vasectomía por incisión única: revisión de 1.800 casos. Arch Esp Urol 1992; 45 (1): 63-64.

18. SAIZ SÁNCHEZ C, GIMÉNEZ FERNÁNDEZ FJ, CORTINA GREUS P.: Vasectomía y cáncer de próstata. Actas Urol Esp 1994; 18 (5): 552-554.

19. LLARENA IBARGUREN R, VESGA MOLINA F, MARÍN LAFUENTE JC, PERTUSA PEÑA C.: Vasitis nodosa. Arch Esp Urol 1997; 50 (5): 534-536

20. PUYOL M, MENÉNDEZ V, GÓMEZ J.: Vasectomía y arteriosclerosis: ¿están relacionadas?. Actas Urol Esp 1997; 21 (6): 609613.

21. PELLICÉ VILALTA C, ALERT CASAS E, PARÉS PUNTAS E, COSME GIMÉNEZ MA, COMAS CASTELLS S.: Alguns considerants varis aprop de les vasectomies. Urologia $i$ Comarques 1998; 7: 1-3.

22. DE DIEGO RODRÍGUEZ E, CORREAS GÓMEZ MA, MARTÍN GARCÍA B, HERNÁNDEZ RODRÍGUEZ R, PORTILLO MARTÍN JA, GUTIÉRREZ BAÑOS JL, DEL VALLE SCHAAN JI, ROCA EDREIRA A, VILLANUEVA PEÑA A, GUTIÉRREZ GARCÍA R.: Gangrena de Fournier post-vasectomía. Arch Esp Urol 2000; 53 (3): 275278.

23. DE LOS RÍOS OSORIO J, CASTRO ÁLVAREZ AC.: Análisis de 5.000 vasectomías de un centro de planificación familiar en Medellin-Colombia. Arch Esp Urol 2003; 56 (1): 53-60.

24. VIDDELEER A C, LYCKLAMA A, NIJEHOLT GA.: Letal Fournier's gangrene following vasectomy. J Urol 1992; 147: 1613.

25. VELA NAVARRETE R.: La controversia de la vasectomía y los nuevos tratamientos del cólico nefrítico. Cuadernos de Urología (editorial) 1993; 11: 1.

26. WEISKE WH.: Review on vasectomy. Andrología 2001; 33: 125134.

27. BERNAL DELGADO E, LATOUR PÉREZ J, PRADAS ARNAL F, GÓMEZ LÓPEZ LI.: The association between vasectomy and prostate cancer: a systematic review of the literature. Fertil Steril 1998; 70 (2): 191-200.

28. PETERSON HB, HOWARDS SS.: Vasectomy and prostate cancer: the evidence to date. Fertil Steril 1998; 70 (2): 201-203.

29. INFORME DE LA ONU.: España será uno de los países con mayor envejecimiento en 2050. Diario Información (Alicante). Miércoles 28 febrero 2001: 62 .

30. HERRANZ RODRÍGUEZ G.: La objetivación de conciencia en Urologia: el caso de la esterilización voluntaria. En: "Bioética y Urología: una nueva perspectiva”. Coordinador José Jara Rascón. Luzán-5, S.A. de Ediciones, Madrid 2001; 4: 71-90. Yamanouchi Pharma, S.A.

31. SCHWINGL PJ, GUESS HA.: Safety and effectiveness of vasectomy. Fertil Steril 2000; 73 (5): 923-936.

32. PHILP T, GUILLEBAUD J, BUDD D.: Complications of the vasectomy: review of 16.000 patients. Br J Urol 1984; 56: 745-748.

33. KHAN AB, CONN IG.: Use of EMLA during local anaesthetic vasectomy. Br J Urol 1995; 75: 671.

34. SCHMIDT SS.: Technics and complications of elective vasectomy. The role of spermatic granuloma in spontaneus recanalization. Fertil Steril 1966; 17: 467-482.

35. SCHMIDT SS.: Vasectomy by section, luminal fulguration and fascial interposition: results from 6248 cases. Br J Urol 1995; 76: 373-375.

36. TILAK G.: Vasectomy by simple midline scrotal incision. $J$ Ind Med Assoc 1963; 41: 548-550.

37. LI S.: Ligation of vas deferents by clamping method under direct vision. Chin Med J 1976; 4: 213-214.
38. LI S, GOLDSTEIN M, ZHU J, HUBER D.: The no-scalpel vasectomy. J Urol 1991; 145: 341-344.

39. GOLDSTEIN M.: Surgery of male infertility and other scrotal disorders. En: "Campbell's Urology. Wals PC, Retik AB, Stamey TA y Vaughan DE". Saunders Company. 1992: 3119-3125. Philadelphia.

40. BENNETT AH.: Vasectomy without complication. Urology 1976; 7: 184.

41. SCHMIDT SS.: Vasectomy. Urol Clin North Am 1987; 14: 149-16.

42. BADRAKUMAR C, GOGOI N K, SUNDARAM SK.: Semen analysis after vasectomy: when and how many?. BJU Int 2000; 86 (4): 479-481.

43. JIMÉNEZ VERDEJO A, CARRILLO DE ALBORNOZ EO, LUNA MALDONADO A, JIMÉNEZ VERDEJO J, ZULUAGA GÓMEZ A.: Estudio comparativo de determinados parámetros bioquímicos en semen de sujetos vasectomizados y no vasectomizados. Arch Esp Urol 1998; 51 (8): 811-817.

44. MERENCIANO CORTINA FJ, ROMERO PÉREZ P, MARTÍN-LOECHES DE LA LASTRA M, RAFIE MAZKETLI W, AMAT CECILIA M.: Espermiograma tras vasectomía: ¿cuántos y cuándo?. Comunicación Póster 33 al VI Congreso de la Sociedad Española de Contracepción "Salud Reproductiva Siglo XXI. Valencia-2002". Palacio Congresos Valencia 5 al 8 marzo 2002. Revista Iberoamericana de Fertilidad y Reproducción Humana 2002; 18 (4): 178.(Especial VI Congreso SEC).

45. O'BRIEN TS, CRANSTON D, ASHWIN P, TURNER E, MACKENZI IZ, GUILLEBAUD J.: Temporary reappearance of sperm 12 months after vasectomy clearance. Br J Urol 1995; 76: 371372.

46. BENGER JR, SWAMI SK, GINGELL JC.: Persistent spermatozoa after vasectomy: a survey of British urologists. Br J Urol 1995; 76: $376-379$.

47. VERHULST A PM, HOEKSTRA JW.: Paternidad después de una vasectomía bilateral. BJU International (edición española) 1999; 83: 152-154

48. ROMERO PÉREZ P.: Calcificación distrófica de conducto deferente en paciente diabético vasectomizado: imagen histológica. Actas Urol Esp (Imágenes en Urología) 2002; 26 (5): 380.

49. CHANTARASAK ND, BASU PK.: Fournier's gangrene following vasectomy. Br J Urol 1988; 61: 984.

50. PATEL A, RAMSAY JW, WHITFIELD HN.: Fournier's gangrene of the scrotum following day case vasectomy. JR Soc Med 1991; 84: 49.

51. FERVENZA FC, CONTRERAS GE, GARRAT KN, STECKELBERG JM.: Staphylococcus lugdunensis endocarditis: a complication of vasectomy?. Mayo Clin Proc 1999; 74 (12): 1227-1230.

52. ASSIMOS DG, BASILE JJ, BOYCE WH.: Uretrhovasocutaneous fistula. Urology 1988; 31: 338.

53. KISER GC, FUCHS EF, KESSLER S.: The significance of vasitis nodosa. J Urol 1986; 136: 42.

54. GIOVANNUCI E, ASCHERIO A, RIMM EB, COLDITZ GA, STAMPFER MJ, WILETT WC.: A prospective cohort study of vasectomy and prostate cancer in US men. JAMA 1993a; 269: 873-877.

55. PLATZ EA, YEOLE BB, CHO E, JUSSAWALLA DJ, GIOVANNUCI E, ASCHERIO A.: Vasectomy and prostate cancer: a case-control in India. Int $J$ Epidemiol 1997; 26: 933-938.

56. COX B, SNEYD MJ, PAUL C, DELAHUNT B, SKEGG DC.: Vasectomy and risk of prostata cancer. JAMA 2002; 287 (23): 3110-3115.

57. ZHU K, STANFORD JUAN LABRADOR, DALING JR et al.: Vasectomy and prostate cancer: a case-control in a health maintenance organization. Am J Epidemiol 1996; 144: 717-722.

58. HEALY B.: Fom the National Institutes of Health. JAMA 1993; 269: 2620 .

59. HEINDENREICH A, BONFIG R, WILBERTDM, STROHMEIER WL, ENGELMANN UH.: Risk factors for antisperm antibodies in infertile men. Am J Reprod Immunol 1994; 31: 69-76. 
60. FLICKINGER CJ, HERR JC, BARAN ML, HOWARDS SS. Testicular development and the formation of spermatic granulomas of the epididymis after obstruction of the vas deferents in immadure rats. J Urol 1994; 154: 539-544.

61. FUCHS EF, ALEXANDER N.: Immunologic considerations before and after vaso-vasostomy. Fertil Steril 1983; 40: 497-499.

62. SCHUMAN LM, COULSON AH, MANDEL JS et al.: Health status of American men: a study of post-vasectomy sequelae. $J$ Clin Epidemiol 1993; 46: 697-958.

63. MASSEY FJ, BERNSTEIN GSO, FALLON WM, SCHUMANN LM, COULSON AH, CROZIER R, MANDEL JS, BENJAMIN RB, BERENDES HW, CHANG PC, DETELS R, EMSLANDER RF, KORELITZ J, KURLAND LT, LEPOW IH, QUIROGA J, SCHMIDT S, SPIVEY GH, SULLIVAN T.: Vasectomy and health; results from a large cohort study. JAMA 1984; 252: 1023-1029.

64. MANSON JE, RIDKER PM, SPELSBERG A, AJANI U, LOTUFO PA, HENNEKENS CH.: Vasectomy and subsequent cardiovascular disease in US physicians. Contraception 1999; 59: 181186.

65. KRONMAL RA, COXON V, WORTLEY P, THOMPSON L, SHERRARD DJ.: Vasectomy is associated with an increased risk for urolithiasis. Am J Kidney Dis 1997; 29: 207-213.

66. ASSOCIATION FOR VOLUNTARY STERILIZATION.: Current status of the endocrinological effects of vasectomy. Biomed Bull 1980; 1: 1-5.

67. MO ZN, HUANG X, ZHANG SC, YANG JR.: Early and late longterm effects of vasectomy on serum testosterone, dihydrotestosterone, luteinizing hormone and follicla-stimulating hormone levels. J Urol 1995; 154: 2065-2069.

68. MOLLER H, KNUDSEN LB, LYNGE E.: Risk of testicular cancer after vasectomy: cohort study of over 73000 men. BMJ 1994; 309: 295-299.

69. HEWITT G, LOGAN CJ, CURRY RC.: Does vasectomy cause testicular cancer?. Br J Urol 1993; 71: 607-608.

70. JORGENSEN N, GIWERCMAN A, HANSEN SW, SKAKKEBAEK EN.: Testicular cancer after vasectomy: origin from carcinoma in situ of the testis. Eur $J$ Cancer 1993; 29: 1062-1064.

71. GIOVANNUCCI E, TOSTESON TD, SPEIZER FE, ASCHERIO A, VESSY MP, COLDITZ GA.: A retrospective cohort study of vasectomy and prostate cancer in US men. JAMA 1993b; 269: 878882.

72. METTLIN C, NATARAJAN M, HUBEN R.: Vasectomy and prostate cancer risk. Am J Epidemiol 1990; 132: 1956-1961.

73. ROSENBERG L, PALMER JR, ZAUBER AG, WARSHAUER ME, STOLLEY PD, SHAPIRO S.: Vasectomy and the risk of prostate cancer. Am J Epidemiol 1990; 132: 1051-1055.

74. LESKO SM, LOUIK C, VEZINA R, ROSENBERG L, SAPHIRO S.: Vasectomy and prostata cancer. J Urol 1999; 161: 1848-1852.

75. GIOVANNUCCI E, TOSTESON TD, SPEIZER FE, VESSY MP, COLDITZ GA.: A long-term study of mortality in men who have undergone vasectomy. $N$ Engl $J$ Med 1992; 326: 1392-1398.

76. MAGNANI RJ, HAWS JM, MORGAN GT, GARGIULLO PM, POLLACK AE, KOONIN LM.: Vasectomy in the United States. Am J Public Health 1999; 89: 92-94.

77. STONE N, BLUM DS, DeANTONI EP, CRAWFORD DE, SCHMID K, EISENBERGER MA, BERGER ER, JEFFERSON P, STAGGERS F, GAMBERT SR.: Prostate cancer risk factor analysis among $>50000$ men in a national study of prostate-specific antigen (PSA). J Urol 1994; 151: 278.

78. HERNÁNDEZ J, SABANEGH ES.: Repeat vasectomy reversal after initial failure: overall results and predictors for success. $J$ Urol 1999; 161: 1153-1156.

79. WIESKE WH.: Mikrochirurgische refertilisierung nach vasektomie-aktueller stand. J Fertil Reprod 2000; 10: 7-14.
80. JEQUIER AM.: Is vasectomy of long-term benefit?. Hum Reprod 1998; 13: 1757-1759.

81. HERNÁEZ MANRIQUE I, RECARTE JA, SANZ JAKA JP.: Vasovasostomía post-vasectomía. Estudio de 6 pacientes. Comunicación póster (P 77) al LIX Congreso Nacional de Urologia. Sitges 1994, Actas Urol Esp (Libro Resúmenes) 1994: 68.

82. MARTÍN E, PÁEZ A, SÁNCHEZ E, RUIZ JC, ZÁRATE E, GAGO A, LUJÁN M, LLORENTE C, BERENGUER A.: Morbilidad y grado de satisfacción del paciente tras vasectomía. Comunicación oral (C 97) al LXI Congreso Nacional de Urología. Santander, 27-30 mayo 1996. Actas Urol Esp (libro resúmenes) 1996: 142.

83. POMEROL JM, NARVÁEZ H, SEGURA A, FERREIRA F: Vasovasostomía microquirúrgica. Comunicación vídeo (V-3) al LXI Congreso Nacional de Urología. Santander, 27-30 mayo 1996. Actas Urol Esp (Libro Resúmenes) 1996: 88.

84. DELGADO MARTÍN JA, BLÁZQUEZ IZQUIERDO J, GÓMEZ VEGAS A, CORRAL ROSILLO J, SILMI MOYANO A, RESEL ESTÉVEZ L.: Vaso-vaso-anastomosis microquirúrgica. Análisis de resultados. Comunicación póster (P 53) al LXIII Congreso Nacional de Urología. Cádiz 14-17 junio 1998. Actas Urol Esp (supl) 1998; 22 (5): 53.

85. VALERO MILLÁN J, SALADIÉ ROIG JM, GELABERT MÁS A.: Resultados de la vaso-vasostomía magnificada sin suturas. Técnica experimental. Comunicación oral al LXIV Congreso Nacional de Urología. Zaragoza, 23-26 mayo 1999. Actas Urol Esp (supl) 1999; 23 (5): 135.

86. VALERO MILLÁN J, SALADIÉ ROIG JM, GELABERT MÁS A: Resultados de la vasovasostomía magnificada simplificada. Técnica experimental. C35 al LXV Congreso Nacional de Urologia. Madrid, 28-31 mayo 2000. Actas Urol Esp (supl) 2000; 24 (5): 30.

87. CLEMENTE RAMOS L, GALMES BELMONTE I, PLATAS A, IZQUIERDO L, ALLONA ALMAGRO A, NISTAL MARTÍN DE SERRANO M.: Infertilidad y agenesia uni o bilateral de conductos deferentes: valor del estudio genético C36 al LXV Congreso Nacional de Urología. Actas Urol Esp (supl) 2000; 24 (5): 31.

88. JIMÉNEZ ARISTU JL, DE PABLO CÁRDENAS A, PINÓS PAÚL MA, RUÍZ RAMO M, JIMÉNEZ CALVO JM, LOZANO URUÑUELA F, HUALDE ALFARO A, SANTIAGO GONZÁLEZ DE GARIBAY AM.: Reparación microquirúrgica tras vasectomía. Comunicación póster (P62) al LXVI Congreso Nacional de Urologia. Granada 2001. Actas Urol Esp (supl) 2001; 25 (5): 95.

89. GÓMEZ DE VICENTE JM, ROMERO CAGIGAL I, BLANCO BARROS C, PASTOR J, MORENO SANTURNINO A, SANTOS ARRONTES D, MIRAVALLES GONZÁLEZ E, BERENGUER SÁNCHEZ A.: Análisis de la persistencia de espermatozoides tras la realización de vasectomía. Comunicación póster (P63) al LXVI Congreso Nacional de Urología. Granada 2001. Actas Urol Esp (supl) 2001; 25 (5): 95.

90. COS CALVET JM, SÁNCHEZ MACÍAS J, GAGO RAMOS J, URÍA GONZÁLEZ-TOVA J, SALADIÉ JM.: Vaso-vasostomía: evolución técnica y resultados tras 103 casos. Póster (P96) al LXVII Congreso Nacional de Urología. Actas Urol Esp 2002; 26 (4): 98.

91. ROMERO MAROTO J, LÓPEZ LÓPEZ C, QUILEZ FENOLL J, REGALADO PAREJA IR, PRIETO CHAPARRO L, BERNABEU R.: Vaso-vasostomía. Nuestra experiencia. Comunicación oral al $X$ Congreso Nacional de Andrología. Alicante 2001: 61.

92. LERTXUNDI R.: Embarazo tras vasectomía: cuántos, cuándo y por qué. Estudio sobre 12.000 casos. Comunicación oral al $X$ Congreso Nacional de Andrología. Alicante 2001: 63.

93. LLOPIS CARTAGENA M.: Espermiograma de control post-vasectomía. ¿cuándo y cuántos?. Póster al X Congreso Nacional de Andrología. Alicante 2001: 77.

94. CANOVAS JA, RAMADA FJ, TRAMOYERES A, RAMOS M, NAVALÓN P, LÓPEZ E, SABATER V, ZARAGOZÁ J.: Seguridad de la vasectomía. Póster al X Congreso Nacional de Andrología. Alicante 2001: 77 . 
95. NUÑEZ J, SARRAT R, ARTILES JY, TORRES, A.: Efectos de la vasectomía sobre la estructura del testículo de rata. Actas Urol Esp 1986; 10 (1): 55-60.

96. McDONALD SW.: Vasectomía y testículos humanos. BMJ International (edición es español) 1991; 3 (1): 8-10.

97. RUIZ ÁLVAREZ-CIENFUEGOS F, LEVA VALLEJO M.: Anticoncepción masculina. En:"Tratado de Urología, JF Jiménez Cruz y LA Rioja Sanz". JR Prous Editores, Barcelona 1993; 1 (56): 913-923.

98. RUIZ-CASTAÑÉ E, POMEROL JM.: Contracepción quirúrgica. En:"Práctica Andrológica. JM Pomerol Monseny y JL Arrondo Arrondo. Ediciones Científicas y Técnicas S.A. Masson Salvat Medicina, Barcelona 1993; 73: 609-618.

99. SALADIÉ ROIG JM, COMET BATLLE J, AREAL CALAMA J, CECCHINI ROSELL L, URÍA GONZÁLEZ-TOVA J.: Vaso-vasostomía simplificada. Arch Esp Urol 1996; 49 (5): 507-510.

100. COZCOLLUELA CABREJAS MR, SARRIA OCTAVIO DE TOLEDO L, MARTÍNEZ-BERGANZA ASENSIO MT, RIPA SALDIA L, MONZÓN MUÑOZ F, SANZ SALANOVA LA, FERNÁNDEZ ROSAENZ J.: Espermatocele complicado como causa de masa escrotal de aspecto sólido. Hallazgos ecográficos. Actas Urol Esp 1996; 20 (8): 750-752.

101. SÁNCHEZ FJ, VILLAPLANA TL, SARTI MM.: Estudio a microscopia óptica del testículo de rata tras vasectomía. Actas Urol Esp 1996; 20 (5): 403-407.

102. BATES CA.: Anticuerpos antiespermáticos e infertilidad masculina. Br J Urol Int 1997; 80 (1): 691-697.

103. DOMÍNGUEZ FREIRE F, LÓPEZ BELLIDO D.: Agenesia unilateral de conducto deferente, un signo clínico útil en el diagnóstico de malformaciones genitourinarias. Actas Urol Esp 2001; 25 (10): $770-773$.

104. PELLICÉ VILALTA C.: Agenesia unilateral de conducto deferente. Actas Urol Esp 2002; 26 (4): 310.

105. GONZÁLEZ P, EGEA MD, MÉNDEZ M, ESTEBAN B, TERRER R, PARRILLA JJ.: Vasectomía con anclaje subcutáneo del cabo testicular. Presentación de 410 casos. Cir Esp 1992; 52 (4): 64-66.

106. NUÑEZ J, SARRAT R, PIZARRO C, GONZÁLEZ P.: Efectos de la vasectomía sobre el testículo de rata. Estudio ultraestructural. Actas Urol Esp 1985; 9 (3): 273-276.

107. NUÑEZ J, SARRAT R, CHESA NY, TORRES A.: Efectos de la vasectomía sobre la estructura del testículo de gato. Actas Urol Esp 1986; 10 (1): 61-64.

108. WHYTE J, ORTÍZ PP, TORRES A, DÍAZ P, LOSTALE F, WHYTE A, MARTÍNEZ MJ, VILORIA A, SARRAT R.: Efectos de la vasectomía en la estructura del conducto epididimario del perro beagle. Rev Exp Anim 1994; 5 (1-2): 27-34.

109. MAZO R.: Influencia de las modalidades técnicas de vasectomía sobre la estructura del testículo. Tesina de Licenciatura. Universidad de Zaragoza 1996.

110. WHYTE J, SARRAT R, TORRES A, DÍAZ P, ORTIZ PP, WHYTE A, MAZO R.: Efectos de la vasectomía sobre la estructura del testículo de perro. Actas Urol Esp 1997; 21 (5): 446-452.

111. LÓPEZ A, CASTIÑEIRAS J, VILCHES J.: Vasectomía y vasovasostomía I. Cambios histológicos a nivel del testículo. Actas Urol Esp 1998; 12 (4): 381-388.

112. LÓPEZ A, CASTIÑEIRAS J, VILCHES J.: Vasectomía y vasovasostomía II. Cambios histológicos a nivel de la vía espermática. Actas Urol Esp 1998; 12 (4): 389-398.

113. WHYTE J, SARRAT E, TORRES A, DÍAZ P, ORTIZ PP, CISNEROS A, WHYTE A, MAZO R.: Vasectomía experimental: comparación de la estructura testicular mediante diferentes técnicas quirúrgicas. Actas Urol Esp 1998; 22 (2): 178-183.

114. RASPA RF.: Complications of vasectomy. Am Fam Physician 1993; 48 (7): 1264-1268.

115. EKMAN EHN B, LILJESTRND J.: A long-term follow-up of 108 vasectomized men. Scand J Urol Nephrol 1995; 29: 477-481.
116. CHOE JM, KIRKEMO AK.: Questionnaire-based outcomes study of nononcological post-vasectomy complications. $J$ Urol 1996; 155 (4): 1284-1286.

117. LESSING MP, CROOK DW, BOWLER IC, GRIBBIN B.: Nativevalve endocarditis caused by Staphylococcus lugdunensis. ${ }_{3} J M$ 1996; 89 (11): 855-858.

118. LEBRECQUE M, BEDARD L, LAPERRIERE L.: Efficacy and complications associated with vasectomies in two clinics in the Quebec region. Can Fam Physician 1998; 44: 1860-1866.

119. KESSLER RB, KIMBROUGH RC JONES SR.: Infective endocarditis caused by Staphylococcus hominis after vasectomy. Clinical Infectius Diseases 1998; 27 (1): 216-217.

120. SEIDI J, BROTZMAN G.: The rate of hydrocele perforation during vasectomy. Is perforation dangerous?. J Fam Pract 2000 49 (6): 537-540.

121. NANGIA AK, MYLES JL, THOMAS AJ Jr.: Vasectomy reversal for the post-vasectomy pain syndrome: a clinical and histological evaluation. J Urol 2000; 164 (4): 1939-1942.

122. FERVENZA FC, CONTRERAS GE, GARRATT KN, STECKELBERG JM.: Staphylococcus luddunensis endocarditis: a complication of vasectomy? (see comments). Mayo Clin Proc 1999; 74 (12): 1227-1230.

123. WEST AF, LEUNG HY, POWELL PH.: Epididymectomy is an effective treatment for scrotal pain after vasectomy. BJU Int 2000; 85 (9): 1097-1099.

124. CHRISTENSEN P, AL-AQIDI OA, JENSEN FS, DORFLINGER T.: Vasectomy. A prospective, randomized trial of vasectomy with bilateral incision versus the Li vasectomy. Ugeskrift for Laeger 2002; 164 (18): 2390-2394.

125. NIELSEN MF, SORENSEN VT, SORENSEN V.: Frequency of recanalization after vasectomy. Experiences from 2563 sterilizations. Ugeskrift for Laeger 2002; 164 (18): 2394-2397.

126. MARTÍNEZ-CALCERRADA L.: La responsabilidad civil médicosanitaria. Colección Jurisprudencia Práctica. Tecnos, Madrid 1992: 35.

127. LERTXUNDI BARAÑANO R.: Embarazos tras vasectomía. Actualidad Andrológica 2000; 8: 70.

128. LEY 26/1984 de 19 de julio. Ley General para la Defensa de los Consumidores y Usuarios.

129. LEY 41/2002 de 14 de noviembre: Ley de Autonomía del paciente. Información y Documentación Clínica. BOE 274, Madrid viernes 15 de noviembre de 2002.

130. LEY 1/2003, de 28 de enero, de la Generalitat Valenciana: Ley de derechos e información al paciente de la Comunidad Valenciana. DOGV. Valencia 31 de enero de 2003; 4430: 2222-2234,

131. DE LORENZO, MONTERO R.: Consentimiento informado en Odontoestomatologia. Bosch. Madrid 1996.

132. GALÁN CORTÉS JC.: Consentimiento informado de los usuarios de la sanidad. Colex. Madrid 1997.

133. MORA ORTEGA J.: Consentimiento informado: una sentencia interesante. Boletín Informativo del Colegio Oficial de Médicos de Huelva, noviembre 1994.

134. THON WF, STIEF CG, JONAS U.: Vasectomy: minor intervention-grave sequelae. Urologe A 1992; 31 (1): 55-57.

135. GINGELL C, CROSBY D, CARROLL R.: Review of the complications and medicolegal implications of vasectomy. Postgraduate Medical Journal 2001; 77 (912): 656-659.

136. PÉREZ-CASTRO ELLENDT E.: Como evitar ser demandado o los Diez Mandamientos. Arch Esp Urol 1990; 43 (6): 593-594.

Dr. P. Romero Pérez

Servicio de Urología. Hospital Marina Alta

Ptda. Plana Est. 4 - 03700 Denia (Alicante)

(Trabajo recibido el 15 septiembre 2003) 